Running Head: MODEL OF ENGAGEMENT FOR CORRECTIONAL PRACTICE

A MODEL OF ENGAGEMENT FOR CORRECTIONAL PRACTICE

BY

LISA GANNAWAY

\begin{abstract}
A thesis
submitted to the Victoria University of Wellington

in fulfilment of the requirements for the degree of

Master of Science in Forensic Psychology
\end{abstract}

Victoria University of Wellington

2018 


\title{
MODEL OF ENGAGEMENT FOR CORRECTIONAL PRACTICE
}

\author{
Abstract \\ Despite recent advances in correctional rehabilitation, rates of treatment attrition \\ remain high and low efficacy rates suggest improvements in treatment development and \\ delivery are needed. Treatment engagement is an important concept which remains poorly \\ understood. In order to enhance understanding and facilitate higher levels of engagement in \\ treatment, robust theoretical models need to be developed. In light of this, two key questions \\ need to be answered; (1) what is engagement? And (2) what are the underlying causal \\ mechanisms which facilitate or hinder engagement? I explore the contributions of current \\ conceptualisations and models of correctional treatment engagement. I explain how \\ evolutionary psychology, agency, norms and the therapeutic alliance can contribute to our \\ theoretical understanding. These concepts are then integrated to form the Model of \\ Engagement for Correctional Practice. Engagement is conceptualised as a set of adaptive, \\ goal-directed behaviours occurring as a result of the dynamic interactions between \\ contextual, psychological and social processes. I argue that these factors influence the nature \\ of the therapeutic alliance and subsequently participant engagement. The model is then \\ evaluated in terms of critical features required for a robust theory of engagement. I then \\ suggest some practice principles and guidelines to demonstrate how this model can be \\ applied to enhance treatment engagement.
}




\section{MODEL OF ENGAGEMENT FOR CORRECTIONAL PRACTICE}

\section{Acknowledgements}

First and foremost, I would like to thank my supervisor, Professor Tony Ward for his guidance and encouragement throughout this journey. I have appreciated all of our thoughtprovoking discussions, your wisdom and keeping me on track. I am honoured to have had the pleasure of working alongside such a knowledgeable, inspirational and passionate researcher and teacher.

I would also like to thank all the students in the Explanation of Psychopathology and Crime Lab for the comradery. I am grateful for the opportunities to work with such a dedicated team. I would especially like to acknowledge Roxy for listening to my musings, for your advice and essentially acting as my mentor on so many occasions.

The completion of this thesis would not have been possible without the love and unconditional support of my family. To my parents, Michael and Julie, thank you for your endless support to help me get through my years of study. Thank you for listening to me when I needed to vent and for always believing in me.

To my husband, Warwick, thank you for walking alongside me every step of the way. Thank you for always believing in me and for your unwavering encouragement. You helped me get through the hard times by reminding me why I was doing it and that I could do it. You are my rock, I will be forever grateful and I hope I can support your to achieve your dreams as you did for me.

To my wonderful sister, Adele, and my close friends; thank you for putting with my thesis ramblings, my absence toward the end of the year, for giving me a boost when I needed it and for your texts of encouragement on the home stretch. 


\section{Table of Contents}

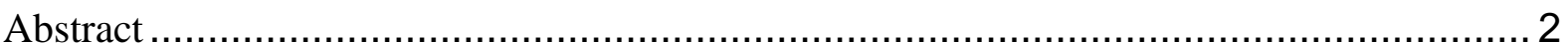

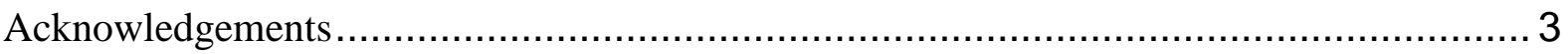

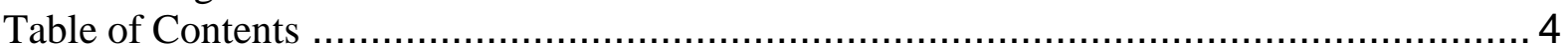

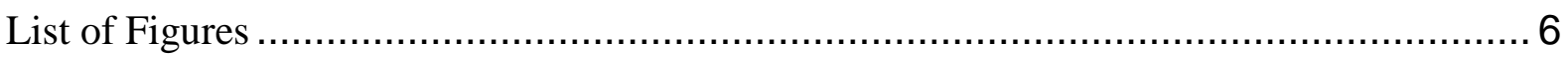

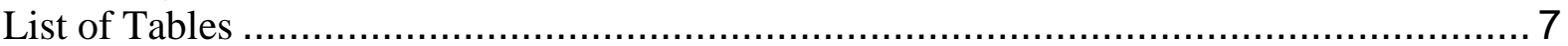

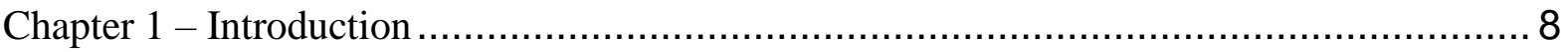

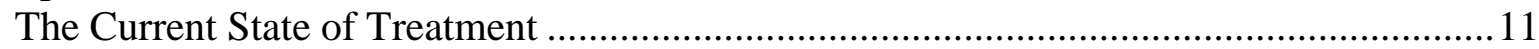

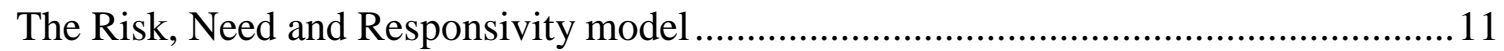

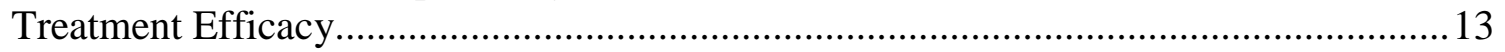

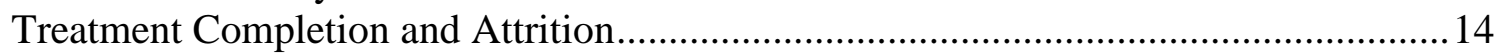

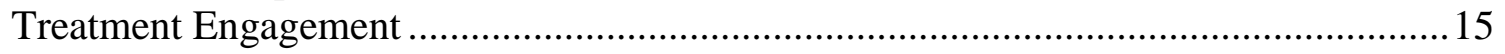

Chapter 2 - Current Approaches to Treatment Engagement.................................... 17

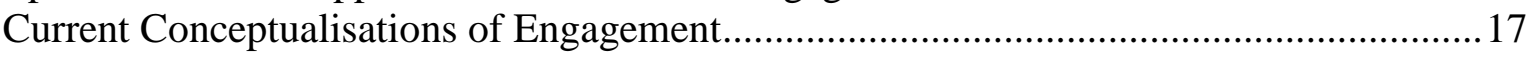

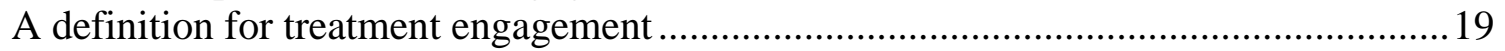

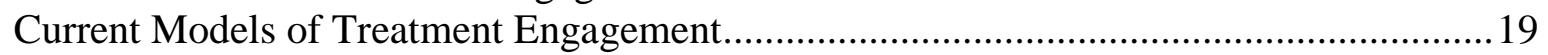

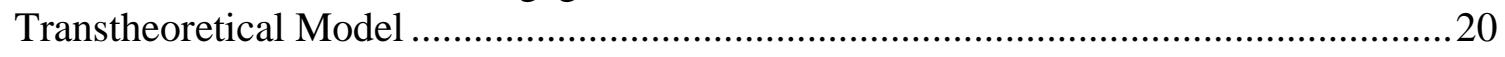

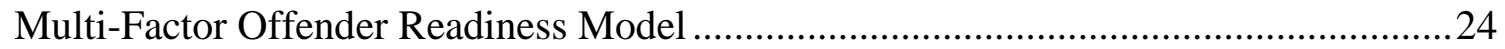

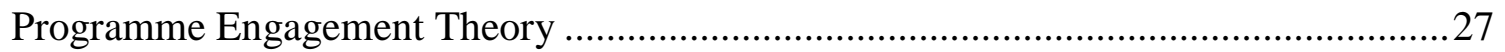

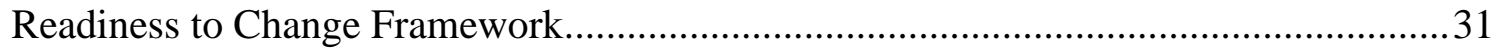

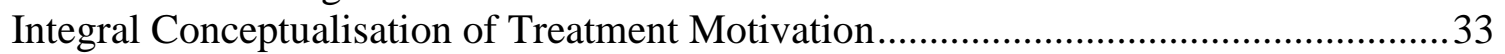

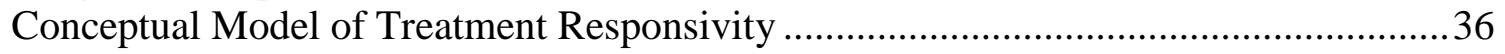

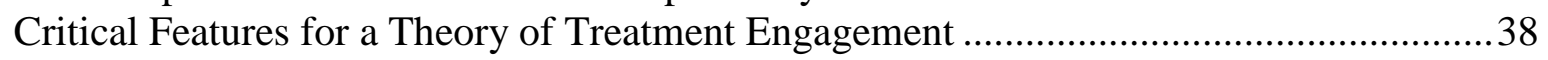

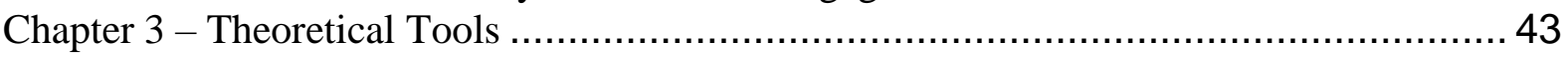

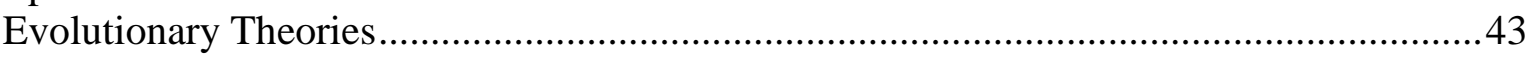

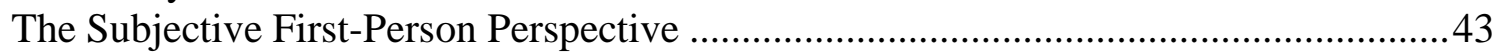

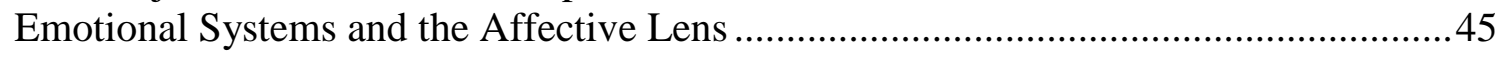

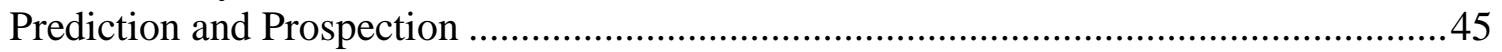

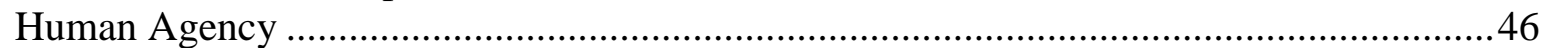

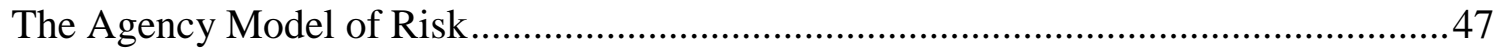

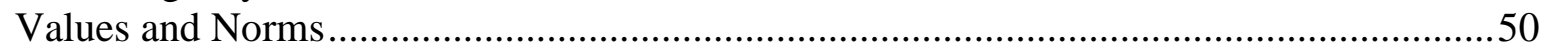

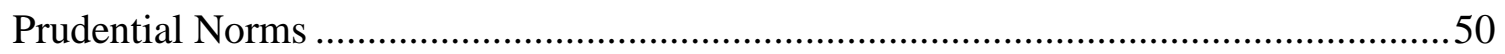

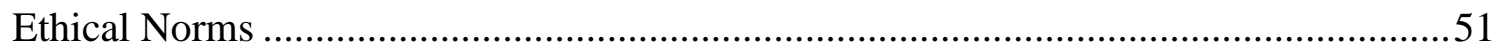

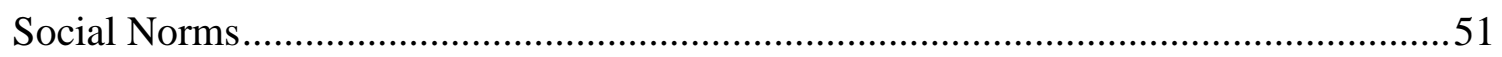

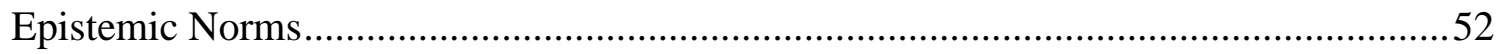

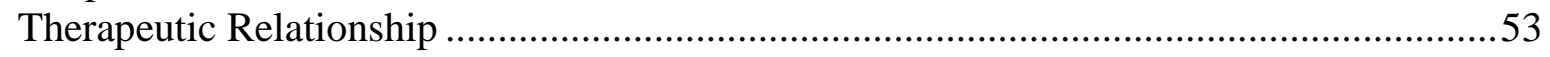

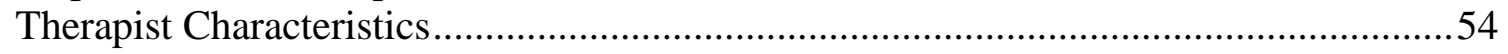

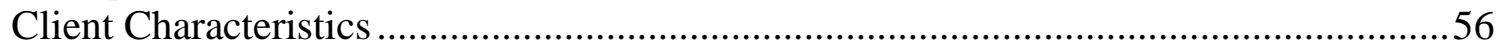

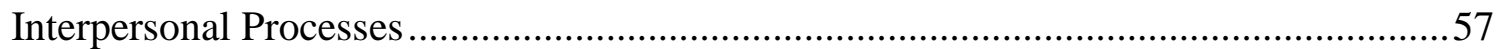

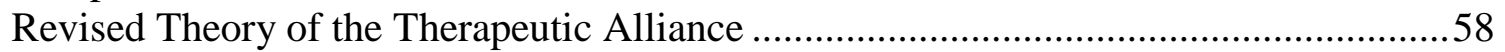

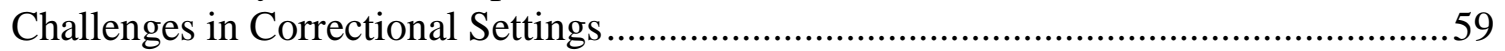

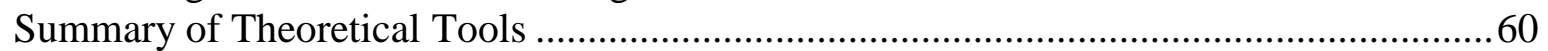

Chapter 4 - The Model of Engagement for Correctional Practice ............................. 62

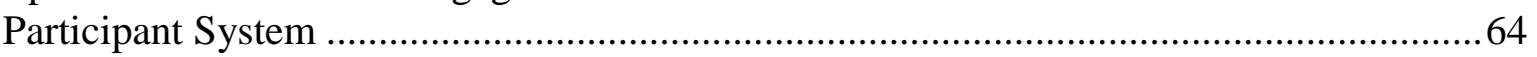

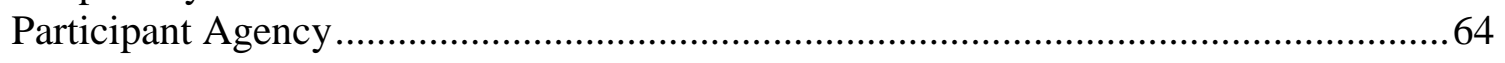

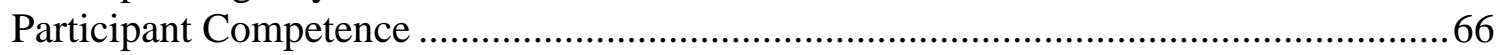

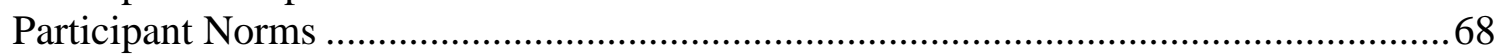

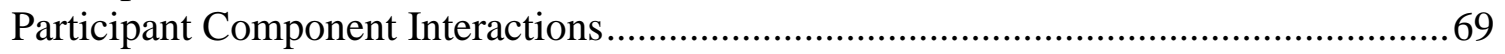


Therapist System

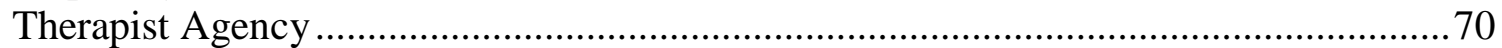

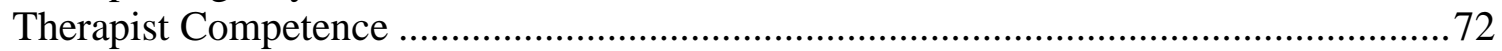

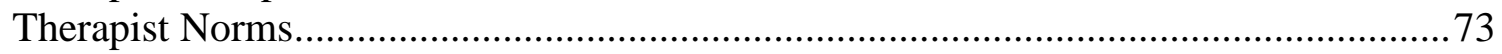

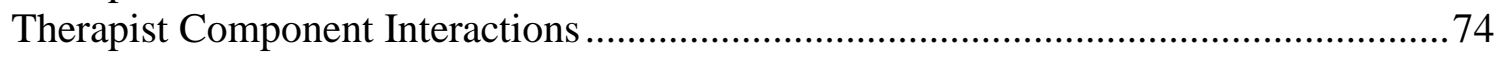

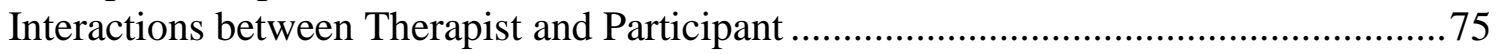

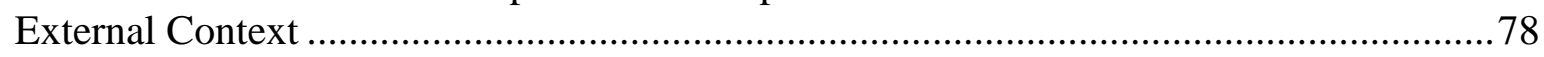

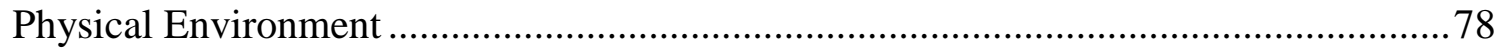

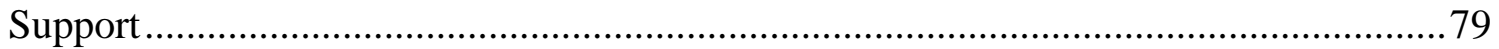

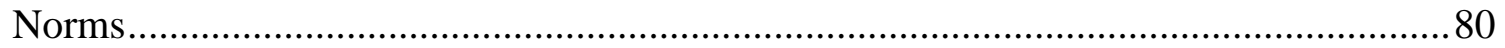

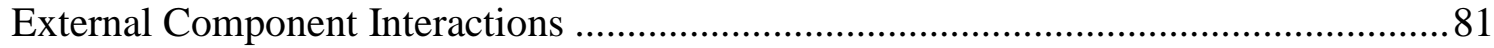

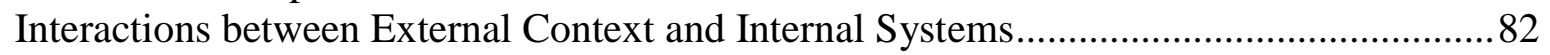

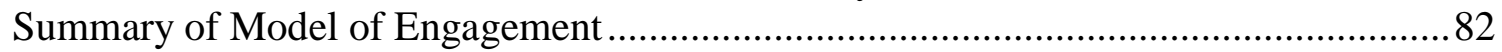

Chapter 5 - Evaluation and Applications to Practice .......................................... 83

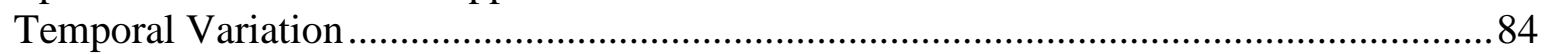

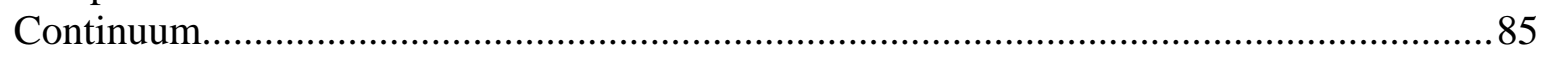

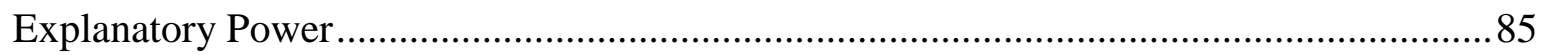

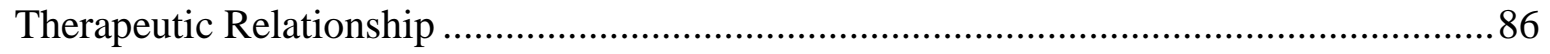

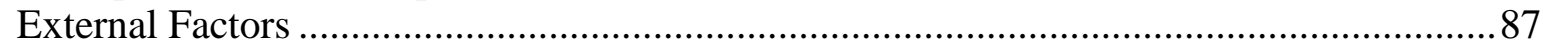

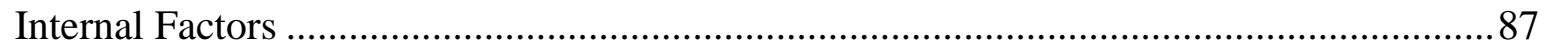

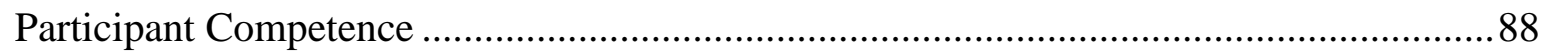

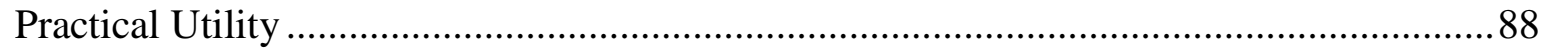

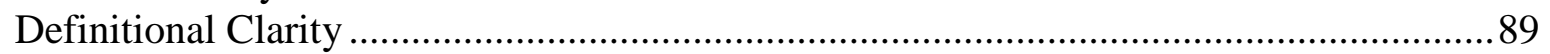

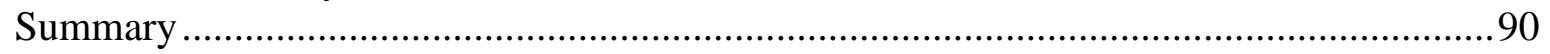

Chapter 6 - The Model of Engagement for Correctional Practice Applied....................... 91

Develop and Deliver Treatment that Facilitates Engagement ........................................91

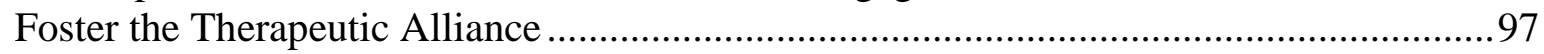

Assess and Prepare Participants for Treatment Engagement ............................................. 101

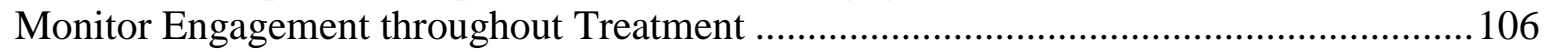

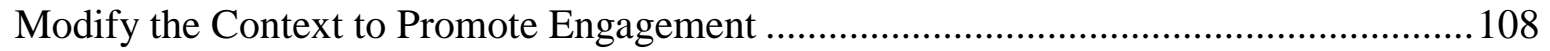

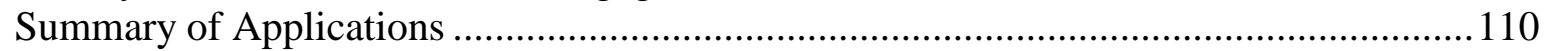

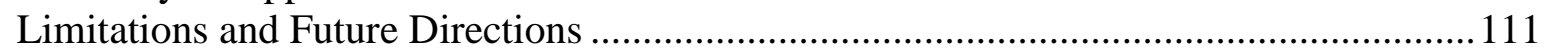

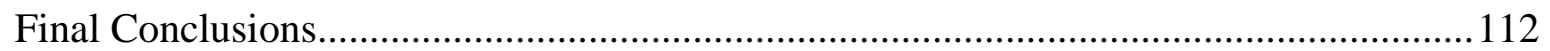

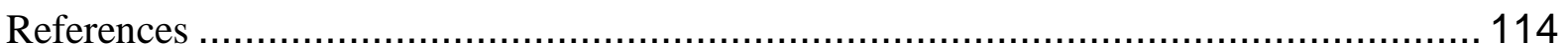




\section{List of Figures}

Figure 1.

Transtheoretical Model: Stages of Change and Associated Processes (Prochaska \&

DiClemente, 1983).

Figure 2.

Multi-Factor Offender Readiness Model (Ward et al., 2004).

Figure 3.

The Programme Engagement Model (Holdsworth et al., 2017).

Figure 4

Readiness to Change Framework: Context of Change (Burrowes \& Needs, 2009).

Figure 5. .34

Integral Conceptualisation of Treatment Motivation (Drieschner et al., 2004).

Figure 6

Conceptual Model of Treatment Responsivity (Serin \& Kennedy, 1997).

Figure 7

Agency Model of Risk (Heffernan \& Ward, 2015)..

Figure 8 .

Revised Theory of the Therapeutic Alliance (Ross et al., 2008)..

Figure 9

The Model of Engagement for Correctional Practice (MECP). 


\section{List of Tables}

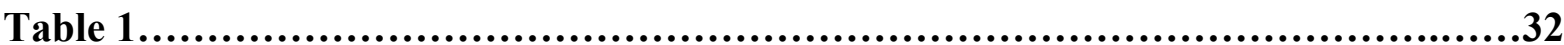

Readiness to change framework: Barriers to change

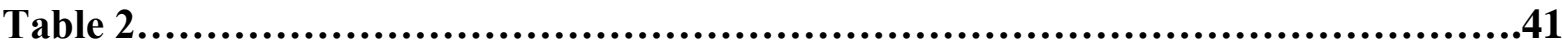

Engagement model adherence to critical features of a theory of engagement.

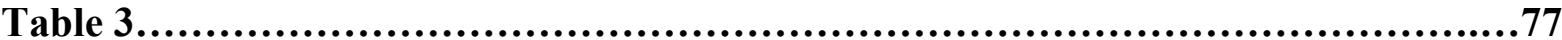

Exemplars of explanations of engagement pratices.

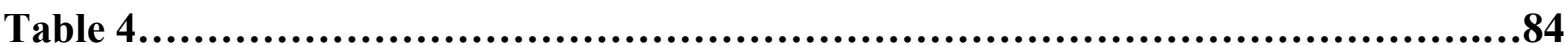

Model adherence to critical features of a theory of engagement, including the Model of Engagement for Correctional Practice (MECP). 


\section{MODEL OF ENGAGEMENT FOR CORRECTIONAL PRACTICE}

\section{Chapter 1 - Introduction}

How and why do some people engage in and complete treatment successfully? Why do some have more difficulty and in many cases fail to complete treatment? Why do others still, show contextually and temporally varying degrees of engagement? These are questions I will be exploring in this thesis.

Over the past few decades, the field of forensic psychology has received growing academic attention in an attempt to enhance our ability to identify, measure and predict the factors that are thought to contribute to offending behaviour. Additionally, and promisingly, practitioners have begun to develop and deliver psychological treatment designed to address these factors so that offending is less likely to reoccur in the future. The literature is rife with empirical research on factors correlating with offending behaviour and as such, there has been a prevailing pre-occupation with risk prediction and management (Ward \& Fortune, 2016). Unfortunately, this has meant that the field has been slower to thoroughly investigate the proximate causes of offending and mechanisms for behaviour change within this population.

As a result, the questions of how and why people commit crime, and how and why they chose to desist from further offending, remain unanswered, although recent research has revealed some promising findings (e.g. Maruna, 2001). This pre-occupation with risk may explain the problem of poor treatment completion rates and, for those that do complete, poor treatment outcomes including high recidivism rates. In light of these gaps in knowledge, two questions come to mind; (1) How can practitioners keep people engaged throughout treatment and ultimately to completion? (2) How can practitioners improve the outcomes including reducing recidivism and improving public safety? In order to effectively respond to the 


\section{MODEL OF ENGAGEMENT FOR CORRECTIONAL PRACTICE}

problem of how to improve treatment efficacy and reduce re-offending, it is first important to understand the causal mechanisms underpinning treatment engagement.

Treatment engagement is a commonly used term in forensic psychological practice, yet the construct remains conceptually and theoretically unclear. In order to develop a theory of engagement, we must answer two questions. Firstly, we need to understand what we are talking about, that is what engagement actually is. We need to develop a clear and robust conceptualisation of engagement in order to 'know it when we see it' and when we are not seeing it. Secondly, we need to understand the process of engagement. This requires an understanding of how engagement happens within treatment and what facilitates and hinders this process. The hope is that in completing this theoretical task, practitioners can better understand how higher levels of engagement can be achieved and thus improve treatment outcomes.

Ward (2014) described theories as "conceptual structures constructed to explain why certain phenomena exist and persist" (p. 134). That is, theories are developed in an attempt to better understand why something is as it is and what the processes and mechanisms are that create and maintain it. The phenomenon to be explained in this thesis is treatment engagement. I will explore what treatment engagement actually is and what mechanisms facilitate or hinder it. Ward (2014) suggests three key considerations in the development of theory; multiple levels of analysis, explanatory targets and causal mechanisms.

Firstly, within the human sciences, theories should be based on our current understanding of human nature across multiple levels of analysis (e.g. physiological, developmental, psychological, social and cultural). Ward (2014) suggests integrative pluralism as a useful explanatory strategy. Integrative pluralism Mitchell (2004) involves linking previously developed theories and empirical research across multiple levels of analysis, in order to provide a more robust theoretical understanding of the phenomenon of 


\section{MODEL OF ENGAGEMENT FOR CORRECTIONAL PRACTICE}

interest. Although this thesis does not attempt to provide any explanation at the physiological level, I will argue that developmental, psychological and social/cultural levels of analysis can and should be incorporated into a theory of treatment engagement. While physiological levels of analysis can provide valuable information about human behaviour, they are arguably less relevant than psychological and social levels when it comes to engagement and the therapeutic relationship, and so fall beyond the scope of this task.

Secondly, Ward (2014) suggests theorists should clearly outline their explanatory targets which are "an agreed on set of phenomena [...] that subsequently becomes the targets of explanation" (p. 136). In regard to treatment engagement, my explanatory targets are: (1) the behavioural presentation of engagement, (2) factors correlating with engagement or nonengagement (e.g. participants' perceptions of treatment, emotional dysregulation; Sturgess, Woodhams, \& Tonkin, 2016) .

Finally, Ward (2014) also suggests theory construction should include developing "models of the mechanisms [...] underlying the specific phenomena and their interrelationships" (p. 137). In constructing this theory, I suggest that engagement involves $a$ complex set of internal and external psychological and social mechanisms acting on and within the treatment environment.

In summary, the purpose of this thesis is to develop a comprehensive theory of treatment engagement; explaining what it is and why it does or does not occur during therapy. Firstly, I will provide an overview of the current state of correctional rehabilitation. The second chapter provides a critical review of the models that currently inform our understandings of treatment engagement. Chapter three will provide a summary of some theoretical tools which can be utilised and integrated to enhance comprehension. In Chapter 4, I will introduce the Model of Engagement for Correctional Practice (MECP). The fifth chapter provides a detailed evaluation of this model in terms of key theoretical tasks and 


\section{MODEL OF ENGAGEMENT FOR CORRECTIONAL PRACTICE}

evaluation criteria. In the final chapter I will then provide insights into how the MECP can be applied to inform forensic treatment and subsequently enhance outcomes. I will discuss some of the limitations of this model and suggest directions for future research.

\section{The Current State of Treatment}

The quality of correctional treatment programmes has improved significantly over the past 30 years. However, rates of re-offending are still high and significant social costs persist. In the United States, $49.3 \%$ of offenders released from prison were re-convicted within eight years of release, with a median time to reconviction of 21 months (Hunt \& Dumville, 2016). In Canada, $40.6 \%$ of prisoners received a new conviction within two years of release (Bonta, Dauvernge, \& Rugge, 2003). While in Australia, 51.1\% of prisoners returned to correctional services within 2 years (Payne, 2007). More recently, the New Zealand Department of Corrections Annual Report (Corrections, 2017) for the 2016/2017 financial year stated that $45.5 \%$ of individuals released from prison were reconvicted within 12 months. Additionally, this report indicated that $86 \%$ of people in prison in that same financial year started and completed a rehabilitation programme. This means, despite many prisoners having access to treatment and the recent advances in correctional treatment, across Westerns societies almost half of released prisoners re-offend within one to five years.

\section{The Risk, Need and Responsivity model}

Treatment for people who have committed crimes has been significantly advanced by Bonta and Andrews' (2017) Risk, Need and Responsivity (RNR) model which is widely utilised to guide practice within correctional settings internationally. This model provides a framework for the development and delivery of treatment programmes aiming to reduce the likelihood individuals will re-offend. The RNR model is centred upon three core principles. 


\section{MODEL OF ENGAGEMENT FOR CORRECTIONAL PRACTICE}

First, the risk principle stipulates that risk can be reliably predicted by careful assessment of an individual's static and dynamic risk factors and individuals who present as higher risk should receive more intensive treatment. Second, the need principle specifies that treatment should be aimed at addressing "criminogenic needs"; the dynamic (changeable) risk factors that, if targeted in treatment, may lower future re-offending rates. The major dynamic risk factors identified within the framework are anti-social personality pattern, anti-social attitudes, anti-social associates, substance abuse, family/marital problems, difficulties with school or employment, lack of pro-social leisure/recreation involvement. Thirdly, the responsivity principle states that in order to maximise treatment effectiveness, cognitivebehavioural therapy and social learning methods should be utilised (i.e. general responsivity). This includes the relationship principle (that the therapist should establish a warm, respectful and collaborative therapeutic relationship with the individual) and the structuring principle (that prosocial modelling and appropriate reinforcement strategies will support learning). The responsivity principle also suggests that the mode and style of delivery should be tailored to match the learning style, personality, motivation and abilities of the individual (i.e. specific responsivity).

The RNR model has been empirically evaluated by numerous researchers internationally (e.g. Dowden \& Andrews, 2004) and in New Zealand, it is the primary model employed to guide treatment development and delivery (Corrections, 2017). Generally, it is widely acknowledged that completion of treatment guided by the RNR principles leads to a reduced likelihood of reoffending (Dowden \& Andrews, 2004; Larochelle, Diguer, Laverdière, \& Greenman, 2011; Lipsey \& Cullen, 2007; McGuire, 2002; McMurran \& Theodosi, 2007). Treatment dropout, on the other hand, is associated with poorer outcomes and higher recidivism (McMurran \& Theodosi, 2007; Olver, Stockdale, \& Wormith, 2011; Wormith \& Olver, 2002). In order to develop and deliver treatment responsively, it is 


\section{MODEL OF ENGAGEMENT FOR CORRECTIONAL PRACTICE}

important that practitioners improve their understanding of engagement and how low levels of engagement can lead to dropout.

\section{Treatment Efficacy}

For those who do complete treatment, outcomes are generally in favour of a positive treatment effect (i.e. reduced recidivism rates); however effect sizes vary considerably across studies and treatment styles. McGuire (2002) completed a large scale review of metaanalyses which looked at the efficacy of correctional treatment programmes between 1985 and 2000 and found a mean reduction in re-offending of 5 to $10 \%$. Dowden and Andrews (2000) completed a meta-analysis of 35 studies adhering to the RNR model and found a "mildly positive" (p. 456) result with an average effect size of -0.07 . This suggests that, on average, those who completed RNR-informed treatment were 7\% less likely to re-offend than those who did not complete treatment. The authors suggested that greater adherence to RNR principles was associated with greater effect sizes, however these results were varied and relied upon subjective interpretation of the level of adherence to the principles.

In another meta-analysis, McMurran and Theodosi (2007) concluded that on average people who completed cognitive-behavioural treatment in a variety of correctional settings were $11 \%$ less likely to re-offend than those who remained untreated. Furthermore, Lipsey and Cullen (2007) found positive effect sizes (ranging from 10\% to 38\%) in all the metaanalyses they reviewed, ultimately supporting treatment efficacy, although to varying degrees. J. Ross, Quayle, Newman, and Tansey (2013) completed a review of ten studies of treatment aimed at reducing violent offending and found overall reductions, albeit highly varied, in violent recidivism following completion of a range of psychotherapeutic interventions. Non-completion, however, has been associated with high rates of recidivism across a variety of treatment programmes including those for perpetrators of domestic violence (Gondolf, 2002), and sexual offending (Sowden \& Olver, 2017). 


\section{MODEL OF ENGAGEMENT FOR CORRECTIONAL PRACTICE}

In New Zealand, the most recent Annual Review produced by the Corrections (2017) showed that individuals who completed at least one medium or high intensity rehabilitation programme in prison were on average $4.1 \%$ less likely to receive a new re-conviction over the 12 month follow-up period than those who did not complete any treatment. The highest efficacy results were for the Special Treatment Unit (10.4\%; for high risk violent offenders), the Medium Intensity Rehabilitation Programme (8.3\%; for medium risk general offenders) and the three-month Drug Treatment Programme (7.3\%; for individuals with identified substance-abuse needs).

\section{Treatment Completion and Attrition}

Despite the fact that RNR-informed treatment is consistently associated with small to modest reductions in risk of re-offending, many people start but then fail to complete treatment. Cullen, Soria, Clarke, Dean, and Fahy (2011) reported a dropout rate of 50\% for people within forensic mental health treatment. Similarly, Ashford, Wong, and Sternbach (2008) found $51 \%$ of people serving community-based correctional sentences and enrolled in a community-based cognitive skills programme failed to complete treatment. In a review of sexual offending treatment studies, Larochelle et al. (2011) found between $15 \%$ and $86 \%$ of individuals who started sexual offending treatment did not complete it. High attrition rates have also been recorded for people attending domestic violence treatment (Olver et al., 2011). For general offending, McMurran and Theodosi (2007) found a mean attrition rate in their meta-analysis of $23.55 \%$, which was less likely in institutional samples (14.66\%) than in the community (45.45\%). Additionally, their findings suggest that those who drop out of treatment have an average $16 \%$ higher likelihood of recidivism than treatment completers. Interestingly, they also found that in general, treatment dropout was associated with higher recidivism risk than not starting treatment. This finding has been found elsewhere (Olver et 


\section{MODEL OF ENGAGEMENT FOR CORRECTIONAL PRACTICE}

al., 2011), suggesting those who start but do not complete treatment have a greater chance of re-offending than those who do not start in the first place.

From these results, it is clear that both completion and efficacy rates vary greatly across treatment style, populations, and the settings in which treatment takes place. What is still unclear is the mechanisms underpinning successful and enduring engagement in treatment. This is crucial given that non-completion of treatment, and poor outcomes when treatment is completed, has high social and financial costs (Corrections, 2017).

\section{Treatment Engagement}

More recently, the concept of treatment engagement has received increased attention in the correctional rehabilitation literature. It seems likely that treatment engagement plays a significant role in the likelihood that someone will complete treatment and demonstrate better outcomes (Drieschner, Lammers, \& van der Staak, 2004; McMurran \& Ward, 2010; O'Brien \& Daffern, 2017; Tetley, Jinks, Huband, \& Howells, 2011; Ward, Day, Howells, \& Birgden, 2004). However, many researchers have found that engagement is generally low within the offending population (Holdsworth, Bowen, Brown, \& Howat, 2014; McMurran, 2002; Ward et al., 2004). How then can we increase engagement in treatment programmes, and thus increase completion rates and improve outcomes? In order to respond to this question, we need to more thoroughly investigate the construct of engagement, the causal mechanisms underpinning it, and develop strategies to facilitate higher levels of engagement in the context of correctional treatment (Drieschner et al., 2004; Holdsworth et al., 2014; McMurran \& Ward, 2010; Mossière \& Serin, 2014).

Despite the importance of this construct, theoretical investigation into treatment engagement has been limited. To my knowledge there is currently no theory or model which adequately describes the underlying psychological processes causing higher or lower levels of engagement. This thesis will draw on the forensic as well as evolutionary, psychological 


\section{MODEL OF ENGAGEMENT FOR CORRECTIONAL PRACTICE}

and sociological literature pertaining to explanations of behaviour, in an attempt to develop an explanation of engagement in correctional treatment. In the following chapter, I will review how the construct of engagement is currently conceptualised and outline why these formulations are problematic. I will then offer an alternative definition of engagement which will be used for the remainder of the thesis. I will then provide a critical review of six models currently available to inform our understanding of engagement. Finally, I will outline the criteria I believe should guide the development and evaluation of a robust theory of engagement. 


\section{Chapter 2 - Current Approaches to Treatment Engagement}

\section{Current Conceptualisations of Engagement}

An important first task in theory development is to clearly identify the phenomena we are trying to explain. In this case, treatment engagement seems straight forward and is a term commonly used within forensic treatment. However, when we begin to review the literature we can see that engagement as a concept remains ambiguous, poorly defined, and varied in terms of how it is measured and studied which has led to interpretational limitations and confusion (Drieschner et al., 2004; Holdsworth et al., 2014; Howells \& Day, 2006; Larochelle et al., 2011; McMurran \& Ward, 2010; Tetley et al., 2011). Indeed, many researchers have highlighted the need for definitional clarity of treatment engagement (Drieschner et al., 2004; Holdsworth et al., 2014; Howells \& Day, 2006; Larochelle et al., 2011; McMurran \& Ward, 2010; Tetley et al., 2011).

Engagement has been defined in terms of motivation, attendance, completion, compliance, participation, and out-of-session behavioural change (Holdsworth et al., 2014). So, what are the problems with these current conceptualisations and how can we more clearly define engagement? Here, I will explore some of the problems associated with using 'completion' or 'attrition' as a measure of engagement, given they seem to be the most widely utilised in the literature (Holdsworth et al., 2014). I will then provide an alternative definition which will be utilised in the MECP.

Firstly, I argue that completion is instead a possible outcome of engagement. That is, when someone is engaged, they are more likely to complete treatment (Drieschner et al., 2004; McMurran \& Ward, 2010; O'Brien \& Daffern, 2017; Ward et al., 2004). It seems likely that when someone is engaged in treatment, it is because they expect it will benefit them in 


\section{MODEL OF ENGAGEMENT FOR CORRECTIONAL PRACTICE}

some way, and this idea is explained the Theory of Reasoned Action (Fishbein \& Ajzen, 2010). Indeed, when individuals believe treatment will help them, they are more likely to complete it (Sturgess et al., 2016). Thus, if an individual sees and experiences positive outcomes from attending sessions, listening to and working with the therapists and practicing the skills taught, they are more likely to continue with those behaviours and thus be more likely to complete treatment. Therefore we cannot be certain that engagement will always lead to completion or that completion is always an indicator of engagement.

Secondly, completion and attrition are retrospective measures which do not provide opportunities to intervene and prevent dropout when engagement is low. This leaves the concept with little practical utility. In order to better conceptualise engagement, we must be able to understand the causal mechanisms underpinning it, thus allowing for the development of strategies to enhance it.

Thirdly, engagement operationalized as completion or attrition is a dichotomous measure - that is one either completes treatment or does not. It is more likely that engagement is continuous in that one can engage to varying degrees at different points in time. By viewing engagement on a continuum, we are able to look at what is going well, what is going wrong and how we can intervene to enhance it.

Finally, using completion as a measure for engagement does not take into account the dynamic nature of engagement and the changes one may see over the course of treatment. It makes the assumption that, if the individual completes treatment, they were engaged throughout the whole programme of treatment. Conversely, if the individual fails to complete treatment, it assumes they were not engaged at all. It seems more likely, however, that individuals will engage to varying degrees under different internal and external conditions. 


\section{MODEL OF ENGAGEMENT FOR CORRECTIONAL PRACTICE}

\section{A definition for treatment engagement}

It is important that researchers in the field agree on a robust definition of engagement in order to progress theoretical understanding of the causal mechanisms underpinning it. I propose that engagement is the behavioural expression of progress toward collaboratively agreed upon therapeutic goals. Engagement is therefore an adaptive, goal-directed practice; a means to achieving a personally meaningful end state (e.g. improved relationships, enhanced psychological functioning, avoiding prison). The behavioural expression will be determined by the requirements of the specific style of treatment (Holdsworth et al., 2014) and should be clearly and collaboratively defined at the commencement of treatment by the therapist and participant. Indeed, Holdsworth et al. (2014) suggest a more useful way to conceptualise engagement is through active participation in treatment tasks and out-of-session efforts toward behavioural change. For example, a participant may be observed to actively challenge their offending-supportive thinking through dialogue with their therapist, practice emotional regulation strategies (e.g. deep breathing, taking time out), share their experiences with others and asking for feedback or verbally explore the costs and benefits of past and future behaviours.

\section{Current Models of Treatment Engagement}

In addition to the absence of a clear and common definition of engagement, there is a lack of theoretically sound and empirically validated models explaining the engagement process. As such, various conceptual frameworks have been used in an attempt to understand it. Some of these, such as the Transtheorectical Model (TTM; Prochaska \& Diclemente, 1982) have been imported from other fields and used within correctional treatment. Other 


\section{MODEL OF ENGAGEMENT FOR CORRECTIONAL PRACTICE}

models, such as the Multi-factor Offender Readiness Model (MORM; Ward et al., 2004) have been developed specifically for use with offending populations.

I will now provide a critical review of these two models in terms of understanding treatment engagement, along with four others: Programme Engagement Theory (PET; Holdsworth, Bowen, Brown, \& Howat, 2017), Readiness to Change Framework (RCF; Burrowes \& Needs, 2009), Integral Conceptualisation of Treatment Motivation (ICTM; Drieschner et al., 2004) and the Conceptual Model of Treatment Responsivity (CMTR; Serin \& Kennedy, 1997). I will then outline important theoretical features I propose should guide the development and evaluation of a theory of engagement.

\section{Transtheoretical Model}

The trans-theoretical model (TTM; Prochaska \& Diclemente, 1982; Prochaska, DiClemente \& Norcross, 1992) is an integrative model which attempts to describe the process of behaviour change. It was initially used to explain smoking cessation, and has since been imported to the treatment addiction and unwanted behaviours, such as offending. The TTM proposes that behavioural change occurs as a stepwise process whereby individuals progress forward through a series of five discrete stages toward permanent behavioural change. This progression is facilitated by the cognitive, affective and behavioural processes of change. There have been a number of different iterations of the model over the years with changes in stages, suggestions for additional processes, and the addition of decisional balance and selfefficacy as core constructs (Norcross, Krebs, \& Prochaska, 2011; Prochaska et al., 1992; Prochaska \& Velicer, 1997). 


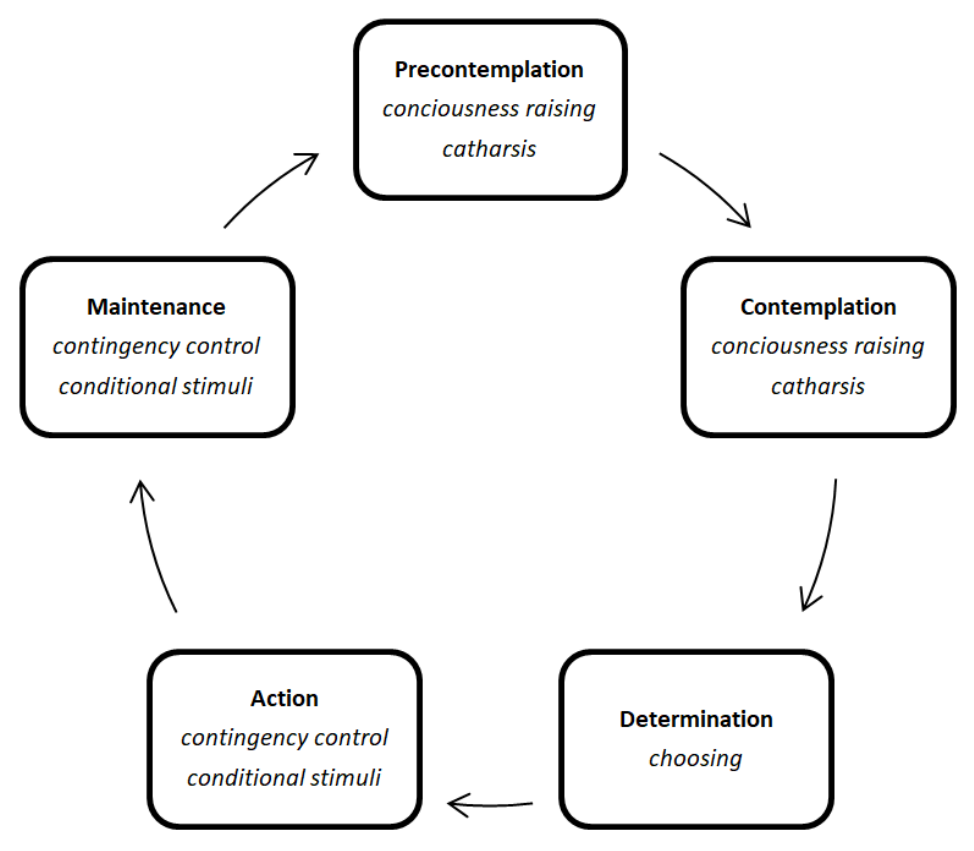

Figure 1. Transtheoretical Model: Stages of Change and Associated Processes (Prochaska \& DiClemente, 1982)

Additionally, the TTM proposes that the efficacy of treatment can be enhanced through the use of stage-matching interventions. That is, specific interventions should be applied depending on which stage of change the individual presents at. These interventions should be determined by the specific processes of change that support progression from the current stage to the next. Figure 1 provides a brief schematic of the stages of change (in bold) and related processes (in italics). The model posits that failure to change behaviour could be explained by the individual regressing to earlier stages or stalling at a particular stage. Individuals would either exit the cycle after successful maintenance of new, desired behaviour resulting in termination, or re-enter the cycle at an earlier stage if they returned to the unwanted behaviour (i.e. relapse). 


\section{MODEL OF ENGAGEMENT FOR CORRECTIONAL PRACTICE}

Some recent research has found further support for the use of the TTM to understand smoking cessation (Velicer, Brick, Fava, \& Prochaska, 2013; Velicer, Norman, Fava, \& Prochaska, 1999). Most research has focused on the validity of the stages of the model and some have found the model applies to other health-related behaviours (Levy, 1997; Miller \& Tonigan, 1996; Prochaska et al., 2005)

Since its conception, empirical support for the TTM has been inconsistent. The TTM is a descriptive model based on stage-theory, the construct validity of which has been questioned (Armitage, 2009; Callaghan, 2004; Casey, Day, \& Howells, 2005; D’Sylva, Graffam, Hardcastle, \& Shinkfield, 2012; Davidson, Roe, Andres-Hyman, \& Ridgway, 2010; Drieschner et al., 2004; Littell \& Girvin, 2002; Sutton, 2001; West, 2005; Williamson, Day, Howells, Bubner, \& Jauncey, 2003). The stage theory of the TTM has been challenged for being an over-simplification of a naturally complex, multi-dimensional process (D'Sylva et al., 2012; Sutton, 2001). The actual number of stages has also been challenged (Carney \& Kivlahan, 1995; Miller \& Tonigan, 1996). Others, still have been unable to find support for discrete, mutually exclusive stages proposed by the TTM and rather advocate for a continuous process (Armitage, 2009; D’Sylva et al., 2012; Drieschner et al., 2004; Sutton, 2001; Williamson et al., 2003).

Another criticism is that the model does not account for social and environmental factors, such as social support, resources and contextual cues, likely to influence behaviour (Casey et al., 2005; Day, Tucker, \& Howells, 2004; West, 2005). Furthermore, non-linear change processes, such as that experienced by mental health clients, are unable to be explained by the TTM model (McMurran et al., 1998). Finally, the body of empirical research is difficult to interpret with any degree of certainty due to the use of different measures to assess what stage an individual is at (Armitage, 2009; Casey et al., 2005; D’Sylva et al., 2012; Littell \& Girvin, 2002; Sutton, 2001; West, 2005). 


\section{MODEL OF ENGAGEMENT FOR CORRECTIONAL PRACTICE}

Inconsistent application of these measures, as well as inconclusive support for their psychometric properties has led to difficulties in the interpretation and generalisation of findings (Armitage, 2009; Casey et al., 2005; D’Sylva et al., 2012; Littell \& Girvin, 2002; Sutton, 2001; West, 2005). For example, the University of Rhode Island Change Assessment Scale (URICA; McConnaughy, Prochaska, \& Velicer, 1983) has been adapted to offending behaviour (Anstiss, Polaschek, \& Wilson, 2011) and has produced mixed results for validity and reliability (Polaschek \& Ross, 2010; Yong, Williams, Provan, Clarke, \& Sinclair, 2015), suggesting the measure and the stages of change construct should only be applied to offending populations with caution (Yong et al., 2015).

Despite limited empirical research into the validity of the TTM as it applies to the offending population, the model has been commonly utilised within correctional practice (Casey et al., 2005). The TTM has been used to evaluate behavioural change for substance abuse (D’Sylva et al., 2012), sexual offending (Tierney \& McCabe, 2001), intimate partner violence (Gilchrist et al., 2015), general violence (Howells \& Day, 2006), forensic mental health treatment (McMurran et al., 1998), juvenile males (Levesque et al., 2012) and motivational programmes (Anstiss et al., 2011; Yong et al., 2015). However, the appropriateness of applying TTM to this population has been debated (Anstiss et al., 2011; Austin, Williams, \& Kilgour, 2011; Burrowes \& Needs, 2009; Casey et al., 2005; Polaschek, Anstiss, \& Wilson, 2010). For example, Casey et al. (2005) and Yong et al. (2015) claim that the evidence does not clearly validate its use with people who are undergoing offending rehabilitation. Additionally, Burrowes and Needs (2009) suggest that the stages of change do not accurately reflect treatment readiness within offending populations.

One aspect of the TTM which has received a large amount of attention in the literature is stage-matching interventions (Prochaska \& DiClemente, 1982). A number of studies have found support for stage-matched interventions for non-psychotherapeutic health- 


\section{MODEL OF ENGAGEMENT FOR CORRECTIONAL PRACTICE}

related behaviour change (McMurran et al., 1998; Norcross et al., 2011; Tierney \& McCabe, 2001; Velicer et al., 2013). On the other hand, some reviews have concluded that stagematched interventions did not produce long-term improvements (Adams \& White, 2003). Norcross et al. (2011) noted they were unable to locate any studies which empirically tested the effect of stage-matched interventions in psychotherapy on treatment outcomes. Therefore, although the TTM appears to have utility in the field of non-therapeutic, healthrelated behavioural change, it remains unclear whether or not the TTM can be reliably applied to therapeutic assessment and treatment, especially for people in correctional settings.

In summary, the TTM has the following limitations in its ability to explain and understand treatment engagement within correctional settings: (1) oversimplification of a multi-faceted process; (2) focus on a linear, staged process over a longer period of time and does not account for moment-to-moment changes in treatment engagement; (3) social and environmental factors are unaccounted for; (4) it is descriptive and therefore lacks explanatory power; (5) the construct itself has not been validated within the offending rehabilitation literature and the measures and methodologies which are currently used to empirically test the theory do not consistently produce psychometrically robust results; (6) it does not account for the influence of the therapeutic alliance, therapist factors and a participant's treatment-related expectations and perceptions on treatment engagement; (7) it does not account for the influence of the individual's capacities or deficits within the change process.

\section{Multi-Factor Offender Readiness Model}

The Multi-Factor Offender Readiness Model (MORM; Ward et al., 2004; Figure 2) identifies a variety of internal and external pre-conditions which are thought to influence treatment engagement and performance. The model posits that these factors influence how ready someone is to commence treatment. The internal pre-conditions for treatment readiness 


\section{MODEL OF ENGAGEMENT FOR CORRECTIONAL PRACTICE}

are the participant's cognitive, affective, behavioural, volitional and identity factors. These take into account internal cognitive factors not addressed by the TTM such as the participant's expectations and perceptions of treatment and treatment providers.

Additionally, in comparison to the TTM, the MORM accounts for external factors which can influence readiness. These include the participants' personal circumstances, treatment location, opportunities, resources, support and programme factors. Whilst the TTM focuses solely on the individual's motivation, the MORM provides more depth through other cognitive factors (e.g. perceptions and expectancies), the individual's capacity (or skills) to actually participate in the treatment being provided, as well as external contextual factors.

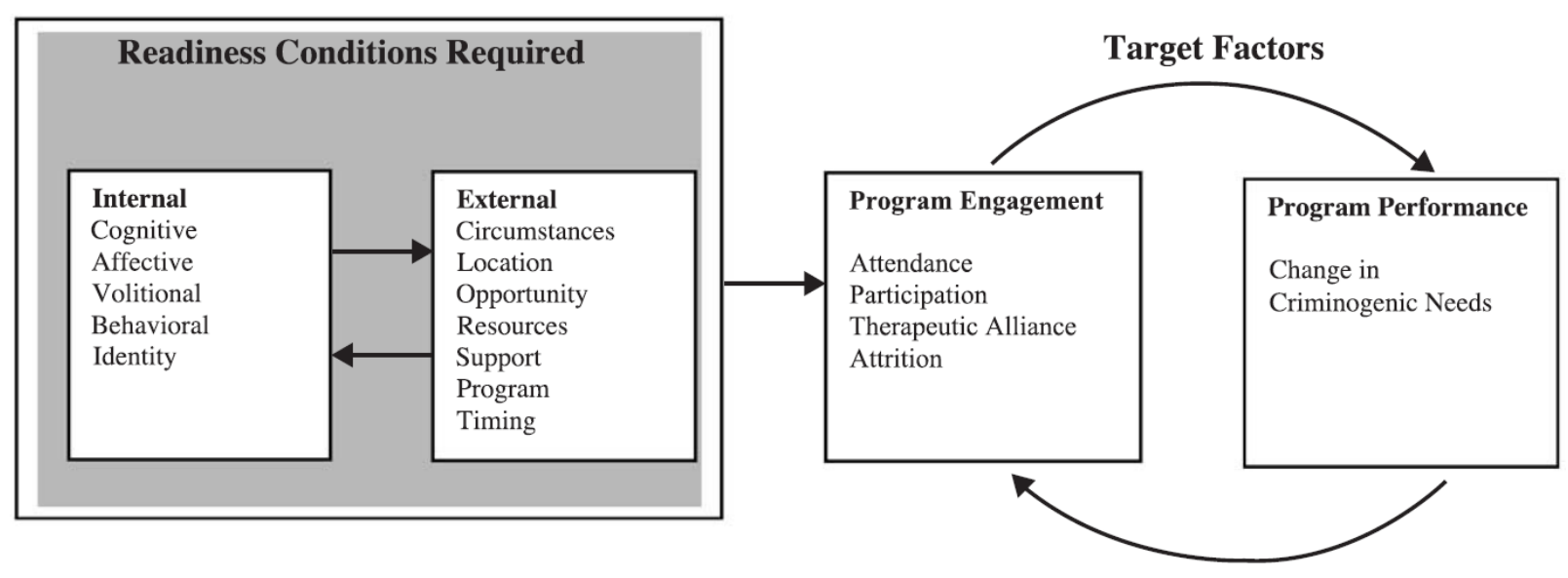

Figure 2. Multi-Factor Offender Readiness Model (Ward et al., 2004)

O'Brien and Daffern (2017) found support for the MORM's assumption that individual characteristics predict treatment completion through their influence on an individual's conduct in therapy. They concluded that impulsivity, a lack of goals and poor behavioural controls lead to poor conduct in therapy, suggesting lower levels of engagement. Casey, Day, Howells, and Ward (2007) developed the Corrections Victoria Treatment Readiness Questionnaire (CVTRQ) to assess factors identified in the MORM. A variety of 


\section{MODEL OF ENGAGEMENT FOR CORRECTIONAL PRACTICE}

studies with forensic populations have found scores on the CVTRQ predict treatment attrition and completion (Alemohammad, Wood, Tapp, Moore, \& Skelly, 2016; Beyko \& Wong, 2005; Bosma, Kunst, Dirkzwager, \& Nieuwbeerta, 2017; Sheldon, Howells, \& Patel, 2010; Tetley, Jinks, Huband, Howells, \& McMurran, 2012; Wormith \& Olver, 2002).

The MORM therefore, provides a significant addition to the understanding and pretreatment assessment of treatment readiness or suitability. However, there are a number of limitations in its application to understanding treatment engagement. Firstly, the MORM makes the assumption that the internal and contextual factors are static, or unchanging. The authors suggest, "those who are ready will engage better in treatment" (Ward et al., 2004, p. 665). Although it makes sense that when one is ready for treatment they will be more likely to engage in treatment, we cannot assume that readiness at pre-treatment will equate to a consistent level of engagement throughout the entire course of treatment. The MORM therefore does not explain and account for temporal variation in engagement.

Secondly, the MORM does not provide a clear definition of readiness or engagement. The authors suggest that engagement is "observably evident from rates of attendance, participation and completion" (Ward et al., p. 665). It makes sense that attendance in treatment is a requirement for engagement to occur (i.e. you can not engage in treatment if you are not there) rather than evidence of engagement and does not necessarily mean someone is engaged every time they are in attendance. Therefore when attendance, and completion (as discussed earlier), are used as proxies for engagement, the question remains; what does engagement look like once the individual is attending the treatment sessions?

The third limitation of the MORM is that although it takes into account contextual factors and the individual's capacity for change within a specific style of treatment it does not account for influence of therapist factors and the therapeutic alliance on treatment engagement. The therapeutic alliance is a critical requirement for successful treatment (Del 


\section{MODEL OF ENGAGEMENT FOR CORRECTIONAL PRACTICE}

Re, Fluckiger, Horvath, Symonds, \& Wampold, 2012; Meier, Barrowclough, \& Donmall, 2005; Patterson, 1984; E. C. Ross, Polaschek, \& Ward, 2008). As social beings, our cognitive, affective and behavioural experiences are shaped not only by our physical environment but also, and perhaps more importantly, by our social world (Ward, 2017; Ward \& Heffernan, 2017). Thus it makes sense that the interactions between the participant and therapist during treatment will also influence the participant's engagement (see chapter three for a full discussion of the therapeutic alliance).

Finally, the model is descriptive in that it provides a framework in which to conceptualise factors that influence readiness for treatment. However, it does not provide any explanation of the causal mechanisms underpinning readiness or treatment engagement. Although the CVTRQ (Casey et al., 2007) appears to predict treatment completion, why and how this is occurs is not answered by the MORM. Therefore the MORM lacks explanatory power and should be considered a framework rather than a robust theory (Ward et al., 2004). Despite these limitations, the model does have practical utility in that it give guidelines for what to consider during pre-treatment assessments of suitability.

In summary, the MORM is useful in that it has practical applications for pre-treatment assessment taking into account a variety of internal and external factors that contribute to an individual's readiness for treatment. The MORM does however have the following limitations in its ability to provide an explanation of engagement; (1) it does not account for temporal variation, (2) it conceptualises engagement as dichotomous, (3) it does not take into account the influence of the therapeutic alliance on the participant, and (4) the model fails to provide a clear definition of treatment engagement.

\section{Programme Engagement Theory}

The Programme Engagement Theory (PET; Holdsworth et al., 2017) is comprised of two models and was developed in an attempt to explain the process of Group Offending 


\section{MODEL OF ENGAGEMENT FOR CORRECTIONAL PRACTICE}

Behaviour Programme (GOBP) engagement. The model is shown in Figure 3 and proposes that a group member's engagement is the result of the group member undergoing the behavioural change process and the facilitator's role in facilitating this process. The PET proposes that this process is made up of three core stages, each comprised of the facilitator's and group member's "mutually contingent" positions, roles and aims within the treatment programme.

The first stage is "getting started". For the facilitators, this involves "setting the scene" by dealing with initial resistance, instilling the perception of choice and shifting the focus from group members' offending to their strengths. For the group members, this involved "negotiating the group" by establishing their position within the group, relating to others by finding commonalities and establishing emotional attachments.

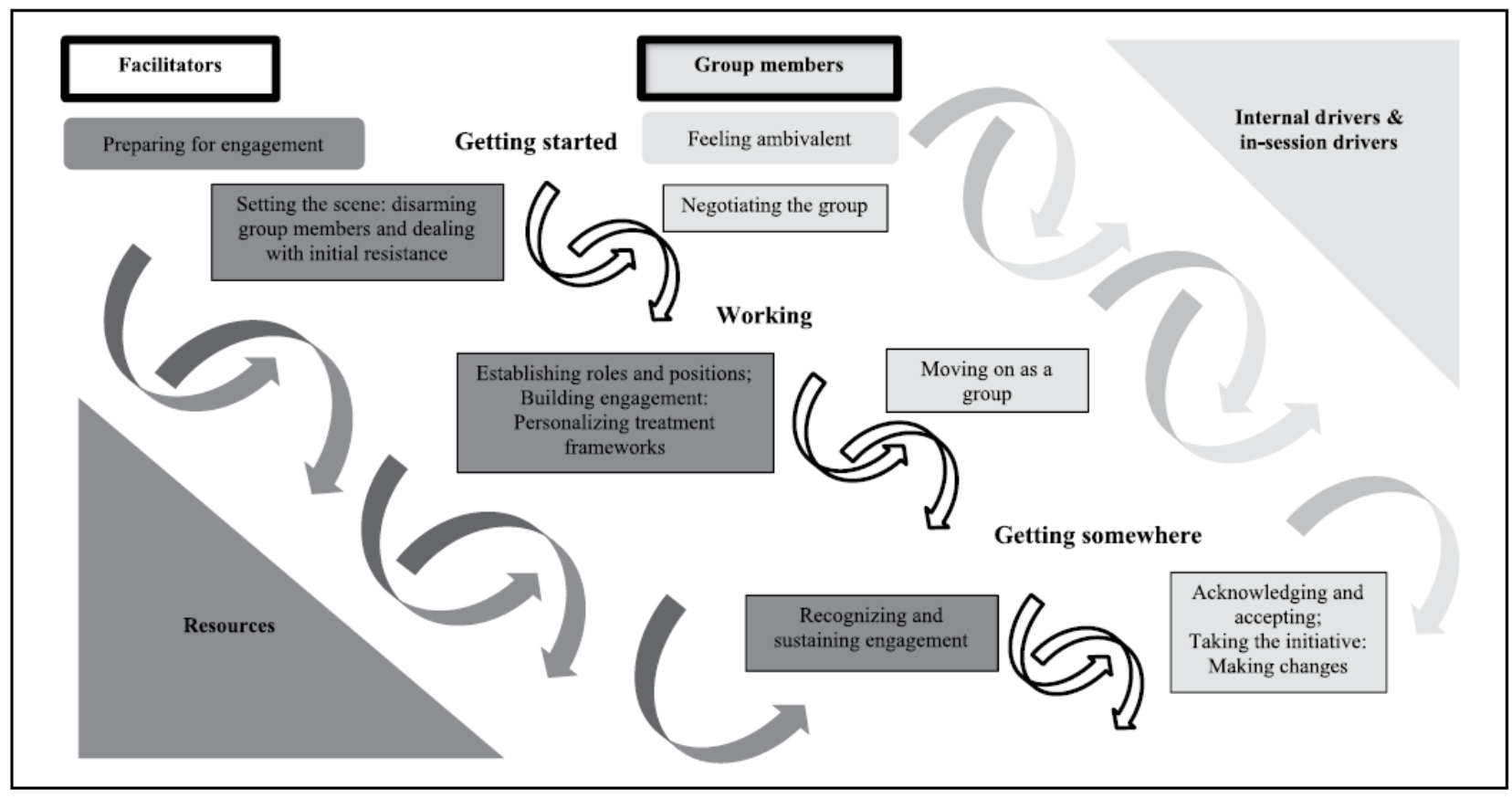

Figure 3. The Programme Engagement Model (Holdsworth et al., 2017) 


\section{MODEL OF ENGAGEMENT FOR CORRECTIONAL PRACTICE}

The second stage is "working". For the facilitators, this involved "establishing their role and position" by managing group members' expectations of them through appropriate personal disclosure, developing personalised treatment plans and linking the content to their personal circumstances. For the participants, this involved "moving on as a group" by carefully considered self-disclosure and working together toward change.

The final stage in the PET is "getting somewhere". For the facilitators, this involved "recognising and sustaining engagement" by acknowledging participation through motivational interviewing techniques such as affirmations, reflective listening and openended questions (Miller, 2013) and other reinforcement contingencies. For group members, this involved "acknowledging and accepting" the past and their offending and taking initiative for making changes by applying the programme concepts and practicing the new skills.

This model progresses theory development in the area of offender rehabilitation engagement in a number of ways. Firstly, it emphasises the role the therapeutic alliance has in establishing and maintaining engagement. The model highlights that the presentation and competence of the facilitator within treatment plays a crucial role in the attitudes of the group members and their willingness to participate. As such, this model incorporates a relational component which many others do not.

Secondly, the PET conceptualises engagement as an integrated process comprising a variety of processes at work to deliver what we see as engagement. A further strength of the PET is its practical utility, or ability to provide guidelines for practice. For example, this model proposes that personalised treatment frameworks support engagement and thus suggests that individualising interventions within manualised group therapy is beneficial. Finally, it is promising that the PET provides a clear definition of engagement as "all the 


\section{MODEL OF ENGAGEMENT FOR CORRECTIONAL PRACTICE}

efforts that clients make during the course of treatment (both within and between sessions) toward the achievement of changes (treatment outcomes)" (Holdsworth et al., 2014, p. 430).

The PET does however have a number of limitations which restrict its explanatory power. Firstly, the model does not account for contextual barriers and facilitators of engagement. Although the authors make mention of the group members' internal determinants, and the "resources" of the facilitators, the model does not explain how these actually influence engagement. Secondly, the model described a staged and linear process of increasing engagement, which is unable to account for temporal fluctuations and contextual variation in engagement, nor can it explain differing levels of engagement between group members. The model description makes no mention of the role that group members' competence or capacities has on their ability to actually do the treatment and thus the influence these have on engagement.

Furthermore, the second stage of the PET, "working", posits that engagement leads to the alignment of group members' knowledge and attitudes to the programme aims. This seems counter-intuitive. The model assumes that when group members' knowledge and attitudes are aligned with the programme, engagement has already occurred. I argue however that this alignment is a pre-requisite to engagement in that when group members' attitudes and the programme aims are in sync, engagement will ensue (e.g. Sturgess et al., 2016). Thus I propose that collaboration on aims and goals between participant and therapist is a requirement for engagement rather than an outcome of it. Finally, the third stage of the PET, "getting somewhere", describes group members making active efforts to apply the programme concepts as part of the engagement process. I argue that this skills application is instead the outcome of high levels of engagement and in fact, is the intended outcome of treatment. 


\section{MODEL OF ENGAGEMENT FOR CORRECTIONAL PRACTICE}

\section{Readiness to Change Framework}

In response to criticisms of the TTM, Burrowes and Needs (2009) developed the Readiness to Change Framework (RCF). This framework was conceived specifically for correctional treatment programmes and is made up of two interacting models. The first model is the 'context of change' which is made up of three parts; (1) the individual/personal factors, (2) the catalyst for change, and (3) the environment in which change is to occur. These three factors interact multi-dimensionally (depicted in Figure 4) to comprise the full context. This context can be impeded by one or more of ten 'barriers to change' which is the second model.

These ten barriers to change are described in Table 1 and are largely made up of the individual's perceptions of treatment and the change process. The RCF makes four core assumptions about the change process. Firstly, an individual's readiness to change is nonlinear, dynamic and fluctuating (as determined by the context of change and presence of barriers to change). Secondly, readiness to change is influenced by internal and external factors. The third assumption is that change requires the lowering of barriers. Finally, barriers to change are common for different types of behaviour.

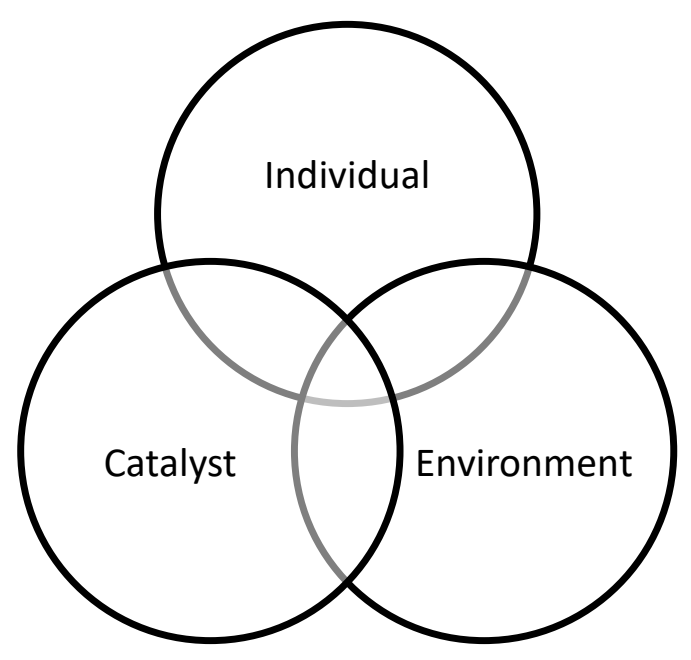

Figure 4. Readiness to Change Framework: Context of Change (Burrowes \& Needs, 2009) 


\section{MODEL OF ENGAGEMENT FOR CORRECTIONAL PRACTICE}

The RCF is therefore a useful tool in conceptualising the different factors that influence someone's readiness to change. It specifically addresses some of the key concerns with the TTM such that the RCF refers to the dynamic and fluid nature of readiness and includes external and contextual factors. Additionally, in comparison to the TTM, the RCF describes important cognitive factors such as an individual's perceptions and expectations, not only of the change process, but also of the means through which they progress toward change (i.e. treatment).

Table 1.

Readiness to change framework: barriers to change.

\begin{tabular}{|l|}
\hline Barriers to Change \\
\hline Perceived importance of change \\
\hline Perceived need for change \\
\hline Perceived level of personal responsibility \\
\hline Perceived costs and benefits of change \\
\hline Perceived sense of urgency to change \\
\hline Perceived ability to change \\
\hline Perceived ability to maintain change \\
\hline Perceived costs associated with the means to change (e.g. treatment) \\
\hline Perceived suitability and efficacy of the means to change (e.g. treatment) \\
\hline The realities of change \\
\hline
\end{tabular}

Unfortunately, the model does not account for the influence of the therapist and therapeutic alliance on the change process. Secondly, this model refers specifically to readiness and not necessarily engagement. The model does not clearly define the concepts of readiness or engagement making it difficult to understand what exactly they are referring to. Additionally, the model is descriptive, and provides a framework which may hold practical utility. It is likely to be useful for treatment providers to guide their pre-treatment assessment, particularly in identifying barriers that could hinder treatment progress. However, it does not 


\section{MODEL OF ENGAGEMENT FOR CORRECTIONAL PRACTICE}

attempt to provide a causal explanation for why the therapist might observe these particular barriers, how they interfere with the context or how the factors making up the context interact and influence readiness. Mossière and Serin (2014) comment that the RCF may "not only be able to indicate whether an offender is ready for change, but may also indicate the particular barriers which appear to be obstructing change" (p. 385). However, at this time, no empirical research has been conducted to validate the model.

\section{Integral Conceptualisation of Treatment Motivation}

Drieschner et al. (2004) highlight the conceptual confusion associated with motivation, engagement and readiness in the literature. They identified three key sources for this confusion including; “(a) negligence of the concepts' intrinsic relationship with behaviour, (b) entanglement of the concept with its determining factors and behavioural consequences, and (c) conceptualization in a stage model" (p. 1115). In light of these concerns, Drieschner et al. (2004) developed the Integral Conceptualisation of Treatment Motivation (ICTM; see Figure 5).

The ICTM model distinguishes treatment motivation from treatment engagement. In this model, treatment motivation is conceptualised as "the patient's motivation to engage in treatment" (p. 1130) and treatment engagement is conceptualised as "the patient's behavioural engagement as required by the particular treatment approach" (p. 1130). The construct of "treatment motivation" is separated into six inter-related "internal determinants" reflecting cognitive and affective factors including: the level of suffering caused by the problem behaviour, outcome expectancy, problem recognition, perceived suitability of treatment, perceived costs of treatment, and perceived external pressures. "Treatment engagement" then arises from the interaction between the internal determinants of treatment motivation and the individual's "limitations to volitional control" (i.e. their capacity to actually do the treatment). Treatment engagement, along with "problem characteristics" (i.e. 


\section{MODEL OF ENGAGEMENT FOR CORRECTIONAL PRACTICE}

the type of problem being treated) and "treatment effectiveness" (i.e. the type of treatment being delivered) leads to "treatment outcomes". The authors emphasise that although contextual factors (such as the individual's circumstances, demographics and events) are important, these effect treatment motivation by influencing the internal determinants. That is, the internal determinants mediate the influence of external factors on treatment motivation.

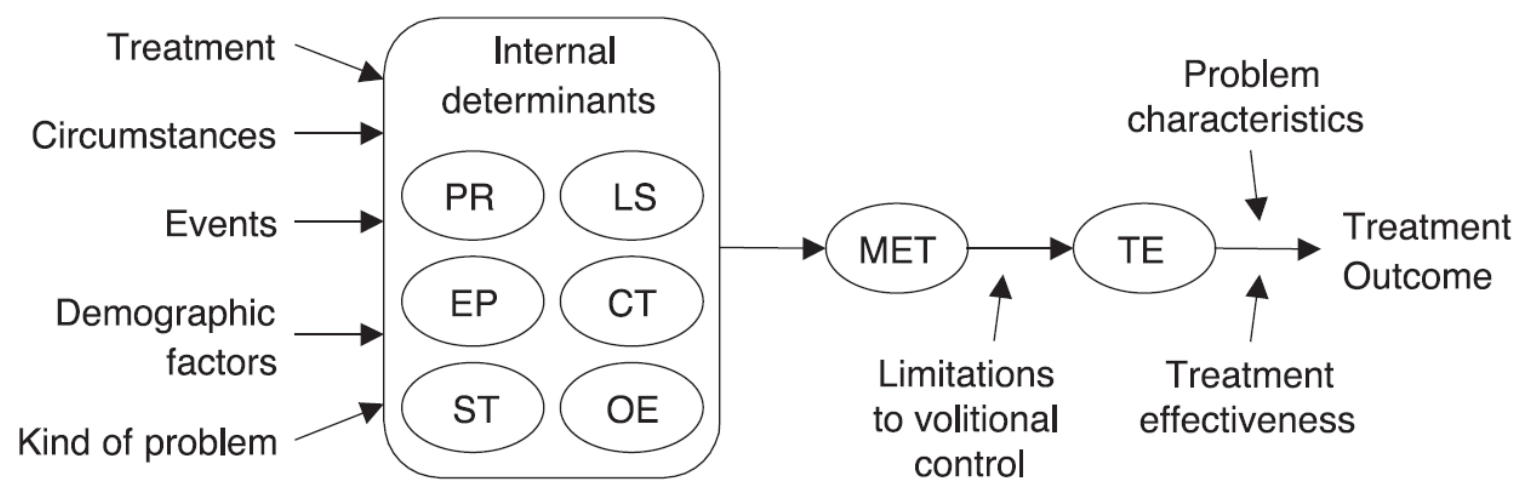

Abbreviations: $P R=$ Problem Recognition; $L S=$ Level of Suffering; EP = External Pressure; $\mathrm{CT}=$ perceived Costs of Treatment; $\mathrm{ST}=$ perceived Suitability of Treatment; OE = Outcome Expectancy; $\mathrm{MET}=$ Motivation to Engage in Treatment; TE = Treatment Engagement

Figure 5. Integral Conceptualisation of Treatment Motivation (Drieschner et al., 2004)

This conceptualisation is useful as it addresses a number of limitations of the models previously described. Firstly, the ICTM explicitly separates the constructs of treatment motivation, engagement and outcomes, accurately identifying them as related and likely predictive but not the same thing. Secondly, the ICTM is dynamic. Within the model, changes to internal determinants can result in changes to treatment engagement. As cognitive and affective processes are fluid, this helps to conceptualise treatment engagement as a dynamic phenomenon, accounting for changes across time.

Thirdly, the model includes both the influence of the individual's capacity to engage (in the ICTM, this is labelled "limitations to volitional control") and separates this from 


\section{MODEL OF ENGAGEMENT FOR CORRECTIONAL PRACTICE}

internal motivation. For example, an individual may be motivated for treatment, but be unable to participate in specific activities due to difficulties with literacy or comprehension. Thus it is also notable they have included the important influence that intervention choice (i.e. treatment effectiveness, problem behaviour) can have on the treatment outcome. However, I would argue that the intervention choice should come before treatment engagement, as the choice of intervention is likely going to determine the ability or willingness of the individual to actually achieve the behavioural expectations of the treatment (i.e. treatment engagement).

Although the ICTM brings us further toward a clearer understanding of the role of treatment in behavioural change, it has two significant limitations. Firstly, although the model makes mention of external determinants (i.e. contextual factors), it does so only in passing, without full exploration of their influence. The ICTM acknowledges the importance of contextual factors but states this is is an indirect relationship mediated by internal determinants, without attempting to explain how they do this. They also do not detail what these external determinants might be. The difficulty with this is that it limits the practical utility of the model in modifying the individual's cognitive and affective states in order to increase motivation and therefore engagement. By excluding a detailed description of external factors, practical application is limited only to modifying the individual rather than the context.

Secondly, the model does not take into account the relational nature of treatment. They mention the therapeutic alliance in their discussion about "perceived suitability of treatment", however this refers specifically to the individual's perceptions and does not discuss how the therapist and their interactions can influence this process. These two details affect the practical utility of the model in so far as they remove two sources of variance (i.e. the therapist and the external factors) which, if changed, could influence treatment 


\section{MODEL OF ENGAGEMENT FOR CORRECTIONAL PRACTICE}

engagement. The model therefore assumes that the only way to enhance treatment engagement is by modifying the individual's cognitive and affective states. However, modifying the individual requires them to be engaged in treatment, creating a 'catch 22 ' type scenario. It is practically useful to also consider the external determinants and therapist factors that can be changed to enhance treatment engagement, which may also be less resource intensive. For example, instead of individual one-to-one motivational interviewing to adjust the individual's perceptions of the costs of treatment, actually reducing the costs of treatment and removing external barriers (e.g. like financial costs, lost wages, high levels of anxiety and safety concerns) may be less resource intensive.

\section{Conceptual Model of Treatment Responsivity}

Serin and Kennedy (1997) first investigated treatment responsivity with offending populations and developed a broad responsivity model called the Conceptual Model of Treatment Responsivity (CMTR; Figure 6). The model described a variety of factors influencing treatment responsivity including the treatment setting, offender characteristics, therapist characteristics, treatment intensity, and motivational issues. Treatment responsivity can influence treatment outcomes. Firstly, "treatment responsivity" is comprised of a variety of inter-related participant, therapist, and contextual factors which contributes to "treatability" and "treatment effectiveness". As a result, variables such as motivation, readiness, compliance, participation and treatment gains are affected, ultimately determining treatment outcomes or "generalization". 

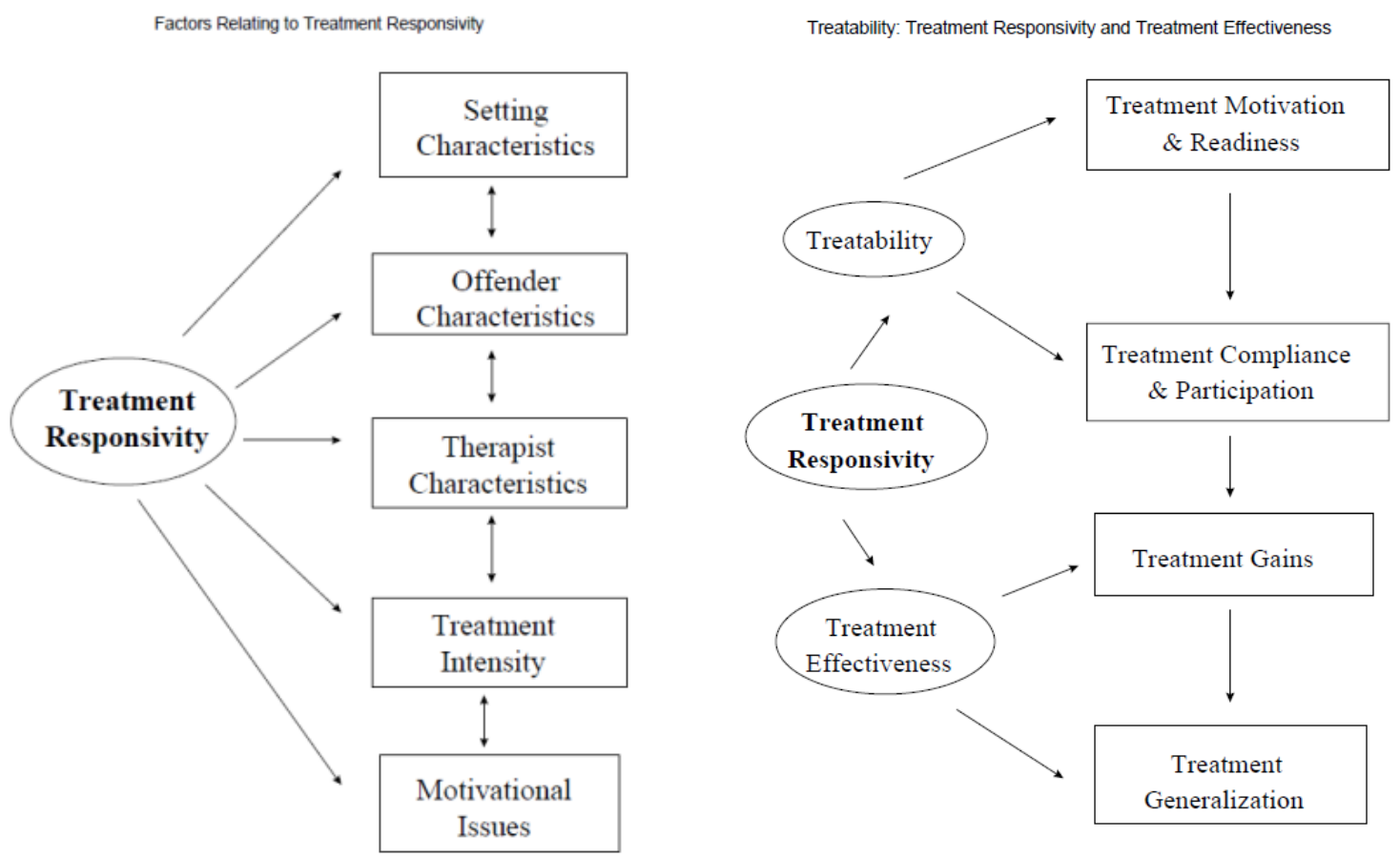

Figure 6. Conceptual Model of Treatment Responsivity (Serin \& Kennedy, 1997)

It is promising that this model has incorporated the therapist, therapeutic alliance and the important role they play in treatment responsivity; highlighting the relational component adds more conceptual depth to our understanding of engagement. Furthermore, they have considered the important role that external and contextual factors play on an individual's presentation in treatment. Another strength of the model is that it encompasses internal factors and some aspects of participant capacity through offender characteristics and motivational issues. Finally, although not discussed by the authors, the model can accommodate temporal variation and the continuous nature of engagement through changes in factors that influence treatment responsivity.

The model itself, however, is very broad, generic and descriptive. It lacks depth and specificity, leaving its practical utility questionable. The model describes how treatment responsivity influences treatment gains through treatability and treatment effectiveness and 


\section{MODEL OF ENGAGEMENT FOR CORRECTIONAL PRACTICE}

provides a very broad list of internal and external factors that can influence responsivity. This list is neither exhaustive nor conceptually clear. It merely provides a framework within which to describe where responsivity sits in the process of treatment delivery.

Another limitation of this model is that responsivity and engagement remain conceptually unclear. Responsivity is likely an outcome of a variety of factors and not necessarily a specific phenomenon in itself (Ward et al., 2004). The problems with the concept of engagement were discussed earlier in this thesis and Day et al. (2010) agree that the concept of responsivity has also not been clearly defined in the literature. Furthermore, this model does not explain the links, or lack thereof, between responsivity and engagement. In the CMTR, Serin and Kennedy (1997) describe motivation, readiness, compliance, participation and treatment gains. However, how these are causally related and how we can influence them to enhance outcomes remains unclear within the CMTR. Unfortunately, this model has not been empirically investigated and indeed Mossiere and Serin (2014) noted there has been no validation of CMTR.

\section{Critical Features for a Theory of Treatment Engagement}

In this chapter, I have reviewed current conceptualisations of engagement as well as six models that attempt to improve understanding of treatment engagement. This literature review highlights a number of requirements that should be met for a theory to be strong and robust. I have identified nine critical features which I believe should be used to evaluate models of engagement. 


\section{MODEL OF ENGAGEMENT FOR CORRECTIONAL PRACTICE}

These nine evaluative criteria are;

- temporal variation

- continuum

- $\quad$ explanatory power

- therapeutic alliance

- external factors

- $\quad$ internal factors

- $\quad$ participant competence

- $\quad$ practical utility

- definitional clarity

Recent research suggests that levels of engagement are dynamic in that they can fluctuate over time in response to changes in psychosocial variables (Holdsworth et al., 2014). Therefore the first evaluative feature is temporal variation. This refers to the ability for a model to accommodate changes to engagement over time. The second feature, continuum refers to the ability for the model to accommodate an individual becoming increasingly or decreasingly engaged due to changes in internal and external cues.

Ward (2014) suggests that a good theory should incorporate the causal mechanisms underpinning the phenomenon of interest. If the model is only concerned with the determinants (e.g. readiness factors) and outcomes (e.g. completion) as proxies for engagement, it is unable to explain and account for what is observed during treatment. If the model includes causal mechanisms underpinning engagement in the treatment process, it has stronger explanatory power.

The therapeutic relationship has been shown to have a significant effect on treatment outcomes across a range of psychotherapeutic interventions (e.g. Orlinsky, Ronnestad, \& Willutzki, 2004), including in correctional treatment settings (e.g. Taxman \& Ainsworth, 


\section{MODEL OF ENGAGEMENT FOR CORRECTIONAL PRACTICE}

2009). Therefore, I argue this is a critical feature for any model of engagement to incorporate.

Here, the therapeutic alliance refers to whether or not the model has incorporated the relationship between the therapist and the participant and the role this has on engagement.

As has been noted by many researchers; the social context and the setting in which treatment takes place play a pivotal role on the presentation of participants within treatment (Holdsworth et al., 2014; McMurran \& Ward, 2010). To accommodate this, the external factors feature refers to whether or not the model explicitly includes the influence of external contextual, social and environmental variables.

Similarly, internal participant characteristics such as motivation, perceptions and expectations influence a participant's engagement in treatment (Holdsworth et al., 2014; McMurran \& Ward, 2010). Thus the internal factors feature refers to whether not the model includes the internal psychological (i.e. cognitive and affective) characteristics of the individual and the role these have on their engagement.

Additionally, participant competence refers to the ability for the individual to actually participate in and do the treatment tasks. There is evidence that individuals who have attained higher levels of education (Bosma et al., 2017; Sturgess et al., 2016) are more likely to participate in and complete treatment. This suggests that the capacity to learn and other competencies such as social skills and emotional regulation support treatment engagement.

As with any model or theory, an important feature is its ability to inform and enhance practice (Ward, 2014). Practical utility refers to whether or not the model can be applied to identify barriers to and facilitators of engagement and to support practitioners to develop strategies to enhance engagement.

Finally, as discussed earlier in Chapter 2, definitional clarity is a critical task in theory development (Ward, 2014) and refers to whether or not the model has provided a clear conceptualisation of engagement. This must be broad enough in scope to accommodate 


\section{MODEL OF ENGAGEMENT FOR CORRECTIONAL PRACTICE}

different styles of treatment, but also specific enough that it can guide the practitioner's assessment of the participant's engagement during a particular programme of treatment.

I have applied these criteria to the six models reviewed earlier in this chapter (Table 2). The column on the left shows the nine critical features described above. The following columns represent my evaluation of whether or not each model has achieved each individual criterion. As can be seen in Table 2, none of the current models adequately accommodates all nine features, with explanatory power lacking across all six models.

Table 2.

Engagement model adherence to critical features of a theory of engagement.

\begin{tabular}{|l|c|c|c|c|c|c|}
\hline Features & TTM & MORM & PET & RCF & ICTM & CMTR \\
\hline Temporally Variation & $\checkmark$ & X & X & $\checkmark$ & $\checkmark$ & $\checkmark$ \\
\hline Continuum & X & X & X & $\checkmark$ & $\checkmark$ & $\checkmark$ \\
\hline Explanatory Power & X & X & X & X & X & X \\
\hline Therapeutic Alliance & X & X & $\checkmark$ & X & X & $\checkmark$ \\
\hline External Factors & X & $\checkmark$ & X & $\checkmark$ & X & $\checkmark$ \\
\hline Internal Factors & $\checkmark$ & $\checkmark$ & $\checkmark$ & $\checkmark$ & $\checkmark$ & $\checkmark$ \\
\hline Participant Competence & X & $\checkmark$ & X & $\checkmark$ & $\checkmark$ & $\checkmark$ \\
\hline Practical Utility & $\checkmark$ & $\checkmark$ & $\checkmark$ & $\checkmark$ & X & X \\
\hline Definitional Clarity & X & X & $\checkmark$ & X & $\checkmark$ & X \\
\hline
\end{tabular}

Note. TTM = The Transtheoretical Model (Prochaska \& DiClemente, 1983; DiClemente \& Norcross, 1992), MORM = Multi-Factor Offender Readiness Model (Ward et al., 2004), PET $=$ Programme Engagement Theory (Holdsworth et al., 2017), RCF $=$ Readiness to Change Framework (Burrowes \& Needs, 2009), ICTM = Integral Conceptualisation of Treatment Motivation (Drieschner et al., 2004), CMTR = Conceptual Model of Treatment Responsivity (Serin \& Kennedy, 1997).

The aim of this thesis is to develop a model of engagement that closes the gaps in our understanding by accounting for all nine features, thus proving to be a sound and robust theory of engagement. These criteria will be revisited in chapter five in order to evaluate the Model of Engagement for Correctional Practice. In the following chapter, I will suggest some 


\section{MODEL OF ENGAGEMENT FOR CORRECTIONAL PRACTICE}

theoretical tools which can be used to enhance our understanding of engagement and which have informed the development of my Model of Engagement for Correctional Practice (MECP). 


\section{MODEL OF ENGAGEMENT FOR CORRECTIONAL PRACTICE}

\section{Chapter 3 - Theoretical Tools}

In the development of the MECP, I have made a number of assumptions which utilise and build on previously validated psychological concepts and ideas. In this chapter, I will provide an overview of the four key theoretical commitments which have informed the development of the MECP; evolutionary theories of human functioning, human agency, values and norms, and the therapeutic relationship.

\section{Evolutionary Theories}

I propose that engagement is a composite construct comprised of multiple adaptive, goal-directed behaviours which are aimed at achieving a particular valued outcome. As such, engagement is best understood as arising from normative psychological and social systems functioning within a given environment. In order to develop a theory of engagement, I must adhere then to a number of theoretical commitments to human functioning and behaviour. Here, I will describe three evolutionary theories I believe provide a sound platform on which to build my theory of engagement. These are (1) subjectivity (Walsh, 2015) and the firstperson perspective (Baker, 2011; Neisser, 2015), (2) emotional systems (Maiese, 2011) and (3) prediction (Hohwy, 2013) and prospection (Seligman, Railton, Baumeister, \& Sripada, 2016).

\section{The Subjective First-Person Perspective}

The first theoretical commitment is to subjectivity (Walsh, 2015) and our unique and robust first-person perspective (Baker, 2011). Humans have evolved the conceptual ability to differentiate ourselves from others and the world around us, and to know that we interact with other people and objects in our environment (Baker 2011; Neisser, 2015). We are able to 


\section{MODEL OF ENGAGEMENT FOR CORRECTIONAL PRACTICE}

orientate ourselves to time and space in relation to other individuals and things in our environment, such as resources and opportunities (Baker, 2011; Neisser, 2015). We also have the capacity to plan for and make predictions about the future (Howhy, 2013; Seligman et al., 2016). This capacity requires us to have adaptive internal working models (i.e. knowledge) of ourselves, other people and the world around us, including an awareness of the potential opportunities for and barriers to the attainment of goals. These adaptive models develop from and are moulded by our experiences.

Evolutionarily, these adaptive models benefited humans in being able to search for food sources, avoid predators, find shelter and seek out appropriate mates (Neisser, 2015). For example, if an animal goes hunting for prey, it must be able to differentiate prey from predator, track the prey, return to its dwelling and chose which other animals to share the food source with. In the modern world, the capacity to mentally represent the world helps us to interact with our environment, establish and maintain relationships, and ensure our physical and psychological needs are being met.

I propose that this subjective, first-person perspective capacity (i.e. to mentally represent our self, others and the world) plays a role in how and why people engage in treatment to varying degrees at different points in time. An individual will act in a manner that is of benefit to him or her, taking into account their models of themselves, other people and their environment. For example, if a participant has models of other people as being untrustworthy and unpredictable, their goal may be to maintain superficial relationships so as to avoid disappointment. They may therefore be less likely to disclose personal information within the treatment setting and present as very quiet so as not to leave themselves vulnerable. 


\section{MODEL OF ENGAGEMENT FOR CORRECTIONAL PRACTICE}

\section{Emotional Systems and the Affective Lens}

The second theoretical commitment is to the emotional systems of human beings (Maiese, 2011). Evolutionarily, emotions systems have assisted organisms to identify beneficial resources and avoid potential dangers. Animals then, including humans, possess what could be referred to as an affective lens (Ward, 2017) or affective frame (Maiese, 2011), a capacity which helps with the appraisal of objects, places and others as either harmful or beneficial, undesired or desired. Emotions therefore assign meaning to the world and this guides the organism's motivation, attention, memory and evaluations.

I posit that this affective lens plays a crucial role in the presentation of behaviours observed within treatment. An individual's emotions are likely indicators for what is harmful or beneficial to them within treatment, thus they will shape the individual's perceptions of their experiences within treatment. For example, when someone experiences high levels of anxiety or embarrassment when receiving constructive feedback, they may interpret this as a personal attack.

\section{Prediction and Prospection}

The third theoretical commitment is to the mind as a predictive engine (Hohwy, 2013) and our capacity for prospection (Seligman et al., 2016). Humans have a unique capacity to predict possible outcomes of different actions, based on prior knowledge, learning and experiences. This predictive capacity (i.e. for prospection) helps individuals to evaluate internal (i.e. cognitive, affective) and external (i.e. social, environmental) cues, assess different options for action, and foresee the potential outcomes for those actions.

Evolutionarily, this would have been beneficial for individuals as they would be able to plan (implicitly or explicitly) for hunting and gathering activities, finding shelter and choosing a mate. Seligman et al. (2016) described this eloquently in their description of prospection; "Prospection is a label for the mental process of projecting and evaluating future 


\section{MODEL OF ENGAGEMENT FOR CORRECTIONAL PRACTICE}

possibilities and using these projections for the guidance of thought and action" (p. 6). The causal models and affective lens discussed above are crucial in guiding this goal-directed cognitive task.

I propose that this process also plays a crucial role within treatment. An individual will implicitly or explicitly evaluate internal and external cues and use these to guide their projections. They will make predictions about what actions are possible and form expectations concerning the consequences (both harmful and beneficial) of those actions at a particular time in the given context. This process supports decision-making, and will ultimately influence the behaviour observed within treatment. It is important to note that prospection is not necessarily a conscious or deliberate cognitive task. In many cases it will be relatively automatic and unconscious, particularly for well-rehearsed behaviours or familiar situations. For example, if a participant has learned that aggression is an effective way to resolve interpersonal problems, they may present within treatment as hostile, threatening or intimidating toward others. In this example, the expectations of violence are positive, such as relief from unpleasant emotions or feeling powerful and in control.

From these three theoretical commitments, it is clear that individuals have a uniquely subjective first-person perspective from which they mentally represent themselves, the world and other people. This is coloured by their affective lens and supports their predictive capacities (i.e. goal-directed tasks). This is all moulded and influenced by their prior experiences and the current external and internal cues. I believe it is important to accommodate this understanding of human functioning into any theory of engagement when engagement is conceptualised as a set of adaptive, goal-directed behaviours.

\section{Human Agency}

My second theoretical commitment is to human agency; the capacity for an individual to act as an independent, autonomous agent where they are able to act on the basis of their 


\section{MODEL OF ENGAGEMENT FOR CORRECTIONAL PRACTICE}

own choices (Durrant \& Ward, 2015; Ward, 2017). In comparison to many other species, humans have the ability to actively and consciously choose which practices to engage in and which practices to avoid. That is, humans can engage in adaptive, goal-directed behaviour. In order to do this, one must be able to formulate goals, identify strategies for achieving those goals, evaluate the effectiveness of those strategies in helping them achieve those goals, and then adjust their practices accordingly. Agency can be defined as the capacity to respond to internal and external cues in a goal-directed manner (Durrant \& Ward, 2015). This was conceptualised in terms of offending by Heffernan and Ward (2015) in their Agency Model of Risk (AMR; Figure 7).

\section{The Agency Model of Risk (AMR; Heffernan \& Ward, 2015)}

The AMR conceptualizes agency as being comprised of three levels; systems, social roles and personal identity, each linked with various needs and values which motivate an action sequence. The action sequence is comprised of three agentic processes; goals, strategies and implementation. The levels of agency are triggered by internal and external cues, which motivate the agent to form a goal in order to meet their needs. The systems level refers to the individual's physiological and biological needs. The social role level refers to the individual's perceptions of themselves in relation to others and the role they play in the world. The personal identity level refers to the individual's values and beliefs about him or herself and their purpose in life.

Different levels are not necessarily separate but each can be more or less salient at different points in time, depending on the contextual cues triggering them. For example, if an individual is attending the first session of a group-based therapy programme, they may prioritise getting to know other group members and their therapists, in order to establish their role within the group and maintain their safety. Motivation could arise at the level of the social role (e.g. I will control the group and keep others safe), personal identity (e.g. I need to 


\section{MODEL OF ENGAGEMENT FOR CORRECTIONAL PRACTICE}

be in control of my situation), systems (e.g. My heart is beating fast, I need to alleviate my anxiety) or any combination of these levels. When a level is activated, the three processes (goals, strategies and implementation) act to transform the value into a tangible goal. As a result strategies are devised, actions are carried out and outcomes are evaluated. It is important to note that this process is not necessarily occurring within the individual's awareness, and that it is an ongoing interaction between the individual and their context.

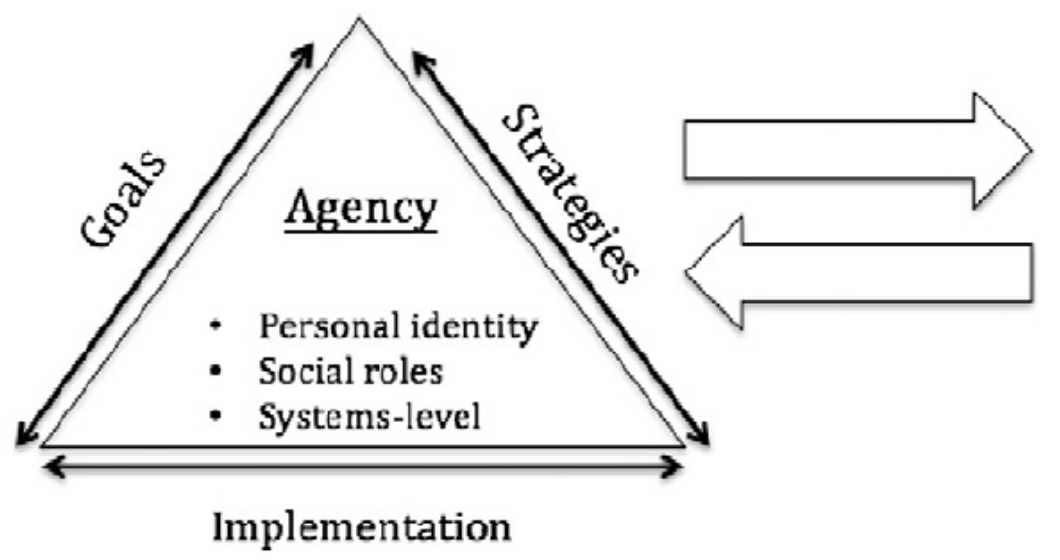

\section{$\underline{\text { Context }}$}

- Social

- Cultural Norms

- Physical

- (Offending)

Figure 7. Agency Model of Risk (AMR; Heffernan \& Ward, 2015).

The goals component involves the individual identifying tangible goals which they can achieve as a means to attain salient values. Goals are the specific outcomes that actions aim to achieve and are determined by the individual's values and beliefs. For example, the individual described in the above example may be motivated by the need to feel a sense of connection with others (e.g. I want others to like me) in the group and may form the goal to quickly establish a bond with other group members.

The strategies are the specific sequence of actions or behaviours that are undertaken to achieve the goal. The individual must identify possible actions and their possible outcomes, essentially using prospection (Seligman et al., 2016). They must then choose what 


\section{MODEL OF ENGAGEMENT FOR CORRECTIONAL PRACTICE}

they expect to be the most effective strategy for achieving their goal. This will be determined by the current context and their previous experiences. It is likely that this process continues to develop over time, becoming more automatic and unconscious as certain goals and strategies are reinforced by their outcomes. Using the example above; if the value is connection and the goal is to develop a bond with other group members, strategies could include flattery of other group members, sharing personal information, offering support, or proving comic relief.

The third process described by Heffernan and Ward (2015) is implementation. This involves applying the strategies and evaluating their effectiveness in goal attainment. Where a strategy was successful, it will be reinforced by the attainment of goals and values and will be more likely to occur again in the future, becoming more embedded in the individuals' psychological and behavioural repertoire. Where a strategy was unsuccessful, the individual will reassess the strategy and/or goal and perhaps formulate other, more effective strategies, or change their goal. Continuing with the above example, if the individual finds that they are unable to form meaningful connections with other group members, they may turn their attention to forming a bond with the therapist. Alternatively, they may find their motivation has changed (e.g. I need to be in control) and so devise alternative goals (e.g. establish himself as the dominant group member) and strategies (e.g. talk over others, stop following instructions).

We can therefore summarise the core capacities required for agency as; (1) the ability to set goals based on salient values, (2) the ability to identify, and predict the outcome of, potential strategies to achieve those goals and (3) the implementation and evaluation of these strategies. In the model described in this thesis, the agency component is comprised of these three core capacities. 


\section{MODEL OF ENGAGEMENT FOR CORRECTIONAL PRACTICE}

\section{Values and Norms}

A third core theoretical commitment guiding the development of this theory of engagement is to values and norms. Values are the enduring beliefs and ideals held by members of a social group that determines what is good, right, beneficial, important, worthwhile and meaningful (Sadler, 2005; Ward \& Heffernan, 2017). Essentially, they are the principles we hold that we chose to live by. Norms are the rules and standards that govern what practices will help us achieve these values, how we evaluate and judge those practices, and how they are to be rewarded or punished (Sadler, 2005; Ward \& Heffernan, 2017). Essentially, norms regulate our actions to support our values. For example, if one values 'fairness', then ensuring equal access to resources would be the norm. If one values 'connection with others', then establishing and maintaining close and meaningful relationships would be the norm.

It is thought that values and norms have their origins in evolutionary processes, where they guided action to optimise the chances of survival (Johnson, 2014). Thus it is likely that norms are informed by and do inform the subjective first-person perspective (Walsh, 2015; Baker, 2011), emotional systems (Maiese, 2011; Ward, 2017) and prospection/projection (Howhy, 2013; Seligman et al., 2016) described above. If values and norms are determined by and influence our subjective first-person perspective and affective lens, it makes sense they will also guide our projections about future possibilities. I propose that there are four types of norms that will influence engagement through their impact on a participant's behaviour within treatment. These are prudential, ethical, social and epistemic norms.

\section{Prudential Norms}

Prudential norms reflect doing what is important and meaningful to the individual and thus what should be prioritised. In other words, prudential norms can be conceptualised as the means to achieving 'goods' or 'human needs' required for wellbeing (McMurran \& Ward, 


\section{MODEL OF ENGAGEMENT FOR CORRECTIONAL PRACTICE}

2004). For example, an individual might strive for the human good of 'relatedness' and hold the norm that helping other people is the right thing to do to achieve this. Within the context of treatment, an individual may value the human good of 'inner peace', free from stress and emotional turmoil. They may maintain an aggressive façade that gives the impression of them being dangerous so that others will not threaten their safety.

\section{Ethical Norms}

Ethical norms are similar to prudential norms in the sense that they reflect morals; the rightness or wrongness of practices, however, in comparison to prudential norms, ethical norms are held by the wider social/cultural group and often reflect an attempt at addressing diversity to achieve overall wellbeing for the whole social group. For example, in general western society ethical norms have led to forbidding behaviour that can harm other people, providing everyone with access to health-care and ensuring all children receive an education. The written law is a reflection of a society's ethical norms.

\section{Social Norms}

Social norms reflect the expected practices of members of a particular social group and/or a social role in order to achieve productivity, cohesion, conformity, collaboration and/or relatedness between members. As such they are associated with a specific social context. For example, the expected behaviours in the role of a mother, like displaying physical affection, may be different to the expected behaviours in the role of a therapist, where displays of physical affection would be inappropriate. Another example would be an individual who, when they are with their peer group, uses drugs but would not do this in front of their children when carrying out their role as a father. Within the treatment context, an individual may find the social norms of therapy incongruent with the social norms of prison culture. For example, talking about their emotional experiences in their peer groups could be punished, but rewarded within therapy. When therapy occurs within a group setting, this 


\section{MODEL OF ENGAGEMENT FOR CORRECTIONAL PRACTICE}

could cause an internal conflict for the individual where they have to decide which normative practices (e.g. to talk about their emotions or to avoid this) to engage in.

\section{Epistemic Norms}

Epistemic norms regulate the acquisition of knowledge, beliefs or ideas; essentially norms about the process of learning. Epistemic norms determine what knowledge is important to acquire and how to acquire it based on the required tasks and the context. They govern the everyday process of learning by influencing what sorts of knowledge one places importance on and what evidence and sources of knowledge one finds trustworthy or useful. Epistemic norms will influence who is called on for advice or information, whether or not it is perceived as worthwhile or helpful and if it is put into action. For some individuals other people may be a reliable and useful source of new information, others may only trust their own experiential learning. Within the treatment context, a participant who holds negative views of authority figures will be unlikely to place value on the learning opportunities provided by therapists, particularly if the therapist displays practices which reinforce their beliefs about authority figures.

In summary, values are overarching principles which guide and motivate our actions whilst norms are the concrete rules governing appropriate practices to achieve our values. It seems plausible to surmise then, that norms and agency are inextricably linked. Where an individual is setting goals, establishing strategies and evaluating their effectiveness, norms will play a role in guiding this process. They will influence what goals are set based on the individuals' values, what strategies are thought to be available and appropriate, how effective those strategies will be and how those strategies are evaluated. Norms will also govern how other people respond to these agentic processes, and whether or not they are rewarded or punished within the context in which they are practiced. Given the pervasiveness of values and more proximately, norms, governing our actions in all aspects of life (Ward \& Heffernan, 


\section{MODEL OF ENGAGEMENT FOR CORRECTIONAL PRACTICE}

2017), along with this suggested influence on agentic processes, it seems prudent to include them in a theory of engagement. If engagement is the set of practices being demonstrated, then norms must be, in some way, guiding those practices.

\section{Therapeutic Relationship}

A fourth and final theoretical tool I utilise in the development of my theory of engagement is the therapeutic relationship as a crucial and pervasive influence on engagement and consequently treatment outcome. The therapeutic relationship has been conceptualised and investigated across a broad range of therapeutic approaches and contexts (Orlinsky et al., 2004). Empirically, the quality of the therapeutic relationship has been positively associated with treatment outcomes across a range of therapeutic styles, presenting problems and treatment settings, including (Barnao, Ward, \& Casey, 2016; Ellis, Simiola, Brown, Courtois, \& Cook, 2017; Hewitt \& Coffey, 2005; Horvath, Re, Flückiger, \& Symonds, 2011; Meier et al., 2005) improved outcomes for domestic violence treatment (Taft \& Murphy, 2007), sexual offending treatment (Beech \& Hamilton-Giachritsis, 2005) and the prison population (Huffman, 2013). Given that there is a general consensus that the therapeutic relationship plays a crucial role in treatment outcomes across the psychological and counselling literatures, it is curious then, that it has received such little theoretical and empirical attention in the field of forensic treatment.

Despite this extensive interest in the therapeutic relationship in the wider therapeutic treatment literature, the concept remains poorly defined due to the use of diverse terminology, measurement tools, and understandings across different therapeutic approaches. The American Psychological Association broadly defines the therapeutic relationship as "the feelings and attitudes that therapist and client have toward one another and the manner in which these are expressed" (Norcross \& Lambert, 2011, p. 5). I will be using this definition 


\section{MODEL OF ENGAGEMENT FOR CORRECTIONAL PRACTICE}

of the therapeutic relationship in the MECP as it is broad enough in scope to accommodate both the intrapersonal and interpersonal processes discussed in much of the literature.

So what then is required for the establishment and maintenance of an effective therapeutic relationship? As mentioned previously, there has been relatively little research investigating the therapeutic relationship as it relates specifically to treatment within correctional settings. Additionally, whilst much empirical research has been undertaken to establish the conditions necessary for the establishment and maintenance of an effective therapeutic alliance, there has been little theoretical advancement in explaining how and why the therapeutic relationship mediates or influences treatment outcomes (Catty, 2004). Metaanalyses and systematic reviews are increasingly providing a detailed picture of the conditions required for the development and maintenance of the therapeutic relationship within psychotherapy and related fields. There is little evidence that demographic factors or disorder-related variables, such as drug use or symptoms, play any significant role in the therapeutic relationship (Meier et al., 2005). There is however support for the effect of other therapist and client characteristics and their interpersonal processes (Meier et al., 2005).

Firstly, I will provide a brief overview of what therapist and client characteristics are thought to support an effective therapeutic relationship and what characteristics can inhibit this developing. I then summarise the Revised Theory of the Therapeutic Alliance, developed by Ross, Polaschek \& Ward (2008) which I believe provides further support for my theory of engagement. Finally, I will review some of the unique challenges a therapist faces when working within the correctional system.

\section{Therapist Characteristics}

Bordin (1979) first defined the working alliance, a component of the therapeutic relationship, identifying the importance of client and therapist collaboratively agreeing to tasks of treatment and the formation of a bond between them. With regard to therapists; 


\section{MODEL OF ENGAGEMENT FOR CORRECTIONAL PRACTICE}

demonstrating warmth, respect, empathy, care, compassion, genuineness, and

collaborativeness as well as being able to establish boundaries and provide direction,

positively influences the therapeutic relationship within correctional settings (Benveniste,

2016; Patterson, 1984; Serran, Fernandez, Marshall, \& Mann, 2003). The therapeutic

relationship may be enhanced when direction is provided through support and guidance but

can be ruptured when this direction is provided in a controlling, dominant or authoritarian manner (Skeem, Louden, Polaschek, \& Camp, 2007). This therapeutic relationship

enhancement or rupture is likely linked to the role that interpersonal schemas play in the therapeutic process as described by Safran (1998; see below for a full description of this process).

Noyce and Simpson (2016) conducted a meta-analysis of studies investigating the therapeutic relationship with mental health clients. They found that clients tended to evaluate the therapist at the commencement of treatment. Clients felt therapist openness and honesty facilitated their own openness, clients connected on a deeper level when they felt listened to and understood, and therapists who were respectful, empowering, non-judgemental, empathic, interested and caring. These factors contributed to the development of stronger therapeutic bonds. This supports earlier findings that affective traits of care, warmth, respect, empathy, openness and honesty are important. Additionally, a non-judgemental and encouraging therapist who listens to and tries to understand their client is more likely to develop a strong therapeutic alliance. Furthermore, being flexible with treatment tasks and goals, working collaboratively alongside the client and supporting autonomy and agency is likely to further enhance the therapeutic alliance.

In addition to their personal characteristics, therapist attachment and interpersonal style is also important. The ability of the therapist to develop close relationships, having a 


\section{MODEL OF ENGAGEMENT FOR CORRECTIONAL PRACTICE}

strong social support network, and a secure attachment style are likely to facilitate the therapeutic relationship (Dunkle \& Friedlander, 1996).

\section{Client Characteristics}

Clients who display higher motivation, demonstrate effective coping strategies, have social support, experienced strong parental bonding, and have secure attachment styles appear more able to develop stronger therapeutic alliances (Mallinckrodt, Porter, \& Kivlighan, 2005; Meier et al., 2005; Taft, Murphy, Musser, \& Remington, 2004). Pretreatment motivation or treatment readiness predicts the quality of the therapeutic alliance (Hiller, Knight, Leukefeld, \& Simpson, 2002), and this appears to hold true for individuals completing sexual offending (Beech \& Hamilton-Giachritsis, 2005) and domestic violence (Taft et al., 2004) treatment.

Unsurprisingly, participants who display hostility and aggression, impulsivity, a lack of concern for the wellbeing of others, self-injurious behaviour, psychopathic traits and chaotic or crisis-prone lifestyles may have more difficulty developing alliances (Puschner, Bauer, Horowitz, \& Kordy, 2005; Taft et al., 2004; Wilson, 2004). This finding is supported by some evidence that suggests it is harder to develop therapeutic relationships with clients diagnosed with personality disorders, especially the Cluster A and B disorders (Lingiardi, Filippucci, \& Baiocco, 2005; Taft et al., 2004).

In addition to personal characteristics, the client's perceptions about the therapist and their expectations of treatment influence the therapeutic relationship and treatment outcomes (Sturgess et al., 2016). For example, if the client has high expectations about treatment and the therapist they may perceive the therapist to be more trustworthy, competent and interested. 


\section{MODEL OF ENGAGEMENT FOR CORRECTIONAL PRACTICE}

\section{Interpersonal Processes}

With regards to interpersonal processes, like any other social interaction, both the client and therapist bring their own unique models of themselves, other people, and the world around them into the treatment setting. Safran (1998) described the following process of interpersonal schemas working within psychotherapy.

Through their life experiences, a client will develop scripts (schemas) for interacting with others. This relational style is then reinforced by how other people respond to them throughout their interactions. This style of interacting is then played out within the therapeutic relationship. I suggest that the development and reinforcement of these scripts are associated with the subjective first-person perspective, affective lens, and prediction. For example, an individual who has grown up with little attention or affection may hold schemas that other people should be kept at a distance, and that other people will not care about them. In therapy then, they may present as quiet, disclose minimal information, and appear disinterested in communicating with the therapist.

The therapist's response to the client plays a crucial role in the therapeutic relationship. The therapist can either respond in a way that reinforces or disproves the schema. When they respond in a way that challenges an unhelpful schema, they begin a corrective process to develop and reinforce new, more helpful schemas. In the example above, the therapist can either disengage from the process by showing little interest in the client or they can challenge the schema by providing unconditional warmth and positive regard, even when faced with the client's distance. The therapist will also bring their own experiences, interpersonal schemas and relational styles which the client will respond to, making this process complex and dynamic. It is interesting then, that there has been no research investigating how this process occurs within therapy in a correctional setting, as such Safran's (1998) model is yet to be empirically validated with this population. 


\section{MODEL OF ENGAGEMENT FOR CORRECTIONAL PRACTICE}

\section{Revised Theory of the Therapeutic Alliance}

Ross et al. (2008) presented a Revised Theory of the Therapeutic Alliance (RTTA;

Figure 8) which built on Bordin's (1979) three-component model of the working alliance; goals, tasks, and bond. Whilst the working alliance provided a succinct three-part process for the therapeutic relationship, it failed to account for therapist, client, relational and contextual factors. In the RTTA the therapist and the client have a variety of characteristics they bring with them into treatment. These then influence their cognitive processes and affective responses within treatment. This in turn influences their behaviour toward each other. These 'therapy-related interactions' in turn influence the goals, tasks, and bond within treatment. The model also accounts for the influence of contextual factors across the whole process including both systemic influences and the therapeutic environment. This is useful in that it provides a dynamic and relational account of the development and maintenance of the therapeutic alliance. As such, this is incorporated into the MECP.

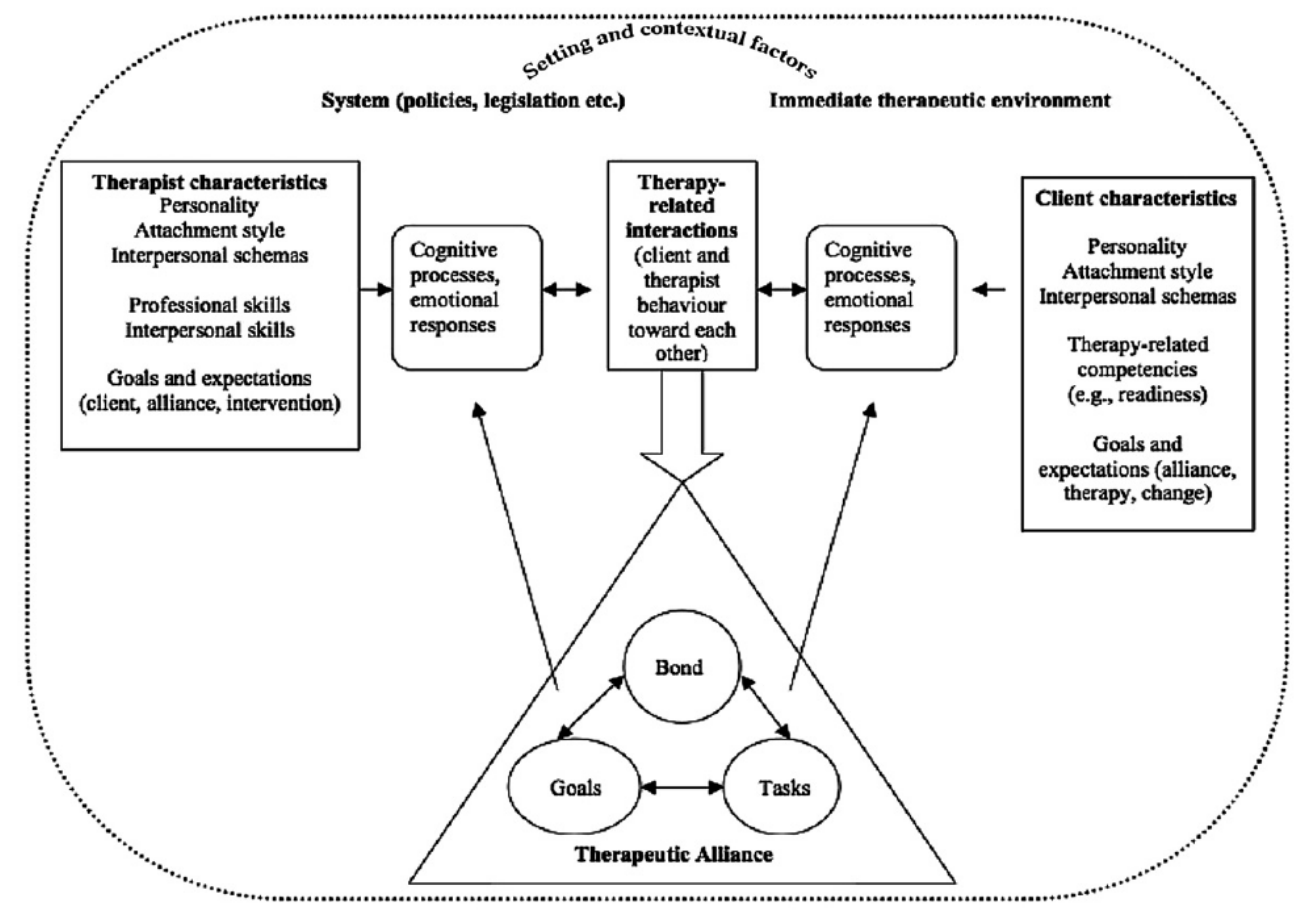

Figure 8. Revised Theory of the Therapeutic Alliance (Ross et al., 2008). 


\section{MODEL OF ENGAGEMENT FOR CORRECTIONAL PRACTICE}

\section{Challenges in Correctional Settings}

Within the field of offending rehabilitation, many factors can undermine, prevent or harm the therapeutic relationship. As a result of legislation and institutional policies treatment is often mandated, involuntary and can be perceived by clients as coercive which may have an impact on outcomes (Day et al., 2004). In this case, it seems human needs such as autonomy and relatedness (Deci \& Ryan, 2000) can be threatened, including in the provision of treatment. For example, collaboration on treatment goals and tasks, ultimately supporting autonomy and agency, is thought to be a necessary condition for the therapeutic alliance (Ross et al., 2008; Meier, 2005). However, in line with RNR principles (Bonta \& Andrews, 2017) many treatment programmes adopt a risk-reduction approach which includes predetermined goals for treatment that aim to address criminogenic needs.

An additional challenge is that clients within correctional settings may hold negative beliefs about and demonstrate hostile behaviour toward correctional staff (Gannon \& Ward, 2014). For example, Hobbs and Dear (2000) found that prisoners were unlikely to perceive correctional staff as sources of support. Given that the client's expectations of the therapist influence the therapeutic alliance, working through this is critical for the development of the therapeutic relationship.

Furthermore, rates of antisocial personality traits and mental health problems are high in correctional populations, including substance abuse, trauma, anxiety and depression (e.g. Corrections, 2017). As noted above, personality disorders, mental health problems and related characteristic such as hostility and aggression negative impact on the therapeutic relationship (Puschner et al., 2005; Lingiardi et al., 2005; Taft et al., 2004; Wilson, 2014). This presents a further challenge for therapists working with this population in that they will likely have to overcome additional obstacles presented by these traits in order to develop a strong working relationship. 


\section{MODEL OF ENGAGEMENT FOR CORRECTIONAL PRACTICE}

Finally, Ward (2013) described the 'dual role' as a critical, but under acknowledged challenge for offending rehabilitation. He noted the inherent conflict in the roles of therapists working in this environment, and the impact this can have on the working relationship in correctional settings. On the one hand, they have a duty to the client, their wellbeing, and confidentiality. Conversely, they have a duty to ensure public safety and risk management. An example of when this dual role could be activated would be a client disclosing previous offending they have not yet been caught for. The conflict is whether or not to share this information with other important stakeholders. There is some evidence that how this is managed is important for the therapeutic alliance (Skeem et al., 2006). If the client perceives the sharing of information as fair and coming from a place of compassion, the therapeutic alliance may be maintained. If it is perceived as a form of control, dominance, or done in an authoritarian manner, the therapeutic alliance could rupture.

\section{Summary of Theoretical Tools}

In summary, this thesis makes a number of theoretical commitments. Firstly, that human beings have a uniquely subjective first-person perspective of themselves, the world and other people. This influences their individual affective lens and their predictive capacities, all of which are moulded by their prior experiences and their current external and internal cues. Secondly, that human agency is an integral part of adaptive human functioning. The three core capacities required for agency are; (1) the ability to set goals based on salient values, (2) the ability to establish an action sequence of strategies to achieve those goals and (3) the implementation and evaluation of the strategies. The third theoretical commitment is that norms are the pervasive behavioural standards which govern our practices in all aspects 


\section{MODEL OF ENGAGEMENT FOR CORRECTIONAL PRACTICE}

of life. Along with their influence on agentic processes, it seems likely then that norms will also guide engagement.

Finally, as humans are inherently social organisms, the therapeutic relationship, like other social interactions, is a critical part of the engagement process. This is influenced by participant and therapist characteristics as well as their interactions with each other. These psychological and social processes interact with, and are influenced by, both the wider external context and the proximate treatment environment. This dynamic and interactional process leads to in the adaptive, goal-directed behaviour we call engagement. In the following chapter, I will introduce the Model of Engagement for Correctional Practice. 


\section{MODEL OF ENGAGEMENT FOR CORRECTIONAL PRACTICE}

\section{Chapter 4 - The Model of Engagement for Correctional Practice}

The Model of Engagement for Correctional Practice (MECP) explains how and why individuals who have committed crimes engage in treatment. Within this model, individuals who have committed crimes and are attending treatment are referred to as participants. This is done so as not identify them only through their behaviour (i.e. as "offenders" or "prisoners") and rather refers to them as human beings who have engaged in harmful behaviour and are now participating in treatment. The treatment providers are referred to as therapists in order to emphasise the critical importance of the therapeutic approach and relationship for engagement to be expressed. The model is presented schematically in Figure 10. The overall model is described briefly first, with extended descriptions of each component and interactions presented throughout this chapter.

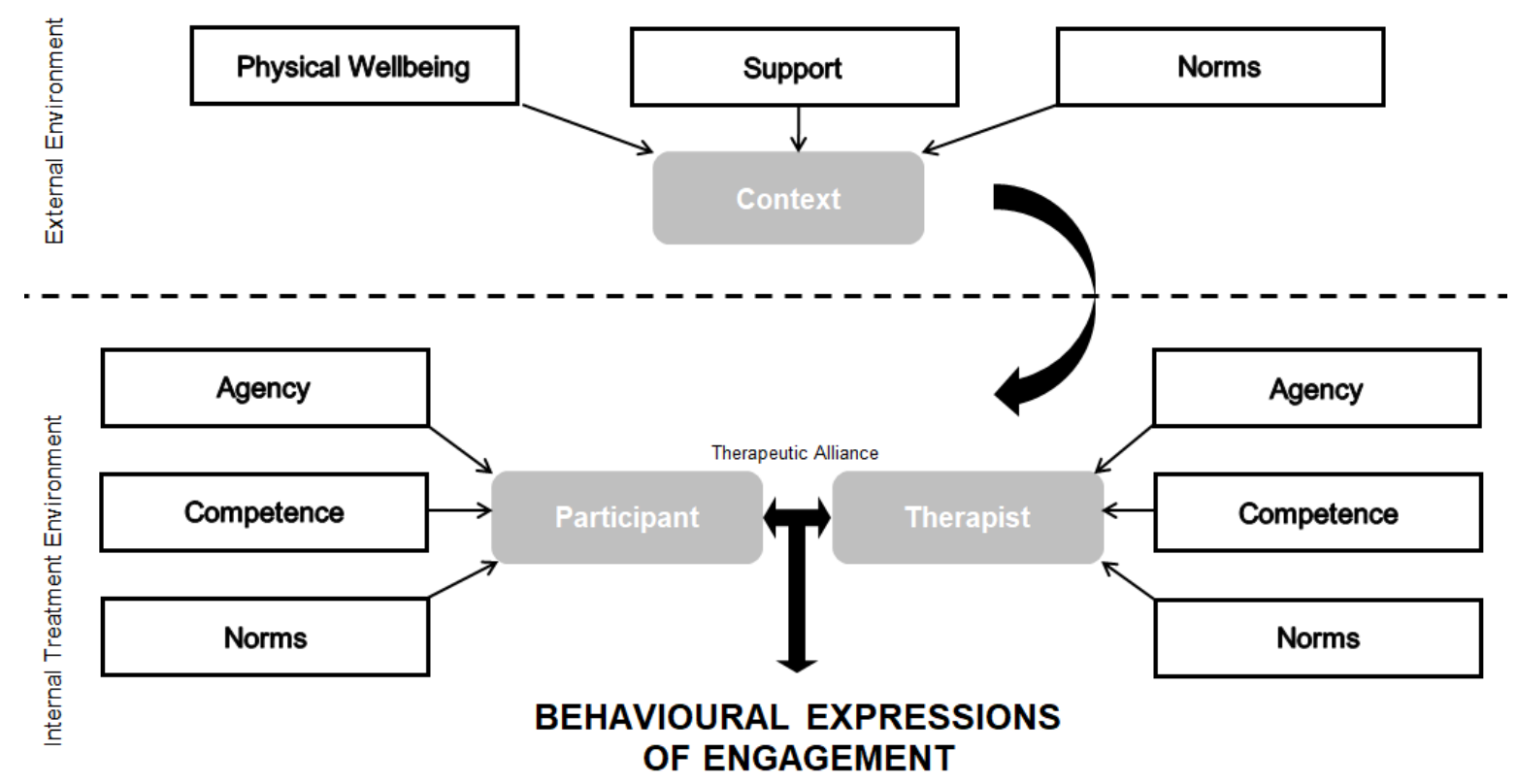

Figure 9. The Model of Engagement for Correctional Practice (MECP). 


\section{MODEL OF ENGAGEMENT FOR CORRECTIONAL PRACTICE}

The MECP is derived from an ecological systems perspective and is comprised of three main 'systems' which interact with each other, influencing a participant's engagement in treatment. The first and second systems exist within the immediate treatment setting, which includes the participant and therapist who, based on the internal and external cues, and their relationship schemas, interact to establish the therapeutic relationship. The third system is the external physical and social context in which the therapist and participant function.

The immediate treatment context is comprised of the internal capacities and psychological processes of the participant and the therapist. I argue that the participant and therapist presentations within treatment are the result of a complex interaction between three core capacities; agency, competence and norms. The focus on and expression of these three capacities differ for participants and therapists, given their differential roles and responsibilities within treatment. They contribute to the psychological processes of the participant and therapist within the treatment space and influence the nature of the therapeutic relationship. The external context comprises the environment within which treatment takes place, the support available to the participant and therapist, and the norms which are guiding the participants' behaviour and therapists' practice.

I argue that engagement can be conceptualised as the adaptive behavioural expression of progress toward collaboratively agreed upon therapeutic goals, which occurs as a result of this therapeutic alliance. Within this model, the behaviours which are considered an expression of engagement will differ depending on the style of treatment and therapeutic goals, and should be collaboratively agreed on at the commencement of treatment. Treatment tasks may include such things as completion of homework, participation in session activities, contributions to group discussions, self-reflection or disclosure, and within and out-of-session skills practice. All aspects of the three systems could promote or hinder engagement through the impact they have on each other and the therapeutic alliance at any point in time. It is 


\section{MODEL OF ENGAGEMENT FOR CORRECTIONAL PRACTICE}

hoped that this model will support the prediction and ongoing measurement of engagement during treatment and provide guidelines for how to prevent and respond to low levels of engagement. I will now discuss each component of the MECP individually as well as how they may interact.

\section{Participant System}

The participant system is a complex interplay of internal psychological processes which influence the participants' interactions with the treatment process. The participant system is made up of three core components; agency, competence and norms. These influence the participant's current internal cognitive and affective cues which in turn influence the therapeutic relationship and subsequently engagement. These capacities are described separately below for clarity and understanding, however it should be noted that it is assumed these capacities interact in a dynamic and multi-dimensional way.

\section{Participant Agency}

In order to engage in treatment, participants must have the capacity to engage in goaldirected behaviour; that is to set goals, make choices about strategies that will help them achieve those goals, evaluate their actions, and adjust them to maximise goal attainment. This is the core function of agency. This requires skills such as self-reflection, behavioural control, emotion regulation, problem-solving, decision-making, reasoning, and counter-factual thinking. All individuals must have at least a minimum degree of agency in order to function as a human being. However, as described in chapter three, agency functions across various levels (i.e. systems, social, personal). The strength of agency-related capacities and the salience of each level at any point in time depend on the individual's circumstances and prior experiences. As such, I argue that the participant's agency is dependent on the specific tasks of treatment (i.e. the immediate situation activating needs across different levels), as well as 


\section{MODEL OF ENGAGEMENT FOR CORRECTIONAL PRACTICE}

being influenced by other components within the model such as competence (i.e. strategies available to them), salient norms (i.e. what is expected), the context and the therapist.

Someone who demonstrates a strong capacity for agency would be able to function independently, establish goals, enact strategies to achieve these, reflect on their actions and adjust them to maximise goal attainment. Someone who demonstrates problems with agency may present as impulsive, be easily distracted or disrupted by others, have difficulty identifying meaningful goals or reasons for their actions, and be highly influenced by external cues and the desire for instant gratification.

The strength of a participant's agency or the most salient level of agency may change throughout the programme, as their autonomy and self-efficacy is challenged or enhanced. For example, at the commencement of treatment prior to the therapeutic alliance being developed, the social level of agency may be more salient as the participant focuses on needs related to connection to the therapist and/or other group members. If the therapist expects extensive self-disclosure before the participant is ready, the personal level of agency (e.g. needs relating to avoiding judgement) may become more salient as the participant tries to protect themselves.

A participant's capacity for agency may be enhanced when the therapist encourages personal goal-setting, allows the participant to make informed choices, builds their confidence, and supports self-efficacy. A participant's agency may also be challenged or enhanced depending on their emotional experience within treatment. If they feel uncomfortable and are unsure how to manage this discomfort, they may feel threatened or intimidated. Alternatively, if they have skills to manage discomfort and are reinforced for practicing these, they could feel more empowered and their agency may be strengthened. Essentially, their emotions (or affective lens) will colour their experiences of treatment, and 


\section{MODEL OF ENGAGEMENT FOR CORRECTIONAL PRACTICE}

play a part on the formation of goals, selection and application of strategies and evaluations of their behaviour.

The MECP predicts that a stronger capacity for agency will result in higher levels of behavioural progress toward goals. Indeed researchers have found that an ability to manage distress (Bosma et al., 2017), effective goal-seeking (Bosma et al., 2017), treatment perceived as supporting personal growth and needs (Sturgess et al., 2016), the absence of coercion (Day et al., 2004), presence of therapist encouragement (Sturgess et al., 2016), a variety of treatment options (Sturgess et al., 2016), being provided with adequate information (Sturgess et al., 2016) and the desire to complete something meaningful (Sturgess et al., 2016) are positively associated with treatment completion and outcomes.

\section{Participant Competence}

Competence in this sense refers to the participant's capacity for learning and ability to carry out the treatment tasks. The specific competencies required will differ depending on the style and expectations of treatment and the tasks involved. Generally though, participants need the capacity to recognise, integrate and use new information and skills in order to learn from treatment. These may include the ability to comprehend new information and relate this to their own circumstances, participate in discussions and complete written work, social skills to develop a therapeutic relationship and problem-solving barriers to participation. Where treatment is provided within a group setting, the competence requirements would likely be more extensive given the additional skills required to follow large group discussions, develop working relationships with other group members, and self-manage when the therapist is not attending to them.

Those participants with greater capacity for learning and integrating new information are expected to show higher levels of progress in treatment. Indeed, higher educational 


\section{MODEL OF ENGAGEMENT FOR CORRECTIONAL PRACTICE}

achievement (Bosma et al., 2017; Taft et al., 2004) has been positively associated with participation in and completion of treatment and may be indicators of higher competence. Additionally, Hanby (2009) found cognitive flexibility, inhibitory control, and knowledge acquisition and application was associated with treatment success in offending rehabilitation programmes.

Someone who has a high level of competence in treatment-related tasks will likely present as more attentive, and demonstrate an ability to concentrate on the tasks at hand with little support from therapists. They will likely demonstrate an ability to retain important information, reflect on treatment content and its application to their own circumstances, be able to follow and contribute meaningfully to group discussions, and be able to manage their time and problem-solve when they experience difficulties. They will also likely demonstrate skills in developing and maintaining relationships such as managing conflict.

Someone who presents with lower competence will likely have difficulty comprehending and retaining new information, be unable to reflect on how this information applies to their personal circumstances, and have difficulty practicing new skills. They may have difficulty solving problems, following and contributing meaningfully to group discussions, resolving conflict or establishing meaningful therapeutic relationships. Someone with limited competence may also present with poor behavioural control, emotional dysregulation and require frequent behaviour management input from therapists.

A participant's competence may change over time. Their competence may improve as they get used to the treatment and learning environment. It may support them to develop attentiveness, memory, emotional regulation, interpersonal skills, self-reflective capacity, comprehension and verbal expression. On the other hand, competence may be challenged. For example, under a high degree of distress a participant may have more difficulty processing new information, thus their competence would be lower. 


\section{MODEL OF ENGAGEMENT FOR CORRECTIONAL PRACTICE \\ Participant Norms}

As described in chapter three, norms play a core role in guiding behaviour. It is therefore likely that a variety of norms will govern the participants' practices within the treatment. The participants will hold norms about what practices are appropriate and how these should be evaluated, rewarded and punished during all aspects of treatment. These may include, for example, norms concerning what and how to change (e.g. their goals), what treatment should and should not encompass, appropriate help-seeking behaviour, their expectations of the therapist, how to behave in that particular treatment setting, and how to form relationships. The salience of different norms will differ across treatment tasks as cognitive, affective, relational and contextual cues change. For example, a participant may have norms that support open discussions but where these become painful or distressing, may become avoidant for self-preservation. They may hold standards about honesty, but withhold information when they feel judged by their peers or the therapist.

At times, participants may experience conflicting norms; where one norm is not compatible with another. I call this a normative conflict. These could play out in a similar way to the dual-relationship problem for therapists. For example, they may hold norms about how to behave within prison (e.g. don't talk about your offending), but these are not compatible with the expectations of a treatment programme (e.g. self-disclosure). Another example may be that they hold norms about appropriate ways of interacting with others (e.g. aggression as a way to resolve conflict), but this is not conducive to forming meaningful relationships within treatment (e.g. talking through conflict and communicating assertively). Furthermore, they may hold beliefs about what is right and wrong that conflict with other beliefs. For example, valuing loyalty to both their gang and their family, but attending to the needs of the gang may put their family at risk. 


\section{MODEL OF ENGAGEMENT FOR CORRECTIONAL PRACTICE}

Someone who holds norms that are congruent with desistance (e.g. that harming others is not ok) will likely demonstrate beliefs that treatment can be helpful, should be attended, and that treatment providers can be understanding and non-judgemental. They may prioritise learning new skills to support an offence-free lifestyle and socially acceptable goals such as caring for family, seeking employment, and engaging in acceptable leisure activities. In this sense, their norms are becoming more congruent with the law. Within treatment they may demonstrate higher levels of self-disclosure and intrinsic motivation and may report personally meaningful reasons for change. They will likely be able to see the benefits of treatment tasks and may show more commitment to skills practice and generalisation outside the treatment environment.

Someone whose norms are congruent with offending (e.g. it is ok to use violence to teach someone a lesson) will likely demonstrate the same characteristics that have been associated with poor outcomes such as negative appraisals of treatment and therapists (Sturgess et al., 2016), and personality characteristics such as hostility, impulsivity, risktaking, denial, psychopathy, and criminal thinking (Olver et al., 2011). This suggests these participants may place more importance on getting their own needs met without regard for others, show little willingness to participate in treatment tasks and collude with offendingsupportive discussion. They may focus on the benefits of offending and have difficulty seeing the benefits of living an offence-free life, and may be called 'unmotivated' by treatment providers. In other words, their norms are incongruent with the treatment goals and it is proposed that this will present a significant obstacle to engagement.

\section{Participant Component Interactions}

These three participant components (agency, competence and norms) interact dynamically and multi-dimensionally, and are expressed through the participant's actions, 


\section{MODEL OF ENGAGEMENT FOR CORRECTIONAL PRACTICE}

mediated by their cognitive and affective states. For example, having strong capacities for agency is only going to enhance engagement if they also have the competence to complete treatment tasks and norms that are congruent with desistance. If they have strong agency but low competence, they could be left feeling frustrated and their confidence challenged. Alternatively, where an individual has strong agency and competence but holds norms that are compatible with continued offending, they will likely present as rigid in their offendingsupportive thinking with low motivation to change.

\section{Therapist System}

The therapist system is comprised of the internal processes and capacities which influence the therapists' cognitive, affective and behavioural presentation within treatment. The therapist system is also made up of the same three components as the participant system. Whilst the components associated with the participant focused on the participant in treatment as a whole person, the components associated with the therapist are role-specific. That is, they refer specifically to the presentation of these components whilst in their role as a therapist within the treatment context. Whilst it is expected that the therapist will come into the role with personal characteristics, there is an expectation that much of this is wellmanaged in order for them to provide safe and ethical practice.

\section{Therapist Agency}

Similar to the participants, therapists must demonstrate agentic capacities in order to carry out their therapeutic tasks. Where participant agency refers to the human agency; the agency of the whole person, therapist agency is role-specific and refers to the core therapeutic capacities. In other words, the social role level of agency is likely to be more salient as the therapist takes on this therapist role within the treatment setting. I refer to these as general therapeutic virtues, those core capacities that enable them to develop and maintain an 


\section{MODEL OF ENGAGEMENT FOR CORRECTIONAL PRACTICE}

effective therapeutic alliance with participants. These were discussed in detail in chapter three and include the demonstration of respect, warmth, empathy, care, compassion, genuineness, collaboration, honesty, and their ability to establish boundaries and provide supportive direction and guidance. This requires a number of skills including emotion regulation, behavioural control, problem-solving, reflective practice, reasoning skills, and counter-factual thinking.

A therapist with strong agency would likely present as confident and demonstrate strong self-management skills. They would likely show evidence of self-reflection, effective emotional management (e.g. being able to manage high levels of stress in the work place), demonstrating objective reasoning, decision-making and problem-solving and engaging in development of their therapeutic skills. They may demonstrate an internal locus of control thus feeling able to adjust their practice to achieve desired treatment outcomes. They will likely engage in more thoughtful and considered use of therapeutic skills and content, and as a result build stronger therapeutic alliances.

A therapist whose agency has been compromised in some way will demonstrate an impaired ability to engage in core therapeutic work. They may demonstrate higher levels of distress and poor emotional management, attributing causes to external factors outside of their control, leaving them feeling disempowered with lower confidence. They will likely show little evidence of self-reflection, limiting their ability to be responsive to participants or develop their therapeutic skills. High levels of distress, coupled with lower levels of objective decision-making and counter-factual thinking will likely result in reactive and impulsive practices. This in turn may reduce their ability to develop and maintain a strong therapeutic alliance with participants because they would be unable to adjust their actions according to the participants' needs. 


\section{MODEL OF ENGAGEMENT FOR CORRECTIONAL PRACTICE}

\section{Therapist Competence}

Just as participants must have core competencies to learn in treatment, the therapists must have core competencies to deliver treatment effectively. The specific skills required will depend on the style and phase of treatment and their professional training (e.g. cognitivebehavioural therapy, family-systems therapy, dialectical behaviour therapy), but will include a variety of therapeutic processing skills, knowledge of the content and responsive delivery practices. Some examples of therapeutic processing skills include socratic enquiry (Padesky, 1993), motivational interviewing (Miller, 2013) and group psychotherapy (Yalom \& Leszcz, 2005). Skills required to ensure responsive delivery of treatment include knowledge of working with different learning styles or disabilities, behavioural reinforcement contingencies, de-escalation techniques, case conceptualisation, and intervention planning.

Regardless of which skills the therapist requires to effectively deliver treatment, someone who demonstrates strong therapeutic competence, will also likely present as more comfortable and confident in their delivery of treatment to participants. Being able to responsively deliver treatment may lead to developing and maintaining a stronger therapeutic alliance. A therapist with lower levels of competence will likely have difficulty with responsive treatment delivery and present as more rigid in their delivery. They may also appear less confident and more anxious.

A therapist's competence can change over the course of treatment. For example, a new therapist who is learning and developing their skills will likely show an increase in competence over time. Alternatively, an experienced therapist who becomes complacent may appear to regress in competence. Competence may change between treatment sessions. For example, if a therapist is feeling distressed during a session, their competence may falter as they lose focus on treatment. Or a therapist may be more competent for some treatment content and less for other content. 


\section{MODEL OF ENGAGEMENT FOR CORRECTIONAL PRACTICE}

\section{Therapist Norms}

Therapists hold a variety of norms about treatment and the participants. I posit that therapists hold three sets of role-specific norms. Firstly, therapists will hold norms about what constitutes safe and ethical therapeutic practice. In this instance, it is unlikely that there would be much variation across therapists given the high standards of safe practice that are generally expected across professional boards. For example, they may view the participant holistically rather than just focusing on their problematic behaviour.

Secondly, therapists will hold norms about the content and style of treatment. This will differ depending on their professional training and will have various costs and benefits depending on the specific circumstances within which treatment takes place. For example, where a therapist is trained in cognitive-behavioural therapy, they may prioritise addressing offending-supportive thinking. They may be more didactic in their approach but this may be an obstacle to therapeutic alliance development. Alternatively a therapist using motivational interviewing techniques may engage in more dialogue, but this may be at the expense of behavioural skills training.

Thirdly, therapists will hold personal or individual norms about relationships and how to interact with others (e.g. avoid any conflict in relationships) which may be helpful or unhelpful for the therapeutic alliance. There is also a potential for conflict between the therapist's role and any personal difficulties they are having (e.g. feeling stressed due to commitments at home and having difficulty maintaining an empathic approach within treatment). Therapists may also hold personal ethical and socio-political values based on their

personal experiences (e.g. what constitutes justice and punishment). Whilst interfering norms are acknowledged within the model, there is an expectation that these are managed to some degree so as not to interfere with their therapeutic tasks in a harmful way. If they do, then practice would cease to be safe and would therefore be unethical. 


\section{MODEL OF ENGAGEMENT FOR CORRECTIONAL PRACTICE}

Where the therapist norms conflict with wider organisational norms, a normative conflict could occur. This exemplifies the dual-relationship problem where one set of norms conflict with another. As discussed earlier, within correctional settings, a common normative conflict is between the values of community protection, social justice and risk reduction (where punishment and confinement are the norm) and the value of individual wellbeing and autonomy (where equality, care and compassion are the norm). In this instance, the therapist can face an ethical dilemma whereby prioritising risk reduction and safety can impinge on the participant's wellbeing. On the other hand, prioritising an individual's autonomy may put the community at risk.

\section{Therapist Component Interactions}

The therapist is comprised of multiple, interdependent processes and capacities (agency, competence and norms) which are dynamic and interactive, influencing the therapist's internal state and behaviour within treatment. For example, a therapist who is high in agency, who is skilled and competent, and whose norms are congruent with desistance, equality and rehabilitation, will likely contribute to increased engagement. They will be able to spend their energy on developing a strong therapeutic alliance whilst delivering clearly structured and responsive treatment. A therapist who demonstrates lower agentic capacity, has lower levels of competence, and holds norms that are incongruent with rehabilitation and the therapeutic alliance, is likely going to have difficulty building the rapport necessary for effective engagement.

Additionally, being high in some capacities and not others can occur and may be problematic. A therapist with a strong sense of agency but who holds norms incongruent with rehabilitation may present as punitive and authoritarian. A therapist with a high level of competence but lower levels of agency may deliver treatment from an "expert role" in a 


\section{MODEL OF ENGAGEMENT FOR CORRECTIONAL PRACTICE}

didactic style without any expression of core therapeutic virtues. A therapist with high levels of agency and norms that are congruent with rehabilitation but lack competence in practice may take on a "friendship role" and demonstrate difficulty maintaining appropriate boundaries.

\section{Interactions between Therapist and Participant}

This model posits that the therapist's and the participant's agency, competence and norms interact in a multi-dimensional and dynamic manner to influence their internal cognitive, affective and behavioural states. The interaction between the therapist and the participant as a result of this will influence the therapeutic alliance, through which engagement occurs. Fluctuations in engagement will be observed over the course of treatment as the therapist's and participant's presentations change and influence the therapeutic alliance. These changes will be further affected by contextual cues and treatment tasks. Some changes to these components can challenge the therapeutic alliance and negatively affect engagement; whilst other changes will facilitate the therapeutic alliance and positively affect engagement.

Whilst there are too many examples of all the possible interactions to describe in detail here, two common examples of how this may occur are detailed in Table 3 below. In the table, there are two exemplars, each with a positive interaction which will facilitate engagement, and a negative interaction which will hinder engagement.

In the first example, when a participant is required to disclose past life experiences he may feel uncomfortable or distressed. If he perceives he has been coerced into this or he is unable to articulate (i.e. lacks competence), his capacity for agency may reduce (e.g. "I have no control"), and norms for self-preservation may active (e.g. avoid discussions, remain quiet). A therapist could interpret this as them being difficult or unmotivated, and their norms regarding appropriate punishment are activated. The therapist may then present as 


\section{MODEL OF ENGAGEMENT FOR CORRECTIONAL PRACTICE}

judgemental or authoritarian and the participant could perceive this as the therapist

dismissing them. Alternatively, if during a discussion about past experiences, the participant has the capacity to manage his distress and feels a sense of autonomy about what he chooses to share, norms for open and honest discussion may be activated. The therapist may respond with praise and validation, reinforcing this response. This will likely facilitate further development of the therapeutic relationship, because the participant feels heard and understood.

In the second example, a therapist may be experiencing difficulties at home and feel upset whilst delivering treatment. Their capacity for agency may be low if they are feeling powerless; they may have difficulty concentrating and may not be expressing those crucial therapeutic virtues. This could lead to unclear content presentation or task delivery. Without the expression of therapeutic virtues and with poor information from the therapist, the participant may be left feeling they have done something wrong or do not understand the tasks. This could leave them with reduced confidence and lower capacity for agency (e.g. there is no point in trying). Alternatively, where a therapist has strong competence and capacity for agency in being able to manage their emotions, they would be able to proceed with treatment deliver as normal. 
Table 3.

Exemplars of explanations of engagement pratices.

\begin{tabular}{|c|c|c|}
\hline Context/Situation & Components Influenced & $\begin{array}{l}\text { Impact on Alliance and Behavioural } \\
\text { Presentations }\end{array}$ \\
\hline \multirow[t]{2}{*}{$\begin{array}{l}\text { Open discussions } \\
\text { about past behaviours } \\
\text { and their influence on } \\
\text { the participant's life } \\
\text { and family }\end{array}$} & $\begin{array}{l}\text { Participant feels } \\
\text { uncomfortable and } \\
\text { coerced, agency reduced, } \\
\text { norms for self-preservation } \\
\text { are activated, therapist } \\
\text { interprets this as } \\
\text { resistance, their norms } \\
\text { supporting punishment } \\
\text { activated }\end{array}$ & $\begin{array}{l}\text { Therapist presents as punitive and } \\
\text { judgemental toward participant } \\
\text { Participant presents as distracted or } \\
\text { argumentative to try to regain sense of } \\
\text { autonomy and avoid discomfort of } \\
\text { disclosure }\end{array}$ \\
\hline & $\begin{array}{l}\text { Participant feels low levels } \\
\text { of discomfort when invited } \\
\text { to only share what they are } \\
\text { comfortable with, agency } \\
\text { is enhanced, norms } \\
\text { supportive of learning and } \\
\text { relationship development } \\
\text { activated }\end{array}$ & $\begin{array}{l}\text { Therapist presents as respectful and } \\
\text { understanding } \\
\text { Participant shares small amount of } \\
\text { personal information, remains attentive } \\
\text { during discussion }\end{array}$ \\
\hline \multirow[t]{2}{*}{$\begin{array}{l}\text { Therapist delivers } \\
\text { treatment whilst } \\
\text { feeling upset about } \\
\text { personal issues }\end{array}$} & $\begin{array}{l}\text { Therapist agency lower as } \\
\text { difficult to remain } \\
\text { empathic when distracted, } \\
\text { competence lower due to } \\
\text { being distracted }\end{array}$ & $\begin{array}{l}\text { Treatment material may be presented } \\
\text { without clarity, therapist may present } \\
\text { as distracted, impatient, therapeutic } \\
\text { virtues negatively affected } \\
\text { Participant agency and competence } \\
\text { challenged, less confidence in therapist } \\
\text { and treatment, participant pays less } \\
\text { attention to therapist, reduced } \\
\text { participation }\end{array}$ \\
\hline & $\begin{array}{l}\text { Agency higher when } \\
\text { emotions managed well, } \\
\text { competence unaffected as } \\
\text { not distracted }\end{array}$ & $\begin{array}{l}\text { Treatment material presented with } \\
\text { clarity, therapist displays expected } \\
\text { therapeutic virtues. } \\
\text { Participant understands content, } \\
\text { learning continues, therapeutic alliance } \\
\text { maintained, reinforced norms that } \\
\text { treatment is useful and providers are } \\
\text { helpful. }\end{array}$ \\
\hline
\end{tabular}




\section{MODEL OF ENGAGEMENT FOR CORRECTIONAL PRACTICE}

\section{External Context}

The external context is made up of the complex interplay between social and physical components of the context which will vary across different settings. The context includes three components; the physical environment, the support and the wider social norms that are operating. These will influence the participants' and therapists' agency, competence, and norms, which in turn influence the therapeutic alliance and thus engagement. These three components of the external context are described in more detail below.

\section{Physical Environment}

This refers to the state of the physical environment, which will differ depending on where the treatment is being delivered, such as in prison or the community. An environment that facilitates a sense of safety and security will promote engagement in the therapeutic process. In prison, participants often experience stigmatisation, feel controlled by others, and feel unsafe (Day \& Doyle, 2010; Toch, 2002). It makes sense that an environment that promotes unsafe practices will be a barrier to engagement.

I propose that the physical environment is a critical component as it determines what level of agency and norms are more salient. Where physical safety is compromised, systemslevel agency (a focus on biological needs) and norms governing practices that facilitate selfpreservation may be more salient. Participant factors associated with poorer outcomes such as high levels of distress and anxiety, lack of trust, feeling powerless, avoiding close relationships, poor concentration, and sleep deprivation (Sturgess et al., 2016) seem more likely in this instance and would likely impact negatively on engagement. Additionally, participants have partially attributed their treatment completion to having practical security measures in place and staff who promote a sense of safety (Sturgess et al., 2016). 


\section{MODEL OF ENGAGEMENT FOR CORRECTIONAL PRACTICE}

\section{Support}

This refers to the level of support the therapists and participants receive from others during the course of treatment, where reinforcement of the desired treatment-supportive practices will facilitate engagement. The participant needs to receive encouragement and reinforcement for progress that is made toward the treatment goals. Sturgess et al. (2016) found that participant's attributed completion to perceived support from therapists and other stakeholders, encouragement from others to pursue treatment, and feedback regarding their therapeutic progress. On the other hand if peers, family and correctional staff are dismissive, discouraging or punish treatment-supportive practices, it will likely hinder engagement through the impact on agency and norms. Some participants have identified peer harassment for treatment attendance as a reason for non-completion (Sturgess et al., 2016). The therapist also needs to be supported and their good work reinforced; for example, receiving feedback about the quality of their treatment delivery, and regular supervision.

The support component additionally refers to the socio-political and organisational support afforded to both the participants and the therapist. This includes the resources and training available to the therapist, treatment options available to the participants, and the support provided by the correctional organisation to both the therapist and participant. This will in a large part be determined by governmental policies, which are determined by societal values and norms (Ward \& Heffernan, 2017; discussed further in the following section). For example, a stronger focus on rehabilitation and lesser focus on punishment and confinement, could promote further treatment development, availability, and delivery in correctional settings. 


\section{MODEL OF ENGAGEMENT FOR CORRECTIONAL PRACTICE}

\section{Norms}

This refers to the norms held by the social group within which the participant and therapist are operating. When the norms of the dominant social group promote treatment, engagement will be enhanced through additional support for therapy and organisational reinforcement of quality delivery and treatment progress. The participant's social groups may be their family, peers, and correctional staff.

For participants, I propose that norms which promote pro-social and help-seeking behaviour, and view the treatment and therapist as supporting them to achieve their goals, facilitate engagement. On the other hand, norms that promote antisocial behaviour, distrust in therapists, devalue help-seeking behaviour and view treatment as unhelpful will present obstacles to engagement. Indeed, it seems that participant's negative appraisals of treatment and treatment providers may be associated with non-completion (Sturgess et al., 2016). For therapists, the social group within which they will be operating whilst delivering treatment will be primarily correctional staff. I propose that norms which support the therapeutic process and value their role in this will promote engagement. Alternatively, norms which devalue therapists and view treatment as unhelpful will likely negatively impact on the therapeutic alliance by promoting negative participant and therapist perceptions and expectations of treatment.

In addition to the values and norms associated with the therapists' and participants' immediate social groups, the norms of the wider socio-political context are important. Norms held by wider society influence governmental policy for correctional practice. This means the development, availability and delivery of treatment is affected by societal norms. There has been a prevailing pre-occupation with risk prediction and risk management (Ward \& Fortune, 2016) within correctional practice. This has resulted in the delivery of treatment programmes designed to remove cognitive, affective and behavioural traits that have been deemed 


\section{MODEL OF ENGAGEMENT FOR CORRECTIONAL PRACTICE}

problematic (offending-supportive). This deficit-focused approach to treatment can be a barrier to engagement. By appeasing the wider society in such a way, this approach could alienate participants because of its risk-focused and punitive tone. For example, some participants who failed to complete treatment have described it as patronising, ineffective, stressful, boring, intrusive, challenging, unnecessary, repetitive, and incompatible with personal goals (Sturgess et al., 2016). Alternatively, perceiving treatment to meet their needs and help them achieve their goals may be associated with completion (Sturgess et al., 2016). I propose that when treatment is more responsive to the participants needs, desires, goals and values (rather than the wider socio-political agenda), they are more likely to engage.

\section{External Component Interactions}

As can be seen above, the interactions between these components is important in that one component can affect the others. For example, if a participant was housed in a prison unit with high inter-gang tension, surrounded by family and staff that devalue treatment, and norms that promote offending-supportive practices they are less likely to engage in treatment. Conversely, a safe environment, with people who encourage and praise participation, and who hold norms that promote desistance will likely promote engagement. In another example, if a therapist is carrying an overwhelming workload, lacks sufficient training and is feeling isolated and disempowered; it is likely they will be distressed and distracted, lack competence in some areas and feel unsupported, leading to poor therapeutic practice. Alternatively, if they have received sufficient training, carry an achievable workload and receive appropriate support, they will be more effective in their delivery. 


\section{MODEL OF ENGAGEMENT FOR CORRECTIONAL PRACTICE}

\section{Interactions between External Context and Internal Systems}

The external context influences the internal components of the therapist and the participant through dynamic and multi-dimensional interactions. As the external context changes, changes to the therapist's and/or participant's agency, competence and norms will ensue. This will lead to changes in their cognitive, affective and behavioural states, which influence the therapeutic alliance and finally engagement. Additionally, changes to internal states of the therapist or participant could lead to altered responses to external cues through changes in agency, norms and competence.

\section{Summary of Model of Engagement}

The MECP seeks to explain how and why engagement occurs to varying degrees within correctional treatment. Engagement is conceptualised as the participant's behavioural expression of progress toward collaboratively agreed upon therapeutic goals. Engagement is therefore construed as a dynamic, multi-faceted phenomenon that can only be explained through a series of interactive psychological and social systems. The MECP describes how the physical environment, support and norms which make up the external context, influence agency, competence and norms of the therapist and participant. These then affect their internal cognitive, affective, and behavioural states which influence the therapeutic alliance. Engagement is the result of all these interactions. In the following chapter, I will evaluate the MECP against the features of a robust theory of engagement which I introduced in chapter two. Then the final chapter will suggest some principle sand guidelines for practice supported by this model. 


\section{MODEL OF ENGAGEMENT FOR CORRECTIONAL PRACTICE \\ Chapter 5 - Evaluation and Applications to Practice}

Throughout the previous chapters, I have argued that developing a robust theoretical understanding of treatment engagement is a critical task for improving offending rehabilitation outcomes. I have proposed that engagement is a composite construct which should be conceptualised as a set of adaptive, goal-directed behaviours and that when engagement is high we will see the behavioural expression of the participant's progress toward collaboratively agreed upon therapeutic goals. The model outlined in this thesis explains how and why individuals who have committed crimes engage in therapeutic rehabilitative treatment. Engagement can be understood through a set of complex and dynamic social and psychological processes which, when aligned with the goals of treatment, lead to higher levels of engagement and improved outcomes.

The next theoretical task is to evaluate the MECP against the critical features of a sound theory of treatment engagement which I introduced in chapter two. These features are provided again in Table 4. As can be observed in the table below, our current understanding of engagement within offending rehabilitation are limited in that none of them are able to provide all the critical features required for a robust theory of engagement. Here, I explain how the MECP adhere to all these evaluative features. 


\section{MODEL OF ENGAGEMENT FOR CORRECTIONAL PRACTICE}

Table 4.

Model adherence to critical features of a theory of engagement, including the Model of Engagement for Correctional Practice (MECP).

\begin{tabular}{|l|c|c|c|c|c|c|c|}
\hline Features & TTM & MORM & PET & RCF & ICTM & CMTR & MECP \\
\hline Temporally Variation & $\checkmark$ & X & X & $\checkmark$ & $\checkmark$ & $\checkmark$ & $\checkmark$ \\
\hline Continuum & X & X & X & $\checkmark$ & $\checkmark$ & $\checkmark$ & $\checkmark$ \\
\hline Explanatory Power & X & X & X & X & X & X & $\checkmark$ \\
\hline Therapeutic Alliance & X & X & $\checkmark$ & X & X & $\checkmark$ & $\checkmark$ \\
\hline External Factors & X & $\checkmark$ & X & $\checkmark$ & X & $\checkmark$ & $\checkmark$ \\
\hline Internal Factors & $\checkmark$ & $\checkmark$ & $\checkmark$ & $\checkmark$ & $\checkmark$ & $\checkmark$ & $\checkmark$ \\
\hline Participant Competence & X & $\checkmark$ & X & $\checkmark$ & $\checkmark$ & $\checkmark$ & $\checkmark$ \\
\hline Practical Utility & $\checkmark$ & $\checkmark$ & $\checkmark$ & $\checkmark$ & X & X & $\checkmark$ \\
\hline Definitional Clarity & X & X & $\checkmark$ & X & $\checkmark$ & X & $\checkmark$ \\
\hline
\end{tabular}

\section{Temporal Variation}

The first requirement for a theory of engagement is that it accounts for temporal variation in engagement. That is, it can account for fluctuations in levels of engagement over time. This may be over the full treatment period, a number of sessions, from session to session, and even within sessions across different treatment tasks. The MECP proposes that this is due to changes in external (social, environmental) and internal (cognitive, affective) cues which influence the therapeutic alliance and subsequently engagement. As can be seen from in table 4 the RCF, ICTM and CMTR frameworks were all able to account for these changes. The MECP also meets this requirement. It can be applied at any point in time as a way to understand why we may be seeing specific behaviours within treatment, thus accounting for moment-to-moment changes in behaviour and longer term improvements to engagement over time.

For example, as a participant becomes more familiar with the treatment style they may develop norms about treatment that are compatible with the expectations of the therapist, and develop a growing capacity for learning. When they feel understood by the therapist, they 


\section{MODEL OF ENGAGEMENT FOR CORRECTIONAL PRACTICE}

are likely to develop a stronger therapeutic alliance. As they develop cognitive dissonance about their offending behaviour and learn new skills, the goals, strategies and evaluations associated with their agency will change. Sometimes however, we may see a regression. This may be because external pressures such as antisocial peers are having a stronger influence than the treatment environment. Or it may be that the therapist has responded in a way that triggers or reinforces unhelpful interpersonal schema, such as being judgemental.

\section{Continuum}

The second feature required is that engagement as a set of behaviours sits within a continuum from higher to lower levels of engagement, rather than merely being present or absent. The TTM and PET, conceptualise engagement as dichotomous, where the individual is either engaged, or not engaged. However, it is unlikely this is the case (Holdsworth et al., 2014). As can be seen in table 4, the MORM, RCF, ICTM and CMTR can all account for engagement as a continuum.

Within group psychotherapy, for example, a participant may be sitting in the room but not talking or listening, they may be listening but not contributing, they may be contributing but only superficially, or they may be making meaningful personal disclosures. I argue that all of these expressions reflect varying levels of treatment engagement, where making meaningful personal disclosures is at the higher end of the continuum.

\section{Explanatory Power}

The third important feature is that the model must have explanatory power, referring to causal mechanisms underpinning the phenomena. The TTM, MORM and CMTR all provide a descriptive framework that merely lists factors correlated with specific treatment outcomes, suggesting when these factors are manipulated outcomes can improve. They fail to explain why these factors have that effect or how they act on the individual to produce a particular outcome. They also fail to explain what happens to engagement during treatment. 


\section{MODEL OF ENGAGEMENT FOR CORRECTIONAL PRACTICE}

Whilst the PET, RCF and ICTM describe a process whereby one factor impacts on the next to produce the outcome; none of these describe why we see that particular outcome through that particular pathway.

I propose that the MECP is unique in that is provides a thorough explanation of behaviour using knowledge of normal human functioning. It can help explain impression management, hostility, non-participation, why someone may be distracted or very quiet, why they may hold particular perceptions of the therapist or treatment, or even why they may chose not to attend a session. The causal mechanisms that provide the explanation are the external context, agency and its components (i.e. affective, causal models, prospection), norms and capacity. These impact on the individual's internal (cognitive, affective, behavioural) state which is played out within the therapeutic relationship.

\section{Therapeutic Relationship}

The fourth feature is that any model of engagement should account for the therapeutic relationship. Participants and therapists have a relationship into which they bring their own interpersonal schemas and models, which are expressed within treatment. It makes sense then that this relationship will influence the participant's presentation within treatment. Therefore, I argue that a framework for engagement that does not account for the therapeutic relationship is incomplete.

It is interesting then that only two of the models reviewed in this thesis have discussed this critical relationship. The PET describes the therapist tasks that enhance engagement. The CMTR highlights therapist characteristics which influence treatment responsivity. However, neither of these models explicitly discuss how the relationship impacts engagement. I argue that the MECP adds more depth, as it explicitly describes the influence of the therapeutic alliance on engagement and also the mechanisms that promote and hinder it. The MECP also 


\section{MODEL OF ENGAGEMENT FOR CORRECTIONAL PRACTICE}

describes how the therapeutic relationship has a direct impact on an individual participant's behaviour within treatment.

\section{External Factors}

A further important feature is that the model must take into account the influence of external factors on engagement. Individuals (both participants and therapists) attend treatment within an environmental and social context which has shaped and continues to shape their values, norms, and causal models, which they bring with them into the treatment setting. The TTM, PET, and ICTM all make note of the influence of the external context on behaviour but argue that because this is mediated by the internal processes of the individual, it is more important to focus on the internal processes.

The MORM, RCF, and CMTR all list a variety of external factors correlated with treatment outcomes, but again they make no attempt to explain how or why this might be the case. This means that these models have the ability to predict who will complete treatment, but does not tell practitioners when or why someone is engaging during treatment. The MECP explicitly explains how different external cues can influence internal psychological processes through agency, norms, and capacities. For example, a participant in an environment that is psychically unsafe is less likely to be engaged in cognitive restructuring, because their goals and strategies will be targeted toward survival and keeping themselves safe (i.e. they may be operating at the systems-level of agency as a result of external threats).

\section{Internal Factors}

The internal psychological factors which influence behaviour were noted, to varying degrees, by all six models reviewed in chapter two. Additionally, the MECP highlights that these internal affective and cognitive processes are the mechanisms mediating influences of the external environment, agentic capacities, norms and competence on the therapeutic relationship. This model does not assign specific cognitions or affective states to this process, 


\section{MODEL OF ENGAGEMENT FOR CORRECTIONAL PRACTICE}

as these will differ depending on the individual's experiences, causal models and salient values. Furthermore, a unique property of this theory is that it highlights the importance of the therapist's cognitive and affective state on participant engagement through their influence on the therapeutic alliance.

\section{Participant Competence}

Participant competence is an additional feature that should be accounted for, given that a participant must be able to actually do the treatment tasks required in order to be able to engage. It is promising that four out of the six models reviewed in this thesis have taken the skills of the participant into account. In the MECP, this is described as a factor that influences the internal processes. Uniquely, the MECP has also highlighted the influence of the therapist competence on engagement. The therapist must have key therapeutic virtues as well as treatment knowledge and skills in order to support the therapeutic relationship.

\section{Practical Utility}

A further key feature of a sound model is that it must have practical utility. The model must provide sufficient depth, specificity, and scope to be applied to enhance practice across treatment styles and settings. Four of the six models reviewed in this thesis appear to demonstrate practical utility. From these models, specific strategies that should enhance engagement can be determined. For example, the TTM provides guidelines for stagematched interventions. The MORM provides a framework for assessing readiness to start treatment. The PET provides suggestions for supporting engagement within therapeutic group work. The RCF lists barriers that, when addressed, may enhance engagement.

The MECP incorporates all of these functions; matching interventions, assessing readiness, enhancing engagement and addressing barriers. As such, I propose that the MECP has wider practical utility in that can help practitioners to understand both participant barriers and targets for treatment, therapist training needs and support and environmental 


\section{MODEL OF ENGAGEMENT FOR CORRECTIONAL PRACTICE}

modifications that will facilitate higher levels of engagement. The practical application of the model is described in more detail in the following chapter.

\section{Definitional Clarity}

The final feature I propose as critical for any model of engagement is definitional clarity. This was highlighted in chapter two and refers to the importance of having a clear conceptualisation of what exactly engagement is and what it is not. This definition needs to be broad enough in scope to account for different treatment styles and tasks but specific enough to 'know it when we see it' and know when we are not seeing it. The ICTM defined engagement as "the participant's behavioural engagement as required by the particular treatment approach" (Drieschner et al., 2004, p. 1130). However, the use of the term engagement within the definition of engagement begs the question again - what is engagement? The PET defined engagement as "all the efforts that clients make during the course of treatment [...] toward the achievement of changes" (Holdsworth et al., 2014, p. 430). This definition is similar to mine in that it highlights the behavioural progress, however, it does not clearly define what is meant by "change".

I argue that the MECP's definition of engagement meets the requirements of definitional clarity. As described throughout this thesis, I have proposed that engagement is an adaptive, goal-directed practice and is the behavioural expression of progress toward collaboratively agreed upon therapeutic goals. The goals of treatment, and what progress looks like will depend on the specific style of treatment and the participant's presenting problems. For example, this may be practicing specified skills in sessions and then trying them outside of sessions. It may involve completion of specific homework tasks, contributions to group discussions on a specific topic, or reductions in aggressive behaviour. When someone is not ready for actual behavioural change, for example, if attending 


\section{MODEL OF ENGAGEMENT FOR CORRECTIONAL PRACTICE}

motivational interviewing interventions, it could also involve exploring the costs and benefits of change or setting goals.

\section{Summary}

I have proposed that a strong theory of engagement should be evaluated against nine features. I have called these temporal variation, continuum, explanatory power, therapeutic relationship, external factors, internal factors, participant competence, practical utility, and definitional clarity. In Chapter 2, I evaluated six models currently used to understand engagement against these features. Whilst they all adhered to some of these requirements, it seems none of them met all nine criteria. I have proposed that the MECP is able to account for all nine important evaluative features. Of special note is the unique explanatory power of this model. This is the only model to provide a full account of the causal mechanisms underpinning engagement.

I suggest the MECP is unique in its ability to provide a robust explanation and understanding of a variety of behaviours that comprise engagement. This model allows practitioners to understand these behaviours as adaptive and goal-directed practices arising from human psychological and social processes. This understanding may support therapists to predict and assess engagement throughout treatment and to develop strategies that facilitate engagement. In the following chapter I provide an overview of principles and guidelines for applying the MECP to enhance correctional practice. 


\section{MODEL OF ENGAGEMENT FOR CORRECTIONAL PRACTICE}

\section{Chapter 6 - The Model of Engagement for Correctional Practice Applied}

The MECP views engagement as arising from interactive systems of human psychological and social processes which act on and within the treatment setting. This unique perspective provides practitioners with a number of avenues through which to enhance engagement. In accordance with this model, in order to achieve improved engagement, it will be important for practitioners to adopt practices; or critical tasks which promote and foster (1) a therapy-supportive context, (2) high levels of agency, (3) participant and therapist competence, (4) norms conducive to treatment goal attainment and (5) a strong therapeutic alliance. I will discuss how working within a positive psychology paradigm can guide practice to achieve these tasks across treatment development and implementation. I propose five broad categories of practice guidelines which I will detail below:

- develop and deliver treatment that facilitates engagement

- foster the therapeutic alliance

- $\quad$ assess and prepare participants for treatment engagement

- monitor engagement throughout treatment

- $\quad$ modify the context to promote engagement

\section{Develop and Deliver Treatment that Facilitates Engagement}

Positive psychology is a useful paradigm to guide treatment development and delivery in order to enhance engagement. Positive psychology has been applied to criminology by Ronel and Segev (2014). They describe how positive criminology can promote desistance through emphasising positive experiences, using a strength-based and solution-focused approach, and fostering social inclusion. They argue that positive experiences such as social 


\section{MODEL OF ENGAGEMENT FOR CORRECTIONAL PRACTICE}

inclusion, acceptance, altruism, positive role-modelling, hope, and self-efficacy help foster change within individuals. Ronel and Segev (2014) suggest some guiding principles for applying positive criminology. These include; providing opportunities for human connection, encouraging ownership of problems and solutions, role modelling prosocial values, fostering a sense of hope and optimism for change, supporting social reintegration, promoting challenges and reinforcing successes, and a focus on developing personal goals and strengths.

Other researchers have suggested similar approaches. In a recent review of the treatment engagement literature, Holdsworth et al. (2014) emphasise encouraging active participation, promoting self-efficacy, autonomy and choice, using motivational interviewing techniques, praising participants' change-supportive behaviours, addressing emotive issues, and developing a strong therapeutic relationship as important practices to enhance engagement. Gannon and Ward (2014) suggest focusing on providing individualised and flexible client-centred interventions, and fostering the therapeutic alliance as important to enhance treatment providers' evidence-based practice.

Furthermore, it seems that when treatment goals align with participant's personal goals, a collaborative partnership between the client and therapist is formed, treatment tasks are negotiated and a therapeutic climate is fostered, individuals are more likely to engage in treatment (Howells \& Day, 2003). Additionally, encouraging emotion recognition and expression is associated with treatment outcomes (Serran \& Marshall, 2010). Inherent within these approaches is a focus on human agency and the therapeutic alliance. Adopting practices that foster a participant's self-efficacy, autonomy, personal values, change-supportive practices, and competence will enhance participants' engagement within treatment.

Another area of research which can guide practice to increase treatment engagement is the desistance literature, which is providing increasing insight into how and why individuals desist from criminal behaviour. Desistance may be described as the cessation or 


\section{MODEL OF ENGAGEMENT FOR CORRECTIONAL PRACTICE}

substantial reduction in frequency or severity of criminal behaviour and is best understood as an on-going process rather than a discrete event (Laws \& Ward, 2011). Self-determination and agency are critical features of desistance theories, as they tend to emphasise the individual's conscious decision to stop offending and the adoption of a new pro-social identity (Giordano, Cernkovich, \& Rudolph, 2002; Laws \& Ward, 2011; Maruna, 2001; Sampson \& Laub, 1990).

Sampson and Laub (1990) and Giordano et al. (2002) suggested that turning points or hooks were a critical feature of the initiation of desistance. They emphasised that important life events (e.g. marriage, gaining employment) could interrupt an offending pathway, leading to identity changes and the reconstruction of relationships and lifestyles. Maruna (2001) and Paternoster and Bushway (2009) have proposed a slightly different pathway in the self-narrative approach to desistance. The individual's identity changes as they become less satisfied with their criminal behaviour and lifestyle, and begin to re-write their life story into a redemption script. This involves integrating their past negative experiences into a script that is coherent with one's true-self. This identity transformation is followed by prosocial changes in lifestyle choices which deter them away from offending.

As discussed in chapter one, the RNR model currently guides most correctional treatment development and implementation. However, RNR informed treatment emphasises the deficits of the individual by aiming to eliminate criminogenic factors through avoidance strategies (Polaschek, 2017; Ward \& Brown, 2004; Ward \& Stewart, 2003). Conversely, desistance-informed treatment emphasises personal strengths, aims to support the individual with their personal goal attainment, and focuses on increasing factors that support an offencefree lifestyle (Polaschek, 2017; Ward \& Brown, 2004; Ward \& Stewart, 2003).

The distinction between offence-related and desistance-focused interventions was also noted by Farrall, Sharpe, Hunter, and Calverley (2011) who emphasised that factors thought 


\section{MODEL OF ENGAGEMENT FOR CORRECTIONAL PRACTICE}

to drive offending are not necessarily the same as the factors associated with desistance. As such it is unhelpful to assume that simply reversing criminogenic factors will result in desistance. Indeed, it seems that removing dynamic risk factors alone is not sufficient for desistance to occur (Serin \& Lloyd, 2009). Instead, McMurran and Ward (2010) suggest that taking into account the participants' hopes and concerns for the future and increasing their sense of control in the process will likely increase treatment readiness. Treatment becomes something that they chose rather than perceiving they have been coerced into, which is associated with poorer outcomes (Day et al., 2004).

Although RNR principles provide some guidance for effective treatment, they do not account for a number of factors that the MECP suggests are key for engagement, such as agency, and norms or values. My argument is not to completely remove RNR informed interventions from correctional treatment because they do demonstrate some treatment effect. I argue that these principles should be complimented with positive psychology approaches that are more conducive to treatment engagement, by supporting the important components in the MECP, in order to increase treatment completion and efficacy. A useful framework that uses the positive psychology approach and may help to enhance treatment engagement is the Good Lives Model (GLM; Ward \& Gannon, 2006).

The GLM emphasises the role that human agency plays in offending. The GLM asserts that all human behaviour can be understood as attempts to attain one or more of the eleven primary goods. The model proposes that primary goods are the values that guide action, such as relatedness, knowledge, mastery and inner peace. Individuals will prioritise attaining different goods depending on their circumstances. Secondary goods are the means by which individuals achieve their primary goods. This is consistent with the Agency Model of Risk discussed earlier where values determine goals which guide strategy selection. 


\section{MODEL OF ENGAGEMENT FOR CORRECTIONAL PRACTICE}

In the GLM, offending is conceptualised as the harmful means by which individuals attain their primary goods and is the result of a flawed "Good Life Plan", rather than flawed primary goods, or values. In other words, offending actions are harmful strategies that an individual implements to achieve their values and goals. As such, the GLM proposes that interventions should address flaws in their "Good Life Plan" and promote primary good attainment through non-harmful strategies. With regards to treatment, it makes sense that incorporating the GLM will promote and foster the core components of the MECP leading to enhanced engagement. For example, the GLM advocates personal goal selection and the exploration of non-harmful strategies for goal attainment. This will support agentic capacities highlighted in the MECP.

In light of this, Ward (2017) suggests interventions should be future-focused, support personal goal attainment, promote non-harmful strategies for achieving these, incorporate personal values, and take into account the processes of normal human functioning across multiple domains. Ward (2017) noted that during assessment therapists should aim to construct a comprehensive understanding of what the individual finds meaningful, and what factors exist in their life that can support non-harmful strategies. This supports a valuesoriented approach which explicitly explores the participant's personal values, goals, barriers and strategies at assessment to inform the tasks of treatment, which may be beneficial to enhancing engagement (Day \& Casey, 2009). This will also lead to a more responsive approach with participants that could help to accommodate any weaknesses in competence and also explore salient norms which may be guiding their actions. The Rokeach Values Survey (RVS; Rokeach \& Ball-Rokeach, 1989) is one way in which values could be operationalised during assessment (Day \& Casey, 2009). The RVS involves the participant ranking two groups of values in order of importance. The two groups are 'terminal values' and 'instrumental values. Terminal values refer to end goals or states of being (e.g. True 


\section{MODEL OF ENGAGEMENT FOR CORRECTIONAL PRACTICE}

friendship, happiness, family security) and instrumental values refer to preferable behaviours to achieve the terminal values (e.g. honesty, courage and forgiveness). Whilst it is unlikely this is a comprehensive list of all possible values, this tool may provide therapists with a simple method for supporting participants to think about behaviours and goals that are important to them. Completion of the RVS may then generate further discussion about where the participant is and where they want to be in terms of these values.

There is a growing emphasis on a more holistic, client-centered approach to treatment, where the participant's agency, context and competence is strengthened. The positive psychology movement further supports the use of the Model of Engagement for Correctional Practice to understand and enhance treatment engagement. Here, I will summarise the practices that are likely to increase engagement that can be incorporated into treatment development. These are categorised into nine principles and associated practice guidelines to develop and deliver treatment that facilitates engagement.

- Emphasise personal goal-setting by exploring with the participant their personal values, hopes, and concerns for the future, then developing a Good Life Plan which will guide treatment goals and tasks.

- Take a strength-based approach by recognising and reinforcing the participant's natural strengths and achievements, and exploring how these can support their Good Life Plan in a non-harmful manner.

- Focus on solutions by introducing other non-harmful approach strategies to achieve their Good Life Plan and attain primary goods.

- Provide opportunities for social inclusion by involving family members and other supporters and stakeholders in the treatment process, as well as encouraging the participant to get involved in out-of-session activities that will support their Good Life Plan. 


\section{MODEL OF ENGAGEMENT FOR CORRECTIONAL PRACTICE}

- Promote positive experiences by providing opportunities for enjoyment within and outside of treatment. Encourage recognition and appropriate expression of emotions. Address and reduce negative emotional experiences within treatment, and encourage the use of non-harmful emotion regulation strategies.

- Foster hope and optimism by praising and reinforcing successful use of nonharmful strategies and goal attainment, whilst also validating and supporting the participant through challenges and obstacles.

- Enhance agency by focusing on their personal goals and strategies, providing choices and encouraging autonomy, reducing perceived coercion, and facilitating decision-making through scenario construction, perspective-taking, and selfevaluation activities.

- Encourage active participation through a stronger focus on real life experiences, challenges and successes, as well as skills practice and role plays in treatment rather than more didactic, theory-driven treatment approaches.

- Take a client-centred approach which individualises treatment as much as possible, being flexible enough to respond effectively to the causes of differing levels of engagement. Use narrative techniques to explore and support their personal identity transformations.

\section{Foster the Therapeutic Alliance}

According to the MECP, the therapeutic alliance is a critical factor associated with engagement. Indeed, therapist characteristics, the client's perception of the therapist, and the therapeutic alliance all appear to facilitate treatment goal attainment (Marshall \& Burton, 2010). Additionally, Day, Kozar, and Davey (2013) note that a "collaborative, client-centred 


\section{MODEL OF ENGAGEMENT FOR CORRECTIONAL PRACTICE}

approach is associated with the highest levels of effectiveness" (p. 630) and this is supported by other researchers (Howells \& Day, 2003; Holdsworth et al., 2014; Gannon \& Ward, 2014; Ward, 2017). The therapists' training, skills and experience and their ability to provide emotional support have been associated with reduced treatment attrition (Roos \& Werbart, 2013). Additionally, treatment engagement is facilitated by therapists who adopt a warm and respectful attitude toward participants (Serran et al., 2003). Furthermore, training staff in the effective use of such attributes has led to enhanced therapy outcomes for individuals in sexual offending treatment programmes (Marshall \& Serran., 2004; Serran et al., 2003) and those with personality disorders (Howells \& Day, 2007).

In order to enhance engagement by building a strong therapeutic alliance, therapists have a responsibility to adopt a belief in the client's ability to change (Maruna, Lebel, Mitchell, \& Naples, 2004), develop their awareness and management of their own attachment style (Degnan, Seymour-Hyde, Harris, \& Berry, 2016) and interpersonal schemas (Safran, 1998), and work collaboratively with participants (Day et al., 2013; Gannon \& Ward, 2014). Gannon and Ward (2014) apply the moral acquaintance model (Ward, 2014) which encourages open, inclusive dialogues that communicate respect and dignity for the intrinsic value of persons.

Barnao et al. (2016) analysed clients' perspectives on forensic mental health treatment. They found important features associated with an enhanced therapeutic relationship. These include; the use of a client-centred approach, being treated with respect and dignity, consistency of care, awareness of their rehabilitation pathway, high levels of agency and a sense of control. Seligman et al.’s (2016) review of psychotherapy suggested the following attributes of therapists were associated with improved outcomes; acceptance of the participant, client support, appropriate therapist self-disclosure, interest in the client, 


\section{MODEL OF ENGAGEMENT FOR CORRECTIONAL PRACTICE}

therapist confidence, motivational approaches and keeping clients on track with treatment goals.

For the therapist, the demonstration of both general therapeutic virtues and treatmentspecific competencies will be important. General therapist attributes include being nonjudgemental and warm, demonstrating interest, empathy, care, and compassion, showing genuineness with appropriate self-disclosure, and taking a supportive and motivational approach (Benveniste, 2016; Marshall \& Burton, 2010; Serran et al., 2003; Serran \& Marshall, 2010). Furthermore, as participants' perceptions of the therapist influence the alliance (Marshall \& Burton, 2010), the MECP suggests therapists should explore these perceptions and address the causes of negative or unhelpful perceptions in order to enhance engagement.

Treatment-specific competencies will differ depending on the professional training of the therapist and style and model of treatment being delivered. Across all styles of treatment however, therapists should be competent in establishing appropriate boundaries, reinforcement and contingencies, and have awareness and management of their own interpersonal processes. Furthermore, given the therapists' internal state will influence the therapeutic alliance, on-going management of their own agency, and cognitive and affective processes will be important.

According to the MECP, the principles and practice guidelines for treatment development and delivery described above are also likely to support the therapeutic relationship through their influence on participant agency, norms and competence. As such, therapists should be competent in their understanding and application of the positive psychology principles and practice guidelines outlined in this chapter such as agency, the Good Lives Model and narrative approaches. 


\section{MODEL OF ENGAGEMENT FOR CORRECTIONAL PRACTICE}

An additional task of therapists is to repair any therapeutic ruptures (Safran, Muran, \& Eubanks-Carter, 2011) that occur. Therapeutic ruptures are tensions or breakdowns in the relationship between the participant and therapist. For example, the alliance can be ruptured when a therapist responds in a controlling, dominant, or authoritarian manner (Skeem et al., 2007). Part of the therapist's role is to manage their own interpersonal responses and attempt to repair these ruptures. This may be achieved by; empathising with and validating the participant's experiences, reinforcing the therapeutic rationale, adjusting treatment tasks or goals, clarifying any misunderstandings, exploring the rupture with the participant openly and without defensiveness, exploring transference interpretations, or resolving the rupture by providing corrective experiences. Thus, therapist training and support to apply these strategies will be important.

Earlier I suggested some principles and practice guidelines for treatment development and delivery. Here I suggest a further five principles and associated practice guidelines for fostering the therapeutic alliance:

- Take a collaborative approach by providing consistent support, facilitating open and inclusive dialogues, negotiating treatment goals and tasks transparently with the participant, and providing feedback on treatment progress.

- Modify client perceptions of the therapist by being genuine and non-judgemental, providing appropriate self-disclosure, exploring their perceptions without defensiveness, and using the MECP to recognise and address causes of unhelpful perceptions.

- Demonstrate therapeutic virtues of warmth, empathy, confidence and compassion whilst treating the participants with interest, dignity, and respect.

- Demonstrate knowledge and application of key therapy skills including treatmentspecific technical skills, Motivational Interviewing, establishing and managing 


\section{MODEL OF ENGAGEMENT FOR CORRECTIONAL PRACTICE}

boundaries, reinforcement contingencies, positive psychology principles, the GLM, narrative techniques, interpersonal processes and repairing therapeutic ruptures.

- Self-reflect and self-manage across all therapy tasks including one's own cognitive, affective and interpersonal processes, and competence. Attend regular supervision for on-going monitoring and guidance.

\section{Assess and Prepare Participants for Treatment Engagement}

During the assessment and the time between the assessment and commencement of treatment, a focus should be on preparing participants for treatment engagement. This will involve the initiation of the therapeutic alliance, increasing the participant's awareness of the treatment on offer, increasing their desire for change through treatment and identifying and addressing potential obstacles to engagement.

Given the inconsistency in the conceptualisation of treatment engagement (see chapters one and two), there are no psychometrically robust tools to measure potential engagement in a meaningful way in terms of the MECP. Although Casey et al. (2007) developed the CVTRQ (see chapter two) to assess treatment readiness; this was found to predict attrition and completion rather than the more dynamic and complex within-treatment engagement. Additionally, the Treatment Readiness Scale (Serin \& Kennedy, 1997) assesses eight internal factors associated with participant's readiness for treatment (as described by the MORM), such as problem recognition, perceived benefits of treatment, treatment goals and motivation. This measure may predict treatment attrition and recidivism (Nunes, Cortoni, \& Serin, 2010). However, it also has not yet been investigated in terms of engagement.

The Personal Aspirations and Concerns Inventory for Offenders (PACI-O; Campbell, Sellen, \& McMurran, 2010) asks the participant about their goals, their importance and the 


\section{MODEL OF ENGAGEMENT FOR CORRECTIONAL PRACTICE}

perceived attainability of those goals. This measure has initially shown some promising psychometric properties and may help the therapist explore the participant's hopes for the future and their confidence they can achieve those goals. Indeed, administering the original PACI at assessment has been associated with enhanced pre-treatment motivation (Campbell et al., 2010). I also suggest that discussing one's own goals is intrinsically less threatening than focusing on criminogenic factors, and thus may also served to aid in the development of the therapeutic alliance. Thus, the PACI-O could be used during the assessment or pretreatment phase to support the therapeutic relationship and possibly enhance engagement.

Coleman and Neimeyer (2014) defined client agency within psychotherapy as; "expectations relating to the active, purposeful use of psychotherapy to meet needs, solve problems, and make life changes" (p. 3). They identified six measures that could be used to assess client agency, but note that more research into the conceptualisation of client agency is needed in order to develop psychometrically robust measures of agency. One promising measure is the Self-Efficacy for Client Behaviours scale (SECB; Longo, Lent, \& Brown, 1992) which operationalises self-efficacy for clients in psychotherapy. This assesses the client's confidence in their ability to achieve treatment tasks on a Likert scale and may positively correlate with outcome expectancies, motivation, positive affect in treatment and scores on the Working Alliance Inventory (WAI; Horvath, 1994). However, further confirmation of the SECB psychometric properties is required. Additionally, self-efficacy is only one psychological capacity required for agency, which also includes prospection and self-regulation, so the ability of the SECB to operationalise agency is limited to just the one component (Coleman \& Neimeyer, 2014).

Lloyd and Serin (2012) developed a measure of agency for use within correctional settings. Their Personal Agency for Desistance Questionnaire (PADQ) uses two scales to assess agency. The agency scale assesses the participant's intention to change, and beliefs 


\section{MODEL OF ENGAGEMENT FOR CORRECTIONAL PRACTICE}

about their ability to change and the expectancies scale assesses the participants' expectations of outcomes regarding offending and desistance. The measure found that positive expectations of desistance and negative expectations of offending were associated with higher agency scale scores. Conversely, negative expectations of desistance and positive expectations of offending were associated with lower levels of agency. The benefit of this measure is that it incorporates the individual's expectancies, or projections, which is a further capacity required for agency.

Initial research on the PADQ shows good internal consistency and construct validity, but it still requires further investigation into its reliability and predictive validity. It would be interesting to investigate if the PADQ can predict treatment engagement, as this would provide practitioners with the first measure of the influence of agency on engagement in correctional treatment. The outcomes of this measure would also provide guidance to practitioners about what is hindering engagement. For example, if scores reflect negative perceptions about their ability to change, practitioners can focus on fostering confidence and competence. If scores reflect positive expectations of offending, practitioners can focus on using motivational interviewing to explore and resolve ambivalence.

There are a number of factors that are thought to impact on engagement. Negative appraisals and perceptions of treatment and therapists, on-going attachment to criminal identity, perceived coercion, lack of external support, poor self-efficacy about ability to do treatment tasks, and feeling powerless have all been associated with lower levels of treatment completion or participation (Sturgess et al., 2016). Conversely, motivation to participate, higher competency, effective goal-setting, perception of treatment as helpful in achieving personal goals, having a variety of treatment options, being provided with adequate information about treatment, perceiving therapists as trustworthy, competent and able to 


\section{MODEL OF ENGAGEMENT FOR CORRECTIONAL PRACTICE}

maintain safety and feeling safe in one's environment have all been attributed to better treatment participation and outcomes (Sturgess et al., 2016).

With regards to interventions that may support enhanced engagement, behavioural contracting and motivational interviewing have shown some promising effects. Behavioural contracting prior to treatment commencement ensures that participant and therapist roles, responsibilities, and expectations are clearly established and goals and tasks of treatment are collaboratively agreed to (Beyko \& Wong, 2005). Within correctional settings, motivational interviewing (Miller, 2013) can improve treatment completion rates, motivation for change and reduce recidivism (McMurran, 2009). Although a low level of motivation is not sufficient to account for all cases of treatment dropout (McMurran \& McCulloch, 2007), enhancing motivation prior to treatment is one way in which engagement could be facilitated.

Furthermore, Ogrodniczuk, Joyce, and Piper (2005) suggest the following techniques that could be incorporated into pre-treatment interventions. Firstly, role induction where the participant is introduced to the treatment rationale and their own and the therapists roles and responsibilities during treatment, could help alleviate anxieties and improve perceptions and expectations of therapy and therapists. Secondly, vicarious training involves showing and discussing with the participant examples of therapy. Finally, experiential training involves therapy simulation. This would provide the participant with a slow and graded exposure to treatment, which could help alleviate anxieties by increasing their understanding of the process and expectations, improve the participants perceptions and expectations of therapy and therapists, allow opportunities for identifying and attending to potential barriers to engagement, and develop the therapeutic alliance. Although pre-training makes sense and sounds promising, there is has been little empirical investigation into its effectiveness in enhancing engagement or retention (McMurran \& Ward, 2010). 


\section{MODEL OF ENGAGEMENT FOR CORRECTIONAL PRACTICE}

There is an increasing evidence base on which to begin developing assessment tools and pre-treatment interventions to enhance engagement. Unfortunately, at this time there are no psychometrically robust measures of within-treatment engagement or causal factors underpinning it, meaning prediction is difficult. Additionally, with very little empirical research into the effect of pre-training interventions on engagement, their positive influence can only be hypothesised. It is likely that initiation of the therapeutic alliance, increasing the participant's awareness of the treatment on offer, increasing their desire for change and treatment, identifying and addressing potential obstacles to engagement and pre-treatment training will positively influence components of the MECP. Thus, these four principles and associated practice guidelines are suggested as ways to assess and prepare participants for treatment to enhance the likelihood that engagement in treatment will occur.

- Develop initial therapeutic alliance by demonstrating the therapeutic virtues and working collaboratively with the participant. Spend time gaining a comprehensive understanding of the individual's values, goals, obstacles, strategies, strengths, and achievements. Take a holistic approach to assessment.

- Increase participant's awareness of treatment through role induction which explores and clarifies the expectations, roles and responsibilities of the therapist and participant. Provide information about treatment. Encourage autonomy and choice in treatment attendance or non-attendance with associated consequences. Provide demonstrations of treatment through vicarious or experiential tasks.

- Increase desire for change by employing motivational interviewing techniques and adopting a narrative approach to underlying values and identity. Explore offending and non-offending expectations and links to values.

- Identify and address potential obstacles to engagement using measures of readiness, agency, and competence. The CVTRQ, PACI-O or the SECB may be 


\section{MODEL OF ENGAGEMENT FOR CORRECTIONAL PRACTICE}

useful here. Provide feedback to participants and work collaboratively with them to resolve any barriers. Engage family or other supporters to increase their understanding of treatment and support for the participant.

- Develop effective pre-treatment training programmes as a useful way to achieve the above tasks. This would need to be delivered flexibly to meet the needs of the participant. It should be collaborative and should emphasise autonomy, incorporate holistic treatment approach, utilise motivational interviewing techniques, include personal goal-setting, role and treatment induction, and identifying and addressing potential engagement barriers.

\section{Monitor Engagement throughout Treatment}

Given that there has been no consistent conceptualisation of treatment engagement in correctional practice, it is unsurprising that there is also a lack of robust and comprehensive measures of engagement within treatment and those that do exist are applied variably (Holdsworth et al., 2014). A number of measures have been used in the literature in an attempt to assess engagement including, the Treatment Participation Questionnaire (Stein et al., 2011) and the Group Engagement Measure (Macgowan, 2000). These measures however tend to be applied variably and so psychometric results are inconclusive.

The Treatment Engagement Rating (TER) scale (Drieschner \& Boomsma, 2008) was developed to investigate the ICTM and has been shown to be reliable and demonstrate predictive validity for attrition and completion (Drieschner \& Verschuur, 2010). Thus, if it demonstrates construct and predictive validity for treatment engagement as it is conceptualised in the MECP, the TER may be a useful way to monitor participants' engagement. The Working Alliance Inventory (WAI; Horvath, 1994) may be a useful tool to 


\section{MODEL OF ENGAGEMENT FOR CORRECTIONAL PRACTICE}

assess the therapeutic relationship. Although a modified version has demonstrated reliability in a community correctional setting (Tatman \& Love, 2010), further research into the validity of the WAI with correctional treatment therapeutic relationships, including its ability to predict treatment engagement, is needed.

In addition to inconsistent conceptualisation and measurement of treatment participation and readiness, the task of monitoring engagement within treatment is further hindered by the fact that it has received little attention in the literature. I propose that ongoing monitoring of engagement on a regular basis over the course of treatment is a critical task for therapists. Given that engagement reflects behavioural progress toward treatment goals, it will be important to collaboratively operationalise what this actually involves prior to treatment commencing, ideally during pre-treatment training. It is likely that the actual behaviours that are involved in engagement will differ between participants and should reflect their personal goals. In addition, the behavioural expectations will vary across different treatment styles and settings. For example, an individual undergoing motivational interviewing may be considering the costs of offending and the benefits of change. An individual undergoing cognitive-behavioural therapy may be correcting unhelpful thinking patterns.

The positive psychology model supports this notion in that the participant's personal goals will determine what constitutes behavioural progress. It does however suggest some important behavioural indicators of increasing engagement that will help to monitor engagement throughout treatment:

- The participant is identifying personal goals and values that support desistance

- The participant is identifying non-harmful means to achieve these

- The participant is practicing new behavioural skills and strategies within treatment

- The participant is attempting to apply new skills to real life situations

- The participant is evidencing identity and narrative transformations 


\section{MODEL OF ENGAGEMENT FOR CORRECTIONAL PRACTICE}

How and when individuals exhibit these behavioural indicators will depend on the multi-dimensional interactions of the components in the MECP. I suggest that these indicators provide an initial starting point for monitoring engagement. However, this concept would need to be empirically investigated.

\section{Modify the Context to Promote Engagement}

The MECP suggests that the context influences the internal treatment setting through its influence on the therapist and participant factors. Therefore, addressing factors that leave participants feeling unsafe and fostering a rehabilitation-friendly environment will likely enhance engagement (McMurran \& Ward, 2010). Treatment delivered within therapeutic communities (TCs) may enhance outcomes (Day \& Doyle, 2010) and special treatment prisons, which provide intensive rehabilitation programmes, are often viewed as more conducive to rehabilitation than mainstream prisons (Day, Casey, Vess, \& Huisy, 2012).

As such, in prisons, I propose that TCs provide an ideal environment within which to complete treatment. This is because they are more likely to promote and foster prosocial support, for example, from well-trained staff and other participants undergoing treatment. The physical environment is also likely to be more conducive to therapy, such as purpose built treatment delivery rooms. Norms are established that are consistent with treatment goals, for example, it may be easier for participants to practice their new behavioural skills if this is considered socially appropriate (i.e. their norms are congruent with treatment tasks). However, this hypothesis needs to be empirically investigated.

Where delivering treatment within a TC is not possible, it would be beneficial for providers to replicate them as much as possible. For example, training staff in the treatment models and therapeutic alliance, sourcing appropriate treatment delivery rooms, separating those undergoing treatment from those individuals who are not yet ready for treatment, and 


\section{MODEL OF ENGAGEMENT FOR CORRECTIONAL PRACTICE}

ensuring participants feel safe. Additionally, the inclusion of family and other supporters in pre-treatment training, as suggested above, may help to adjust to priorities, values, and norms of the participant's support system.

Furthermore, the context also includes the wider socio-political environment with regards to the treatment of people who have committed crime. Governmental policies are inherently determined by the values and norms held by society (Ward \& Heffernan, 2017). As such, how crime, punishment, justice and rehabilitation are viewed by the wider society will determine the extent of funding, resources and support available for correctional treatment. Additionally, the development and delivery of treatment will be determined by the offending rehabilitation models that are valued. For example, since its conception, RNR informed treatment has dominated correctional rehabilitation practice. This is in spite of the fact that treatment adhering to these principles has consistently been shown to yield only small effect sizes (e.g. Corrections, 2017).

We have an ethical obligation to consider the person receiving treatment as a whole person experiencing the same human processes as everyone else, and to treat them with dignity and respect. Adopting a positive psychology approach to correctional treatment will likely lead to better outcomes as it reinforces this obligation, by placing the participant at the centre and making treatment work for them, rather than them having to fit into the treatment currently available. Additionally, it provides opportunities for role modelling positive experiences and approaches to the participants.

I suggest the following principles and practice guidelines for modifying the context to promote engagement:

- Ensure safety and security of the environment to reduce participants feeling unsafe. Therapists should be competent and confident in managing hostile or 


\section{MODEL OF ENGAGEMENT FOR CORRECTIONAL PRACTICE}

aggressive behaviours. Treatment environment has security measures.

Hostility and aggression outside of treatment is managed by others.

- Enhance pro-social support by increasing opportunities for family and other supporters' involvement in treatment. Reduce anti-social influences by separating those who are ready for change with those who are not.

- Prioritise values of respect, dignity and equality including adopting correctional practices that reflect these and putting the participants needs at the centre.

- Provide adequate resources such as appropriate staff recruitment, training and ongoing support (e.g. supervision, adequate treatment rooms, delivery resources).

\section{Summary of Applications}

The MECP conceptualises engagement as a set of adaptive, goal-directed practices where high levels of engagement reflect behavioural progress toward collaboratively agreed upon treatment goals. I have described how positive psychology can help to apply the MECP to correctional practice in order to enhance treatment engagement. According to the MECP, promoting and fostering (1) a therapy-supportive context, (2) high levels of agency, (3) participant and therapist competence, (4) norms conducive to treatment goal attainment and (5) a strong therapeutic alliance will be critical tasks that must be achieved in order to facilitate engagement. As such, I have suggested some principles and associated practice guidelines that will support practitioners to complete these tasks. In order to enhance engagement, we must develop and deliver treatment that facilitates engagement, foster the therapeutic alliance, assess and prepare participants for treatment engagement, monitor 


\section{MODEL OF ENGAGEMENT FOR CORRECTIONAL PRACTICE}

engagement throughout treatment, and modify the context to promote engagement. I now briefly discuss my final conclusions, limitation and directions for future research.

\section{Limitations and Future Directions}

The MECP provides a unique understanding of engagement. Whilst other models have focused on predictors and outcomes of engagement, the MECP has focused on proximate mechanisms. By integrating multiple levels of analysis (i.e. developmental, social, psychological) and associated validated theories of psychological and social functioning (i.e. agency, values, norms, evolutionary perspectives), the model is unique in its ability to draw attention to the dynamic and interactional processes of the underlying cognitive, affective, behavioural and interpersonal causes of behaviour. As a result the model is able to explain the relationship between the predictors and outcomes that have been used as proxies for engagement in previous research. The broadness of this conceptualisation of engagement means it is able to account for the highly variable presentation of engagement across different treatment styles and settings, as well as temporal and contextual changes throughout treatment. The systemic and interactional nature of the model highlights the influence of social and environmental cues on internal states. The MECP can accommodate a variety of engagement presentations and causal processes, thus offering a complete explanation of treatment engagement. However, it is a preliminary model, and further theoretical work to develop more specific understandings of each component is warranted.

Empirical validation of each of the causal processes underlying engagement could provide further insight into their interactions and influences. Operationalisation of engagement as it is conceptualised in this model can help to resolve the inconsistencies that exist in the current literature. Once these tasks have been achieved, investigation into the 


\section{MODEL OF ENGAGEMENT FOR CORRECTIONAL PRACTICE}

impact of positive psychology approaches on engagement may provide further support for the MECP.

\section{Final Conclusions}

At present, the phenomenon of treatment engagement is inconsistently conceptualised and poorly understood. The current body of literature has illuminated the need for a coherent theory to explain the construct. As a result, the aims of this thesis have been to (1) develop a robust conceptualisation of engagement, and (2) provide an explanation of engagement in terms of its underlying causal mechanisms. I have reviewed the literature and demonstrated how evolutionary theories of human functioning, agency, values, norms, and the therapeutic relationship provide a sound platform on which to build such a theory.

The MECP draws multiple levels of psychological theory into an integrated understanding of engagement. The MECP conceptualises engagement as a set of adaptive, goal-directed practices that reflect a participant's behavioural progress toward collaboratively agreed upon treatment goals. These practices occur through interactions between dynamic internal and external systems which act on and within treatment. Understanding these practices as responses to these social and psychological processes gives meaning and context to the behaviour observed within treatment. Through their experiences across the lifetime, participants and therapists develop capacities for agency, values and norms and competencies that, in response to environmental and contextual cues, influence their internal cognitive and affective states. These internal states then impact how the therapist and participant interact with each other within treatment. It is this therapeutic relationship that influences how the participant responds to and behaves within treatment. The MECP incorporates a range of empirical and theoretical research to provide a behavioural explanation of engagement. When conceptualising engagement in this way, positive psychology provides a useful paradigm 
MODEL OF ENGAGEMENT FOR CORRECTIONAL PRACTICE

with which to develop principles and practice guidelines that will facilitate higher levels of engagement in correctional treatment, ultimately supporting desistance. 


\section{MODEL OF ENGAGEMENT FOR CORRECTIONAL PRACTICE}

\section{References}

Adams, J., \& White, M. (2003). Are activity promotion interventions based on the transtheoretical model effective? A critical review. British Journal of Sports Medicine, 37, 106-114. Doi: 10.1136/bjsm.37.2.106

Alemohammad, M., Wood, J. L., Tapp, J., Moore, E., \& Skelly, A. (2016). Support for the predictive validity of the multifactor offender readiness model (MORM): forensic patients' readiness and engagement with therapeutic groups: Internal MORM, treatment readiness and engagement. Retrieved from http://onlinelibrary.wiley.com/doi/10.1002/cbm.2008/abstract

Anstiss, B., Polaschek, D. L. L., \& Wilson, M. (2011). A brief motivational interviewing intervention with prisoners: When you lead a horse to water, can it drink for itself? Psychology, Crime \& Law, 17(8), 689-710. doi:10.1080/10683160903524325

Armitage, C. J. (2009). Is there utility in the transtheoretical model? British Journal of Health Psychology, 14(Pt 2), 195-210. doi:10.1348/135910708X368991

Ashford, J. B., Wong, K. W., \& Sternbach, K. O. (2008). Generic correctional programming for mentally ill offenders. Criminal Justice and Behavior, 35(4), 457-473. doi:10.1177/0093854807313356

Austin, K., Williams, M., \& Kilgour, G. (2011). The effectiveness of motivational interviewing with offenders: An outcome evaluation. New Zealand Journal of Psychology, 40(1), 55-67.

Baker, L. R. (2011). First-personal aspects of agency. Metaphilosophy, 42(1), 1-16. Doi: 10.1111/j.1467-9973.2010.01677.x 


\section{MODEL OF ENGAGEMENT FOR CORRECTIONAL PRACTICE}

Barnao, M., Ward, T., \& Casey, S. (2016). Taking the Good Life to the institution: Forensic service users' perceptions of the Good Lives Model. International Journal of Offender Therapy and Comparative Criminology, 60(7), 766-786.

doi:10.1177/0306624X15570027

Beech, A. R., \& Hamilton-Giachritsis, C. E. (2005). Relationship between therapeutic climate and treatment outcome in group-based sexual offender treatment programs. Sexual Abuse: A Journal of Research and Treatment, 17(2), 127-140.

doi:10.1177/107906320501700204

Benveniste, D. H. (2016). Changing Substance Abuse and Criminal Behavior Through Therapeutic Relationships. In SpringerLink (Ed.): London, UK: Palgrave Macmillan

Beyko, M. J., \& Wong, S. C. P. (2005). Predictors of treatment attrition as indicators for program improvement not offender shortcomings: A study of sex offender treatment attrition. Sexual Abuse: Journal of Research and Treatment, 17(4), 375-389. doi:10.1177/107906320501700403.

Bonta, J. \& Andrews, D. A. (2017). The Psychology of Criminal Conduct. (Sixth Ed.): New York: Routledge.

Bonta, J., Dauvernge, M., \& Rugge, T. (2003). The Reconviction Rate of Federal Offenders. Canada: Public Works and Government Services Canada. Retrieved from https://www.publicsafety.gc.ca/cnt/rsrcs/pblctns/rcnvetn-rt-fdrl/rcnvetn-rt-fdrleng.pdf. 


\section{MODEL OF ENGAGEMENT FOR CORRECTIONAL PRACTICE}

Bordin, E. S. (1979). The generalizability of the psychoanalytic concept of the working alliance. Psychotherapy: Theory, Research \& Practice, 16(3), 252-260. Doi: $10.1037 / \mathrm{h} 0085885$

Bosma, A. Q., Kunst, M. J. J., Dirkzwager, A. J. E., \& Nieuwbeerta, P. (2017). Treatment readiness as a determinant of treatment participation in a prison-based rehabilitation program: An exploratory study. International Journal of Offender Therapy and Comparative Criminology, 61(8), 857-873. doi:10.1177/0306624X15605609

Burrowes, N., \& Needs, A. (2009). Time to contemplate change? A framework for assessing readiness to change with offenders. Aggression and Violent Behavior, 14(1), 39-49. doi:10.1016/j.avb.2008.08.003

Callaghan, R. C. (2004). An examination of the construct validity of the Transtheoretical Model in three longitudinal substance-abuse treatment studies (PhD). University of Toronto, Canada.

Campbell, J., Sellen, J. L., \& McMurran, M. (2010). Personal aspirations and concerns inventory for offenders: Developments in the measurement of offenders' motivation. Criminal Behaviour and Mental Health, 20(2), 144-157. doi:10.1002/cbm.761

Carney, M., \& Kivlahan, D. (1995). Motivational subtypes among veterans seeking substance abuse treatment: Profiles based on Stages of Change. Psychology of Addicitve Behaviours, 9(2), 135-142. Doi: 10.1037/0893-164X.9.2.135

Casey, S., Day, A., \& Howells, K. (2005). The application of the transtheoretical model to offender populations: Some critical issues. Legal and Criminological Psychology, 10(2), 157-171. doi:10.1348/135532505x36714 


\section{MODEL OF ENGAGEMENT FOR CORRECTIONAL PRACTICE}

Casey, S., Day, A., Howells, K., \& Ward, T. (2007). Assessing suitability for offender rehabilitation. Criminal Justice and Behavior, 34(11), 1427-1440. doi:10.1177/0093854807305827

Catty, J. (2004). 'The vehicle of success': Theoretical and empirical perspectives on the therapeutic alliance in psychotherapy and psychiatry. Psychology and Psychotherapy, 77, 255-272. doi: 10.1348/147608304323112528

Coleman, R. A., \& Neimeyer, R. A. (2014). Assessment of subjective client agency in psychotherapy: A review. Journal of Constructivist Psychology, 28(1), 1-23. doi:10.1080/10720537.2014.939791.

Cullen, A. E., Soria, C., Clarke, A. Y., Dean, K., \& Fahy, T. (2011). Factors predicting dropout from the reasoning and rehabilitation program with mentally disordered offenders. Criminal Justice and Behavior, 38(3), 217-230.

doi:10.1177/0093854810393659

Department of Corrections. (2017). Annual Report. Retrieved from https://www.corrections.govt.nz/resources/strategic_reports/annual-reports.html.

D’Sylva, F., Graffam, J., Hardcastle, L., \& Shinkfield, A. J. (2012). Analysis of the stages of change model of drug and alcohol treatment readiness among prisoners. International Journal of Offender Therapy and Comparative Criminology, 56(2), 265-280. doi:10.1177/0306624X10392531

Davidson, L., Roe, D., Andres-Hyman, R., \& Ridgway, P. (2010). Applying stages of change models to recovery from serious mental illness: Contributions and limitations. Isrealian Journal of Psychiatry and Related Sciences, 47(3), 213-221. 


\section{MODEL OF ENGAGEMENT FOR CORRECTIONAL PRACTICE}

Day, A., \& Casey, S. (2009). Values in forensic and correctional psychology. Aggression and Violent Behavior, 14(4), 232-238. doi:10.1016/j.avb.2009.03.008

Day, A., Casey, S., Vess, J., \& Huisy, G. (2012). Assessing the therapeutic climate of prisons. Criminal Justice and Behavior, 39(2), 156-168. doi:10.1177/0093854811430476.

Day, A., \& Doyle, P. (2010). Violent offender rehabilitation and the therapeutic community model of treatment: Towards integrated service provision? Aggression and Violent Behavior, 15(5), 380-386. doi:10.1016/j.avb.2010.06.006

Day, A., Kozar, C., \& Davey, L. (2013). Treatment approaches and offending behavior programs: Some critical issues. Aggression and Violent Behavior, 18(6), 630-635. doi:10.1016/j.avb.2013.07.019

Day, A., Tucker, K., \& Howells, K. (2004). Coerced offender rehabilitation - A defensible practice? Psychology, Crime \& Law, 10(3), 259-269. doi:10.1080/10683160410001662753

Deci, E. L., \& Ryan, R. M. (2000). The "what" and "why" of goal pursuits: Human needs and the self-determintation of behaviour. Psychological Inquiry, 11(4), 227-268. Doi: 10.1207/S15327965PLI1104_01

Degnan, A., Seymour-Hyde, A., Harris, A., \& Berry, K. (2016). The role of therapist attachment in alliance and outcome: A systematic literature review. Clinical Psychology \& Psychotherapy, 23(1), 47-65. doi:10.1002/cpp.1937

Del Re, A. C., Fluckiger, C., Horvath, A. O., Symonds, D., \& Wampold, B. E. (2012). Therapist effects in the therapeutic alliance-outcome relationship: A restricted- 


\section{MODEL OF ENGAGEMENT FOR CORRECTIONAL PRACTICE}

maximum likelihood meta-analysis. Clinical Psychology Review, 32(7), 642-649. doi:10.1016/j.cpr.2012.07.002

Dowden, C., \& Andrews, D. A. (2000). Effective correctional treatment and violent reoffending: A meta-analysis. Canadian Journal of Criminology, 42(4), 449-467.

Dowden, C., \& Andrews, D. A. (2004). The importance of staff practice in delivering effective correctional treatment: a meta-analytic review of core correctional practice International Journal of Offender Therapy \& Comparative Criminology, 48(2), 203214. Doi: 10.1177/0306624X03257765

Drieschner, K. H., \& Boomsma, A. (2008). The Treatment Engagement Rating scale (TER) for forensic outpatient treatment: Description, psychometric properties, and norms. Psychology, Crime \& Law, 14(4), 299-315. doi:10.1080/10683160701858206

Drieschner, K. H., Lammers, S. M. M., \& van der Staak, C. P. F. (2004). Treatment motivation: An attempt for clarification of an ambiguous concept. Clinical Psychology Review, 23(8), 1115-1137. doi:10.1016/j.cpr.2003.09.003

Drieschner, K. H., \& Verschuur, J. (2010). Treatment engagement as a predictor of premature treatment termination and treatment outcome in a correctional outpatient sample. Criminal Behaviour \& Mental Health, 20(2), 86-99. doi:10.1002/cbm.757

Dunkle, J. H., \& Friedlander, M. L. (1996). Contribution of therapist experience and personal characteristics to the working alliance. Journal of Counseling Psychology, 43(4), 456460. doi:10.1037/0022-0167.43.4.456

Durrant, R., \& Ward, T. (2015). Evolutionary Criminology: Towards a Comprehensive Explanation of Crime. San Diego, CA: Academic Press. 


\section{MODEL OF ENGAGEMENT FOR CORRECTIONAL PRACTICE}

Ellis, A. E., Simiola, V., Brown, L., Courtois, C., \& Cook, J. M. (2017). The role of evidence-based therapy relationships on treatment outcome for adults with trauma: A systematic review. Journal of Trauma Dissociation, 1-29.

doi:10.1080/15299732.2017.1329771

Farrall, S., Sharpe, G., Hunter, B., \& Calverley, A. (2011). Theorizing structural and individual-level processes in desistance and persistence: Outlining an integrated perspective. Australian \& New Zealand Journal of Criminology, 44(2), 218-234. doi:10.1177/0004865811405136

Fishbein, M., \& Ajzen, I. (2010). Predicting and Changing Behavior: The Reasoned Action Approach. London, UK: Psychology Press.

Gannon, T. A., \& Ward, T. (2014). Where has all the psychology gone? Aggression and Violent Behavior, 19(4), 435-446. doi:10.1016/j.avb.2014.06.006

Gilchrist, G., Radcliffe, P., McMurran, M., Gilchrist, L., Crane, C. A., Schlauch, R. C., \& Eckhardt, C. I. (2015). Dyadic violence and readiness to change among male intimate partner violence offenders. Criminal Behaviour \& Mental Health 25(4), 287. doi: 10.1002/cbm.1977.

Giordano, Peggy C., Cernkovich, Stephen A., \& Rudolph, Jennifer L. (2002). Gender, crime, and desistance: toward a theory of cognitive transformation. American Journal of Sociology, 107(4), 990-1064. doi:10.1086/343191

Gondolf, E. (2002). Assessing the effect of batterer program completion on reassault: An instrumental variables analysis. Journal of Quantitative Criminology, 18(1), 71-98. doi: $10.1177 / 0886260504268005$ 


\section{MODEL OF ENGAGEMENT FOR CORRECTIONAL PRACTICE}

Hanby, L. (2009). Offender competencies and their relation to correctional programme performance (masters thesis). Ontario, Canada: Carleton University.

Heffernan, R., \& Ward, T. (2015). The conceptualization of dynamic risk factors in child sex offenders: An agency model. Aggression and Violent Behavior, 24, 250-260. doi:10.1016/j.avb.2015.07.001

Hewitt, J., \& Coffey, M. (2005). Therapeutic working relationships with people with schizophrenia: Literature review. Journal of Advanced Nursing, 52(5), 561-570. doi:10.1111/j.1365-2648.2005.03623.x

Hiller, M. L., Knight, K., Leukefeld, C., \& Simpson, D. D. (2002). Motivation as a predictor of therapeutic engagement in mandated residential substance abuse treatment. Criminal Justice and Behavior, 29(1), 56-75. doi:10.1177/0093854802029001004

Hobbs, G. S., \& Dear, G. E. (2000). Prisoners' perceptions of prison offenders as sources of support. Journal of Offender Rehabilitation, 31(1), 127-142. doi: 10.1300/J076v31n01_09

Hohwy, J. (2013). The Predictive Mind. Oxford, England: Oxford University Press.

Holdsworth, E., Bowen, E., Brown, S., \& Howat, D. (2014). Offender engagement in group programs and associations with offender characteristics and treatment factors: A review. Aggression and Violent Behavior, 19(2), 102-121. doi:10.1016/j.avb.2014.01.004

Holdsworth, E., Bowen, E., Brown, S., \& Howat, D. (2017). The development of a program engagement theory for group offending behavior programs. International Journal of 


\section{MODEL OF ENGAGEMENT FOR CORRECTIONAL PRACTICE}

Offender Therapy and Comparative Criminology, 61(13), 1479-1499. doi:10.1177/0306624X15624177.

Horvath, A. O. (1994). Empirical validation of Bordin's pantheoretical model of the alliance: The Working Alliance Inventory perspective. In A. O. Horvath \& L. S. Greenberg (Eds.). The working alliance: Theory, research, and practice (pp. 109-128). Oxford, England: John Wiley \& Sons.

Horvath, A. O., Del Re, A. C., Flückiger, C., \& Symonds, D. (2011). Alliance in individual psychotherapy. Psychotherapy, 48(1), 9-16. doi:10.1037/a0022186.

Howells, K., \& Day, A. (2003). Readiness for anger management: Clinical and theoretical issues. Clinical Psychology Review, 23(2), 319-337. doi:10.1016/S02727358(02)00228-3

Howells, K., \& Day, A. (2006). Affective determinants of treatment engagement in violent offenders. International Journal of Offender Therapy and Comparative Criminology, 50(2), 174. doi:10.1177/0306624X05281336

Howells, K., \& Day, A. (2007). Readiness for treatment in high risk offenders with personality disorders. Psychology, Crime \& Law, 13(1), 47-56. doi:10.1080/10683160600869767

Hunt, K. S., \& Dumville, R. (2016). Recidivism amoung federal offenders: A comprehensive overview. Washington, DC: United States Sentencing Commission Retrieved from http://www.ussc.gov/sites/default/files/pdf/research-and-publications/researchpublications/2016/recidivism_overview.pdf. 


\section{MODEL OF ENGAGEMENT FOR CORRECTIONAL PRACTICE}

Larochelle, S., Diguer, L., Laverdière, O., \& Greenman, P. S. (2011). Predictors of psychological treatment noncompletion among sexual offenders. Clinical Psychology Review, 31(4), 554-562. doi:10.1016/j.cpr.2010.12.004

Laws, D. R., \& Ward, T. (2011). Desistance from sex offending: Alternatives to throwing away the keys. London: Guilford Press.

Levy, R. K. (1997). The transtheoretical model fo change: an application to bulimia nervosa. Psychotherapy, 34(3), 278-285. Doi: 10.1037/h0087651

Lingiardi, V., Filippucci, L., \& Baiocco, R. (2005). Therapeutic alliance evaluation in personality disorders psychotherapy. Psychotherapy Research, 15(1-2), 45-53. doi:10.1080/10503300512331327047

Lipsey, M. W., \& Cullen, F. T. (2007). The effectiveness of correctional rehabilitation: A review of systematic reviews. Annual Review of Law \& Social Sciences, 3, 297-320. Doi: 10.1146/annurev.lawsocsci.3.081806.112833

Littell, J. H., \& Girvin, H. (2002). Stages of change: a critique. Behaviour Modification, 26(2), 223-273. Doi: 10.1177/0145445502026002006

Lloyd, C. D., \& Serin, R. C. (2012). Agency and outcome expectancies for crime desistance: Measuring offenders' personal beliefs about change. Psychology, Crime \& Law, 18(6), 543-565. doi:10.1080/1068316x.2010.511221

Macgowan, M. J. (2000). Evaluation of a measure of engagement for group work. Research on Social Work Practice, 10(3), 348-361. doi:10.1177/104973150001000304 


\section{MODEL OF ENGAGEMENT FOR CORRECTIONAL PRACTICE}

Maiese, M. (2011). Embodiment, emotion, and cognition. Baginstoke, UK: Palgrave MacMillan.

Mallinckrodt, B., Porter, M. J., \& Kivlighan, D. M. (2005). Client attachment to therapist, depth of in-session exploration, and object relations in breif psychotherapy. Psychotherapy: Theory, Research, Practice, Training, 42(1), 85-100. doi:10.1037/0033-3204.42.1.85

Marshall, W. L., \& Burton, D. L. (2010). The importance of group processes in offender treatment. Aggression and Violent Behavior, 15(2), 141-149. doi:10.1016/j.avb.2009.08.008

Maruna, S. (2001). Making Good: The rhetoric of redemption. In S. Maruna (Ed.). Making Good: How Ex-Convicts Reform and Rebuild their Lives (pp. 85-108). Washington DC: American Psychological Association

Maruna, S., Lebel, T. P., Mitchell, N., \& Naples, M. (2004). Pygmalion in the reintegration process: Desistance from crime through the looking glass. Psychology, Crime \& Law, 10(3), 271-281. doi:10.1080/10683160410001662762

McConnaughy, E., Prochaska, J. O., \& Velicer, W. F. (1983). Stages of change in psychotherapy: Measurement and sample profiles. Psychotherapy: Theory, Research, and Practice, 20, 368-375. Doi: 10.1037/h0090198

McGuire, J. (2002). Offender rehabilitation and treatment: Effective programmes and policies to reduce re-offending. J. McGuire (Ed.). New York: J. Wiley.

McMurran, M. (2002). Motivating offenders to change: A guide to enhancing engagement in therapy. New York: Chichester. 


\section{MODEL OF ENGAGEMENT FOR CORRECTIONAL PRACTICE}

McMurran, M. (2009). Motivational interviewing with offenders: A systematic review. Legal and Criminological Psychology, 14(1), 83-100. doi:10.1348/135532508x278326

McMurran, M., \& McCulloch, A. (2007). Why don't offenders complete treatment? Prisoners' reasons for non-completion of a cognitive skills programme. Psychology, Crime \& Law, 13(4), 345-354. doi:10.1080/10683160601060424

McMurran, M., \& Theodosi, E. (2007). Is treatment non-completion associated with increased reconviction over no treatment? Psychology, Crime \& Law, 13(4), 333-343. doi:10.1080/10683160601060374

McMurran, M., Tyler, P., Hogue, T., Cooper, K., Dunseath, W., \& McDaid, D. (1998). Measuring motivation to change in offenders. Psychology, Crime \& Law, 4(1), 43-50. doi:10.1080/10683169808401746

McMurran, M., \& Ward, T. (2004). Motivating offenders to change in therapy: An organizing framework. Legal and Criminological Psychology, 9, 295-311.

McMurran, M., \& Ward, T. (2010). Treatment readiness, treatment engagement and behaviour change. Criminal Behaviour \& Mental Health, 20(2), 75-85. doi:10.1002/cbm.762

Meier, P. S., Barrowclough, C., \& Donmall, M. C. (2005). The role of the therapeutic alliance in the treatment of substance misuse: A critical review of the literature. Addiction, 100(3), 304-316. doi:10.1111/j.1360-0443.2004.00935.x

Miller, W. (2013). Motivational interviewing helping people change (3rd ed.). New York: Guilford Press. 


\section{MODEL OF ENGAGEMENT FOR CORRECTIONAL PRACTICE}

Miller, W., \& Tonigan, J. (1996). Assessing drinkers' motivation for change: The Stages of Change Readiness and Treatment Eagerness Scale (SOCRATES). Psychology of Addicitve Behaviours, 10(2), 81-89. Doi:10.1037/0893-164X.10.2.81

Mitchell S. (2004). Why integrative pluralism?. Biology and Philosophy, 6(1), 81-91. 10.emerg/10.17357.11d83e47a431de178809e07bd6d74c4b

Mossière, A., \& Serin, R. (2014). A critique of models and measures of treatment readiness in offenders. Aggression and Violent Behavior, 19(4), 383-389. doi:10.1016/j.avb.2014.06.004

Neisser, J. (2015). The science of subjectivity. Basingstoke, UK: Palgrave MacMillan.

Norcross, J. C., Krebs, P. M., \& Prochaska, J. O. (2011). Stages of change. Journal of clinical psychology, 67(2), 143-154. doi:10.1002/jclp.20758

Norcross, J. C., \& Lambert, M. J. (2011). Psychotherapy relationships that work. Psychotherapy, 48(1), 4-8. doi:doi:10.1037/a0022180

Noyce, R., \& Simpson, J. (2016). The experience of forming a therapeutic relationship from the client's perspective: A metasynthesis. Psychotherapy Research, 1-16. doi:10.1080/10503307.2016.1208373

Nunes, K. L., Cortoni, F., \& Serin, R. C. (2010). Screening offenders for risk of drop-out and expulsion from correctional programmes. Legal and Criminological Psychology, 15(2), 341-356. doi:10.1348/135532508x401887

O'Brien, K., \& Daffern, M. (2017). An exploration of responsivity among violent offenders: Predicting access to treatment, treatment engagement and programme completion. 


\section{MODEL OF ENGAGEMENT FOR CORRECTIONAL PRACTICE}

Psychiatry, Psychology and Law, 24(2), 259-277.

doi:10.1080/13218719.2016.1230923

Ogrodniczuk, J. S., Joyce, A. S., \& Piper, W. E. (2005). Strategies for reducing patientinitiated premature termination of psychotherapy. Harvard Review of Psychiatry, 13(2), 57-70. doi:10.1080/10673220590956429

Olver, M. E., Stockdale, K. C., \& Wormith, J. S. (2011). A meta-analysis of predictors of offender treatment attrition and its relationship to recidivism. Journal of Consulting Clinical Psychology, 79(1), 6-21. doi:10.1037/a0022200

Orlinsky, D. E., Ronnestad, M. H., \& Willutzki, U. (2004). Fifty years of psychotherapy process-outcome research: Continuity and change. In L. M. J. (Ed.), Bergin and Garfield's Handbook of Psychotherapy and Behavior Change (Vol. 5, pp. 307-389). New York: Wiley.

Padesky, C. A. (1993). Socratic Questioning: Changing Minds or Guiding Discovery? Paper presented at the European Congress of Behavioural and Cognitive Therapies, London.

Paternoster, R., \& Bushway, S. (2009). Desistance and the "feared self": Toward an identity theory of criminal desistance. The Journal of Criminal Law and Criminology, 99(4), 1103-1156. doi: 10.1177/0093854816651905

Patterson, C. H. (1984). Empathy, warmth and genuiness in psychotherapy: A review of reviews. Psychotherapy, 21, 431-438. doi: 10.1037/h0085985

Payne, J. (2007). Recidivism in Australia: Findings and future research. Australia: Australian Institute of Criminology. Retrieved from http://www.aic.gov.au/media_library/publications/rpp/80/rpp080.pdf. 


\section{MODEL OF ENGAGEMENT FOR CORRECTIONAL PRACTICE}

Polaschek, D. L. L. (2017). Protective factors, correctional treatment and desistance. Aggression and Violent Behavior, 32, 64-70. doi:10.1016/j.avb.2016.12.005

Polaschek, D. L. L., Anstiss, B., \& Wilson, M. (2010). The assessment of offending-related stage of change in offenders: Psychometric validation of the URICA with male prisoners. Psychology, Crime \& Law, 16(4), 305-325. doi:10.1080/10683160802698766

Polaschek, D. L. L., \& Ross, E. C. (2010). Do early therapeutic alliance, motivation, and stages of change predict therapy change for high-risk, psychopathic violent prisoners? Criminal Behaviour \& Mental Health, 20(2), 100-111. doi:10.1002/cbm.759

Prochaska, J. O., \& DiClemente, C. C. (1982). Transtheoretical therapy: Toward a more integrative model of change. Psychotherapy: Theory, Research \& Practice, 19(3), 276-288. doi:10.1037/h0088437

Prochaska, J. O., DiClemente, C. C., \& Norcross, J. C. (1992). In search of how people change: Applications to addictive behaviors. American Psychologist, 47(9), 11021114. doi: 10.1037/0003-066X.47.9.1102

Prochaska, J. O., \& Velicer, W. F. (1997). The transtheoretical model of health behavior change. American Journal of Health Promotion, 12(1), 38-48. Doi: 10.4278/0890$1171-12.1 .38$

Prochaska, J. O., Velicer, W. F., Redding, C., Rossi, J. S., Goldstein, M., DePue, J., Plummer, B. A. (2005). Stage-based expert systems to guide a population of primary care patients to quit smoking, eat healthier, prevent skin cancer, and receive regular 


\section{MODEL OF ENGAGEMENT FOR CORRECTIONAL PRACTICE}

mammograms. Preventitive Medicine, 41(2), 406-416.

doi:10.1016/j.ypmed.2004.09.050

Puschner, B., Bauer, S., Horowitz, L. M., \& Kordy, H. (2005). The relationship between interpersonal problems and the helping alliance. Journal of Clinical Psychology, 61(4), 415-429. doi:10.1002/jclp.20050

Rokeach, M., \& Ball-Rokeach, S. J. (1989). Stability and change in American value priorities. American Psychologist, 44, 775-784. doi: 10.1037/0003-066X.44.5.775

Ronel, N., \& Segev, D. (2014). Positive criminology in practice. International Journal of Offender Therapy \& Comparative Criminology, 58(11), 1389-1407. doi:10.1177/0306624X13491933

Roos, J., \& Werbart, A. (2013). Therapist and relationship factors influencing dropout from individual psychotherapy: A literature review. Psychotherapy Research, 23(4), 394418. doi:10.1080/10503307.2013.775528

Ross, E. C., Polaschek, D. L. L., \& Ward, T. (2008). The therapeutic alliance: A theoretical revision for offender rehabilitation. Aggression and Violent Behavior, 13(6), 462-480. doi:10.1016/j.avb.2008.07.003

Ross, J., Quayle, E., Newman, E., \& Tansey, L. (2013). The impact of psychological therapies on violent behaviour in clinical and forensic settings: A systematic review. Aggression and Violent Behavior, 18(6), 761-773. doi:10.1016/j.avb.2013.09.001

Sadler, J. Z. (2005). Values and psychiatric diagnosis. New York: Oxford University Press. 


\section{MODEL OF ENGAGEMENT FOR CORRECTIONAL PRACTICE}

Safran, J. D. (1998). Widening the scope of cognitive therapy: The Therapeutic Relationship, Emotion, and the Process of Change. Northvale, NJ: Jason Aronson, Inc.

Safran, J. D., Muran, J. C., \& Eubanks-Carter, C. (2011). Repairing alliance ruptures. Psychotherapy, 48(1), 80-87. doi:10.1037/a0022140

Sampson, R. J., \& Laub, J. H. (1990). Crime and Deviance over the Life Course: The Salience of Adult Social Bonds. American Sociological Review, 55(5), 609-627. doi:10.2307/2095859

Seligman, M. E. P., Railton, P., Baumeister, R., \& Sripada, C. (2016). Homo Prospectus. New York: Oxford University Press.

Serin, R. C., \& Kennedy, S. (1997). Treatment Readiness and Responsivity: Contributing to Effective Correctional Programming: Prepared by Correctional Services Canada, Research Branch. Retrieved from http://www.csc-scc.gc.ca/research/092/r54_e.pdf

Serin, R. C., \& Lloyd, C. D. (2009). Examining the process of offender change: The transition to crime desistance. Psychology, Crime \& Law, 15(4), 347-364. doi:10.1080/10683160802261078

Serran, G., Fernandez, Y., Marshall, W. L., \& Mann, R. E. (2003). Process issues in treatment: application to sexual offender programs. Professional Psychology: Research and Practice, 34(4), 368-374. doi:10.1037/0735-7028.34.4.368

Serran, G., \& Marshall, W. L. (2010). Therapeutic process in the treatment of sexual offenders: A review article. British Journal of Forensic Practice, 12(3), 4-16. doi: 10.5042/bjfp.2010.0421 


\section{MODEL OF ENGAGEMENT FOR CORRECTIONAL PRACTICE}

Sheldon, K., Howells, K., \& Patel, G. (2010). An empirical evaluation of reasons for noncompletion of treatment in a dangerous and severe personality disorder unit. Criminal Behaviour \& Mental Health, 20(2), 129-143. doi:10.1002/cbm.760

Skeem, J. L., Louden, J. E., Polaschek, D., \& Camp, J. (2007). Assessing relationship quality in mandated community treatment: blending care with control. Psychological Assessment, 19(4), 397-410. doi:10.1037/1040-3590.19.4.397

Sowden, J., \& Olver, M. (2017). Sexual offender treatment readiness, responsivity, and change: linkages to treatment completion and recidivism. Journal of Forensic Nursing, 13(3), 97. doi:10.1097/JFN.0000000000000160

Stein, L., Colby, S. M., Barnett, N. P., Monti, P. M., Golembeske, C., \& Lebeau-Craven, R. (2011). Enhancing substance abuse treatment engagement in incarcerated adolescents. Psychological Services, 3(1), 25-34. Doi: 10.1037/1541-1559.3.1.0

Sturgess, D., Woodhams, J., \& Tonkin, M. (2016). Treatment engagement from the perspective of the offender. International Journal of Offender Therapy \& Comparative Criminology, 60(16), 1873-1896. doi:10.1177/0306624X15586038

Sutton, S. (2001). Back to the drawing board? A review of applications of the transtheoretical model to substance use. Addiction, 96(1), 175-186. doi:10.1080/09652140020017049

Taft, C. T., \& Murphy, C. (2007). The working alliance in intervention for partner violence perpetrators: recent research and theory. Journal of Family Violence, 22(1), 11-18. doi: 10.1007/s10896-006-9053-Z

Taft, C. T., Murphy, C. M., Musser, P. H., \& Remington, N. A. (2004). Personality, interpersonal, and motivational predictors of the working alliance in group cognitive- 


\section{MODEL OF ENGAGEMENT FOR CORRECTIONAL PRACTICE}

behavioral therapy for partner violent men. Journal of Consulting and Clinical Psychology, 72(2), 349-354. doi:10.1037/0022-006X.72.2.349

Tatman, A. W., \& Love, K. M. (2010). An offender version of the Working Alliance Inventory-Short Revised. Journal of Offender Rehabilitation, 49(3), 165-179. doi:10.1080/10509671003666560

Taxman, F. S., \& Ainsworth, S. (2009). Correctional milieu: The key to quality outcomes. Victims \& Offenders, 4(4), 334-340. doi:10.1080/15564880903227347

Tetley, A., Jinks, M., Huband, N., \& Howells, K. (2011). A systematic review of measures of therapeutic engagement in psychosocial and psychological treatment. Journal of clinical psychology, 67(9), 927--941. doi:10.1002/jclp.20811

Tetley, A., Jinks, M., Huband, N., Howells, K., \& McMurran, M. (2012). Barriers to and facilitators of treatment engagement for clients with personality disorder: A Delphi survey. Personality and Mental Health, 6(2), 97-110. doi:10.1002/pmh.1176

Tierney, D., \& McCabe, M. (2001). The evaluation of self-report measures of cognitive distortions and empathy amoung Australian sex offenders. Archives of Sexual Behaviour, 30(5), 495-519.

Toch, H. \& Adams, K (2002). Acting Out: Maladaptive Behavior in Confinement. Washington DC: American Psychological Association.

Velicer, W. F., Brick, L. A., Fava, J. L., \& Prochaska, J. O. (2013). Testing 40 predictions from the transtheoretical model again, with confidence. Multivariate Behavioural Research, 48(2), 220-240. doi:10.1080/00273171.2012.760439 


\section{MODEL OF ENGAGEMENT FOR CORRECTIONAL PRACTICE}

Velicer, W. F., Norman, G. J., Fava, J. L., \& Prochaska, J. O. (1999). Testing 40 predictions from the transtheoretical model. Addictive Behaviours, 24(4), 455-469.

Walsh, D. M. (2015). Organisms, Agency, and Evolution. Cambridge, UK: Cambridge University.

Ward, T. (2013). Addressing the dual relationship problem in forensic and correctional practice. Aggression and Violent Behavior, 18(1), 92-100.

doi:10.1016/j.avb.2012.10.006

Ward, T. (2014). The explanation of sexual offending: From single factor theories to integrative pluralism. Journal of Sexual Aggression, 20(2), 130-141. doi:10.1080/13552600.2013.870242

Ward, T. (2017). Prediction and agency: The role of protective factors in correctional rehabilitation and desistance. Aggression and Violent Behavior, 32, 19-28. doi:10.1016/j.avb.2016.11.012

Ward, T., \& Brown, M. (2004). The good lives model and conceptual issues in offender rehabilitation. Psychology, Crime \& Law, 10(3), 243-257. doi:10.1080/10683160410001662744

Ward, T., Day, A., Howells, K., \& Birgden, A. (2004). The multifactor offender readiness model. Aggression and Violent Behavior, 9(6), 645-673. doi:10.1016/j.avb.2003.08.001

Ward, T., \& Fortune, C.-A. (2016). From dynamic risk factors to causal processes: A methodological framework. Psychology, Crime \& Law, 22(1-2), 190-202. doi:10.1080/1068316x.2015.1117080 


\section{MODEL OF ENGAGEMENT FOR CORRECTIONAL PRACTICE}

Ward, T., \& Gannon, T. A. (2006). Rehabilitation, etiology, and self-regulation: The comprehensive good lives model of treatment for sexual offenders. Aggression and Violent Behavior, 11(1), 77-94. doi:10.1016/j.avb.2005.06.001

Ward, T., \& Heffernan, R. (2017). The role of values in forensic and correctional rehabilitation. Aggression and Violent Behavior, 37, 42-51. doi:10.1016/j.avb.2017.09.002

Ward, T., \& Stewart, C. (2003). Criminogenic needs and human needs: A theoretical model. Psychology, Crime \& Law, 9(2), 125-143. doi:10.1080/1068316031000116247

West, R. (2005). Time for a change: Putting the Transtheoretical (Stages of Change) Model to rest. Society for the Study of Addiction, 100, 1036-1039. doi:10.1111/i.13600443.2005.01139.x

Williamson, P., Day, A., Howells, K., Bubner, S., \& Jauncey, S. (2003). Assessing offender readiness to change problems with anger. Psychology, Crime \& Law, 9(4), 295-307. doi:10.1080/1068316031000073371

Wilson, N. J. (2004). New Zealand high-risk offenders: Who are they and what are the issues in their management and treatment? Department of Corrections Psychological Service. Retreived from: http://www.corrections.govt.nz/public/research/

Wormith, J. S., \& Olver, M. E. (2002). Offender treatment attrition and its relationship with risk, responsivity, and recidivism. Criminal Justice and Behavior, 29(4), 447-471. doi:10.1177/0093854802029004006

Yalom, I., \& Leszcz, M. (2005). Theory and Practice of Group Psychotherapy (5th ed.). New York: Ingram Publisher. 


\section{MODEL OF ENGAGEMENT FOR CORRECTIONAL PRACTICE}

Yong, A., Williams, M., Provan, H., Clarke, D., \& Sinclair, G. (2015). How do offenders move through the stages of change? Psychology, Crime \& Law : PC \& L, 21(4), 375397. doi:10.1080/1068316X.2014.989166 